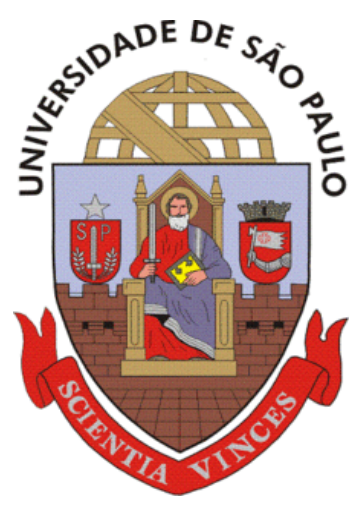

\author{
Universidade de São Paulo - USP \\ Escola de Engenharia de São Carlos - EESC \\ Departamento de Engenharia Elétrica \\ Programa de Pós-Graduação em Engenharia Elétrica
}

Estudo de Sistemas com Multiportadoras Ópticas Ortogonais e Coerentes

Rafael Jales Lima Ferreira

São Carlos 

Rafael Jales Lima Ferreira

\section{Estudo de Sistemas com Multiportadoras Ópticas Ortogonais e Coerentes}

Dissertação de Mestrado apresentada à Escola de Engenharia de São Carlos da Universidade de São Paulo, como parte dos requisitos para obtenção do título de Mestre em Ciências Programa de Engenharia Elétrica.

Área de Concentração: Telecomunicações Orientadora: Profa. Dra. Mônica de Lacerda Rocha

\section{São Carlos}


AUTORIZO A REPRODUÇÃO TOTAL OU PARCIAL DESTE TRABALHO, POR QUALQUER MEIO CONVENCIONAL OU ELETRÔNICO, PARA FINS DE ESTUDO E PESQUISA, DESDE QUE CITADA A FONTE.

J26e Jales Lima Ferreira, rafael
Estudo de Sistemas com Multiportadoras Ópticas
Ortogonais e Coerentes / rafael Jales Lima Ferreira;
orientadora Mônica De Lacerda Rocha. São Carlos, 2013.
Dissertação (Mestrado) - Programa de Pós-Graduação
em Engenharia Elétrica e Área de Concentração em
Telecomunicações -- Escola de Engenharia de São Carlos
da Universidade de São Paulo, 2013.
1. Orthogonal Frequency Division Multiplexing. 2.
recepção óptica direta e coerente. 3. geração de
multiportadoras ópticas. 4. modulação digital híbrida.
5. supercanal óptico. I. Título.




\section{FOLHA DE JULGAMENTO}

Candidato: Bacharel RAFAEL JALES LIMA FERREIRA

Título da dissertação: "Estudo de sistemas com multiportadoras ópticas ortogonais e coerentes".

Data da defesa: 27/03/2013

\section{Comissão Julgadora:}

Prof ${ }^{\mathrm{a}}$. Dr ${ }^{\mathrm{a}}$. Mônica de Lacerda Rocha (Orientadora)

(Escola de Engenharia de São Carlos/EESC)

Prof. Titular Amílcar Careli Cesar

(Escola de Engenharia de São Carlos/EESC)
Resultado:

APROVADO

APDOVDDO

Dr. Daniel Moutinho Pataca

(Centro de Pesquisa e Desenvolvimento da Telebrás/Fundação CPqD)

Coordenador do Programa de Pós-Graduação em Engenharia Elétrica e Presidente da Comissão de Pós-Graduação:

Prof. Titular Denis Vinicius Coury 


\section{Agradecimentos}

Gostaria de agradecer inicialmente a conquista deste trabalho à minha orientadora, Mônica de Lacerda Rocha, porque mais do que cumprir sua missão, ela participou de todo o processo de desenvolvimento desta dissertação, contribuindo para a realização de simulações e buscando novas referências e caminhos até alcançarmos resultados satisfatórios; gostaria de agradecer também ao $\mathrm{CPqD}$, pois forneceu suporte ao ensino dos temas relacionados à dissertação e forneceu 0 executável do Algoritmo de Processamento de Sinal; em especial aos pesquisadores Daniel Moutinho Pataca, Vitor Bedotti Ribeiro e Stenio Magalhães Ranzini, por não terem medido esforços para ajudar na conclusão dessa dissertação durante as reuniões realizadas.

Este trabalho também não seria concluído sem o apoio da minha família. Durante toda a sua realização tive o privilégio de contar com o incentivo dos meus pais (Antonio Augusto, Celene Jales), e do meu avô Benedito Afonso. O esforço deles teve uma contribuição enorme para que eu continuasse com toda força no término desse trabalho. À minha namorada Camila Fantin por estar sempre ao meu lado me dando apoio e todo incentivo para seguir adiante, e pelo apoio no vários momentos que precisei, principalmente na reta final deste trabalho.

Não posso esquecer-me dos amigos de São Carlos e dos colegas do Laboratório de Telecomunicações do Departamento de Engenharia Elétrica, Arturo, Larissa, Mariana, Willian, Thiago, Pedrão, Rafael, Fabão, Remy, Marcelo, Fabbio, Dudu, Ricardo, Tati, Luciana e Thais, pelos conhecimentos transmitidos, a amizade e os vários momentos de descontração e apoio.

Aos meus grandes amigos, que mesmo estando distante, estão sempre ajudando de alguma maneira e me dando forças para continuar.

Registro também um muito obrigado ao CNPq (Conselho Nacional de Desenvolvimento Científico e Tecnológico), que apoiou financeiramente o estudo realizado.

Por fim, agradeço a Deus pela saúde e paz para que durante os últimos anos eu pudesse enfrentar os desafios do Mestrado. 


\section{SUMÁRIO}

Resumo

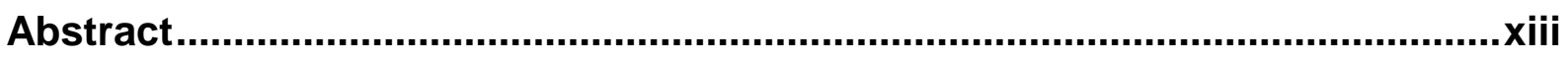

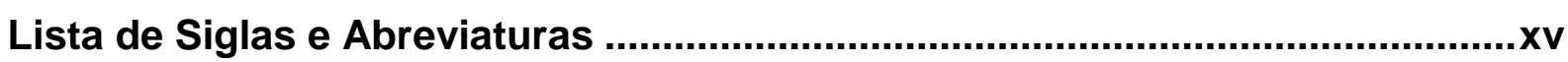

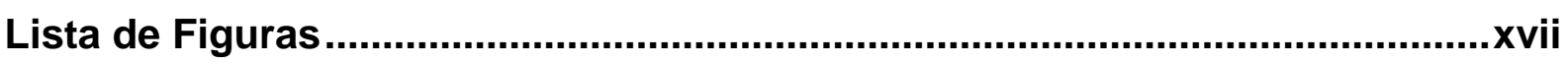

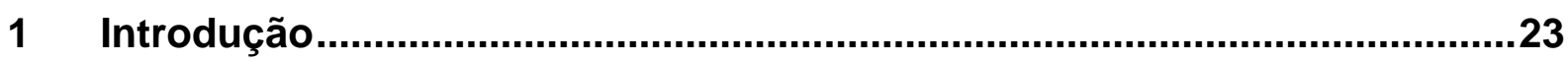

1.1 Revisão Histórica e Perspectivas Futuras ...........................................25

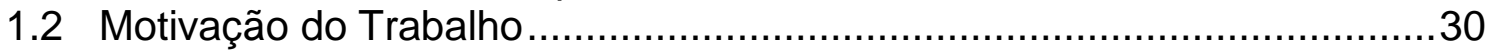

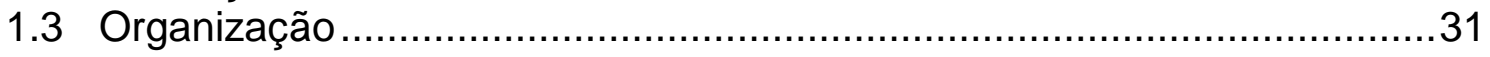

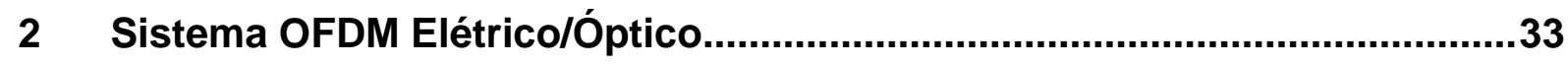

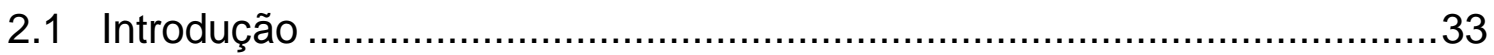

2.2 Multiplexação por Divisão de Frequência (FDM - Frequency Division Multiplexing) .............................................................................3

2.3 Multiplexação por Divisão de Frequência Ortogonal (OFDM - Orthogonal Frequency Division Multiplexing) ..........................................................34

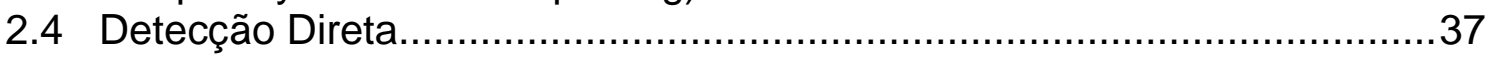

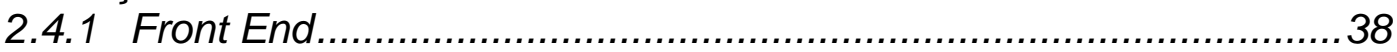

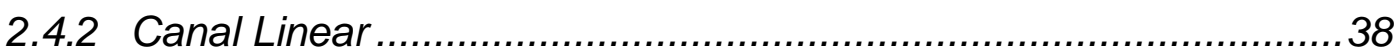

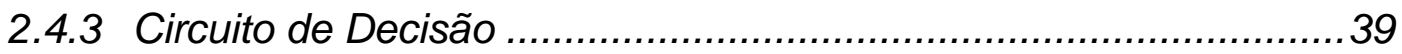

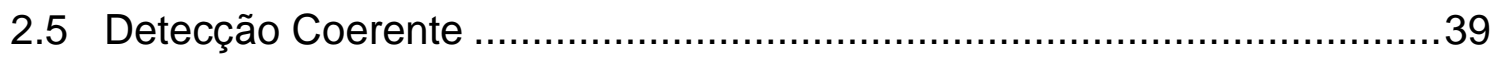

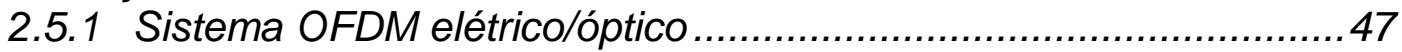

2.6 Resultados OFDM elétrico/óptico …………....................................51

2.6.1 Projeto do sistema OFDM elétrico/óptico com detecção Direta......51

2.6.2 Projeto do sistema OFDM elétrico/óptico com detecção coerente .57

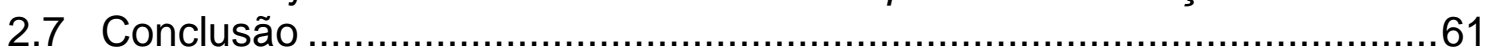

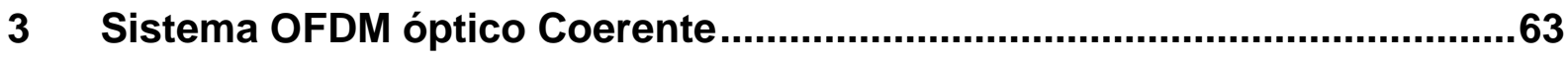

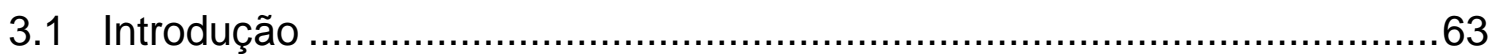

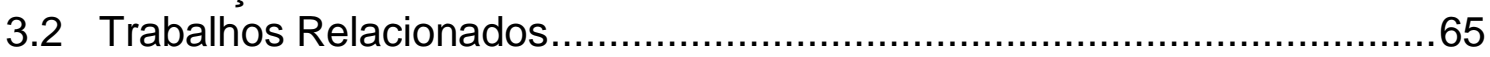

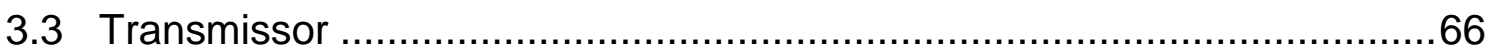

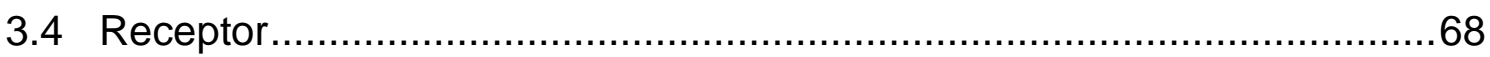

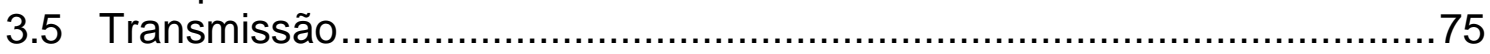

3.6 Geradores ópticos "Comb" .............................................................

3.6.1 Recirculating Frequency Shifting (RFS) .................................. 78

3.6.2 Cascateamento de moduladores Mach-Zehnder..........................81

3.6.3 Laser de Modo discreto ............................................................ 83

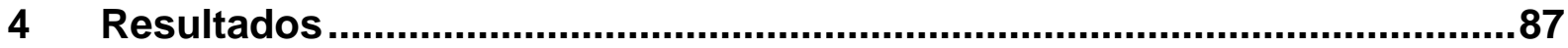

4.1 Transmissão de um supercanal óptico - validação da paleta de simulação 87

4.2 Desempenho sistêmico das três técnicas de geração de supercanais ópticos 93

4.2.1 Efeito da Concatenação de Filtros Ópticos.

4.2.2 Efeito da Concatenação de Amplificadores Ópticos e Enlaces de Fibra 98

4.2.3 Outras considerações. 


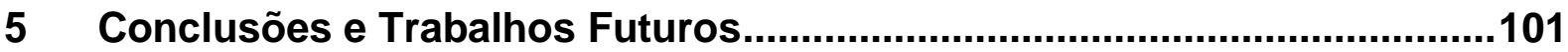

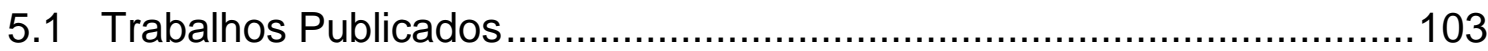

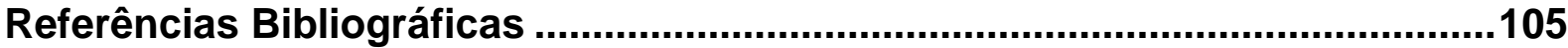




\section{Resumo}

Neste trabalho a técnica de multiportadoras OFDM (Orthogonal Frequency Division Multiplexing), aplicada a sistemas ópticos, é estudada, com foco principal na geração e transmissão dos chamados "supercanais ópticos" modulados em altíssimas taxas (até Terabits/s). O OFDM prevê um melhor aproveitamento da largura de banda e, quando comparada à técnica FDM (Frequency Division Multiplexing), permite uma redução de aproximadamente $50 \%$ do espectro ocupado. Esta economia proporcionada pela técnica torna-a forte candidata para uso em redes ópticas reconfiguráveis, pois provê melhor eficiência espectral aos sinais com reconfiguração de tráfego remoto. Dois cenários serão abordados: o primeiro, em que o sinal com multiportadoras moduladas de forma híbrida (QAM - quadradure amplitude modulation) é gerado no domínio elétrico para, em seguida, modular uma portadora óptica; e o segundo, no qual as multiportadoras são geradas no domínio óptico e, posteriormente, moduladas individualmente também no domínio óptico - e neste caso o formato de modulação pode variar. Para o segundo caso, três técnicas de geração de supercanais serão estudadas e avaliadas a fim de se realizar uma comparação entre elas. Neste trabalho também serão comparadas as técnicas de recepção óptica direta e coerente, aplicadas a sistemas OFDM. Os resultados para o estudo da geração de multiportadoras ópticas, obtidos através de simulações no software Optisystem v.9.0, são validados por resultados experimentais obtidos no Laboratório de Comunicações Ópticas da Fundação CPqD.

Palavras Chave: Orthogonal Frequency Division Multiplexing, recepção óptica direta e coerente, geração de multiportadoras ópticas, modulação digital híbrida, supercanal óptico. 


\section{Abstract}

This manuscript presents a study on the multicarrier modulation technique OFDM (Orthogonal frequency division multiplexing) applied to optical systems. The OFDM technique provides a better use of bandwidth and, compared with FDM (Frequency Division Multiplexing), provides a nearly $50 \%$ reduction of the occupied bandwidth. This feature makes the OFDM technique an ideal candidate for reconfigurable optical networks because it allows better spectral efficiency to the signals with remote traffic reconfiguration.

The study focuses, mainly, on the theoretical investigation of OFDM applied to the transmission of the so-called "optical superchannels", modulated at very high bit rates (above Terabits/s). Two scenarios are discussed: in the first, the multicarrier signal, modulated in a hybrid format (QAM - quadrature amplitude modulation), is generated in the electrical domain before modulating the optical carrier, and in the second the multicarrier beam is generated in the optical domain and subsequently each subcarrier is digitally modulated. In this second approach, three superchannel generation techniques are studied and evaluated for being compared. This work will also compare the direct and coherent detection techniques applied to OFDM systems.

The results for the optical multicarrier generation study, obtained by numerical simulation (platform Optisystem v.9.0), are validated by experimental results obtained at the Laboratory of Optical Communication CPqD Foundation.

Keywords: Orthogonal Frequency Division Multiplexing, the direct and coherent detection techniques, optical multicarrier generation, modulated signal in a hybrid format. 


\section{Lista de Siglas e Abreviaturas}

WDM Wavelength Division Multiplexing

OOK On/Off Keying

NRZ Non Return to Zero

$\mathrm{RZ}$

Return to Zero

OFDM Orthogonal Frequency Division Multiplexing

CO-OFDM Coherent-OFDM

LAN Local Area Network

DAV Digital áudio/vídeo

DAB Digital Audio Broadcast

DSL Digital Subscriber Line

PAPR Peak-to-Average Power Ratio

EDFA Erbium doped Fiber Amplifier

CD Chromatic Dispersion

PMD Polarization Mode Dispersion

FDM Frequency Division Multiplexing

QAM Quadrature Amplitude Modulation

CW Continuous Wave

SNR Signal to Noise Ratio

BER Bit Error Rate

IDFT Inverse Discrete Fourier Transform

DFT Discrete Fourier Transform

ISI Intersymbol Interference

ADSL $\quad$ Asymmetric Digital Subcriber Line 
VDSL Very-high bit-rate Digital Subscriber Line

WLANs Wireless Local Area Networks

$\mathrm{ICl} \quad$ Intercarrier Interference

ISE Intrachannel Spectral Efficiency

OCG Optical Comb Generator

FEC Forward Error Correction

SSB-SC Single Sideband Supressed Carrier

LMS Least Mean Square

DD-LMS Decision Directed LMS

MIMO Multiple Input Multiple Output

FIR Finite Impulse Response

FFPE Feed Forward Phase Recovery 


\section{Lista de Figuras}

Figura 1.1 - Avanço dos sistemas de transmissão por fibras ópticas, em termos de números de canais WDM e taxa de dados por canal [1].

Figura 1.2 - Crescimento do Tráfego da Internet para 2012 [23]........................28

Figura 1.3 - Previsão do Tráfego Global de Dados por Região [23] .......................29

Figura 2.1 - Espectro de um sinal (FDM), modulação multiportadora sem sobreposição......................................................................... 34

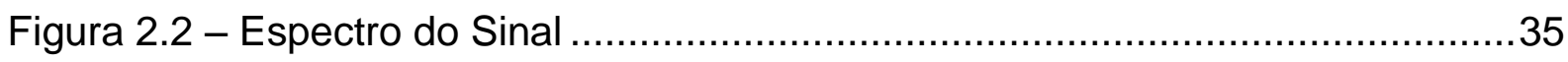

Figura 2.3 - Espectro de um sinal OFDM com 5 subportadoras ...........................36

Figura 2.4 - Espectro de um sinal OFDM, modulação multiportadora com sobreposição.

Figura 2.5 - Diagrama de um receptor Digital ......................................... 38

Figura 2.6 - Modulador de fase e quadratura (IQM) ...................................... 40

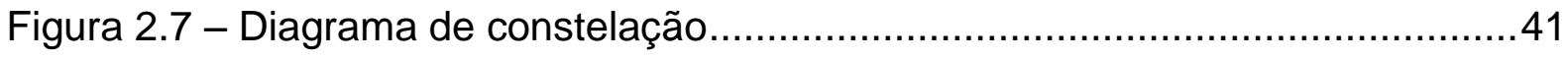

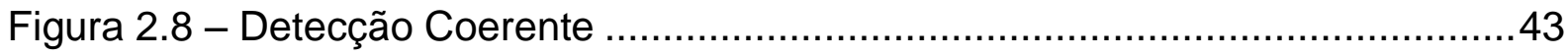

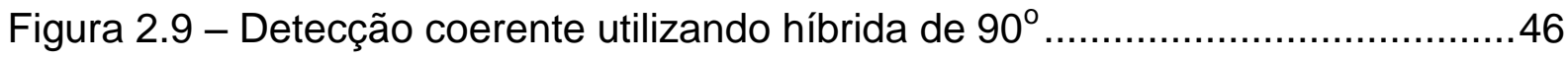

Figura 2.10 - Diagrama de um sistema OFDM elétrico-Óptico .............................48

Figura 2.11 - Transmissor OFDM no software Optisystem ..............................50

Figura 2.12 - Espectro das subportadoras no domínio da frequência ....................50

Figura 2.13 - Sistema OFDM com detecção direta........................................52

Figura 2.14 - (a) Espectro do sinal em banda base(domínio elétrico), (b)

Espectro do sinal no domínio óptico com banda lateral dupla ........................53

Figura 2.15 - (a) Espectro do sinal no domínio óptico após o filtro suprimir a banda lateral, (b) espectro do sinal após percorrer $100 \mathrm{~km}$ de fibra ................54

Figura 2.16 - BER x OSNR do sistema DD-OFDM.....................................55

Figura 2.17 - (a) Constelação do sinal recebido em back to back, (b) Constelação do sinal recebido após percorrer uma fibra de $100 \mathrm{~km}$.................57

Figura 2.18 - Sistema OFDM óptico coerente ..........................................58

Figura 2.19 - BER x OSNR do sistema Co-OFDM ...................................... 59 
Figura 2.20 - BER em função da distância percorrida na fibra. 60

Figura 2.21 - (a) Constelação do sinal recebido em back to back, (b) Constelação do sinal recebido após percorrer uma fibra de 100km.

Figura 3.1 - Subportadoras Ortogonais no Domínio da Frequência 65

Figura 3.2 - Transmissor OFDM com portadoras amarradas em frequência. Os espectros (a), (b), (c) são ilustrados conforme cada etapa

Figura 3.3 - Polarizações Ortogonais e constelações da Polarização X e Y da modulação DP-QPSK

Figura 3.4 - Polarization Beam Splitter ....

Figura 3.5 - Receptor óptico coerente com fase e polarização

Figura 3.6 - Diagrama de blocos do algoritmo de processamento digital de sinais [52].

Figura 3.7 - Diagrama de constelação do sinal recebido........................................71

Figura 3.8 - Bloco de normalização e ortogonalização ...........................................71

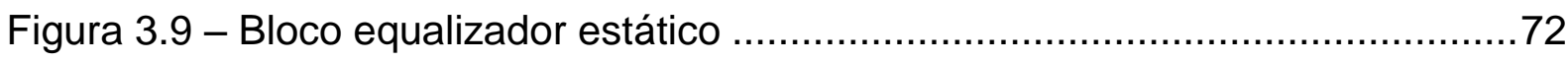

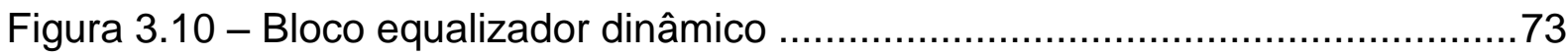

Figura 3.11 - Bloco estimador de frequência ........................................................73

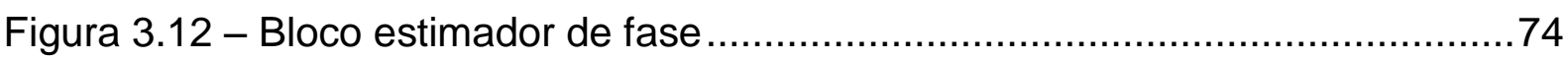

Figura 3.13 - Bloco de análise de constelação ………………………………....75

Figura 3.14 - Diagrama esquemático de um Gerador óptico comb ..........................79

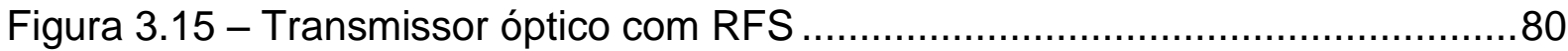

Figura 3.16 - Espectro óptico na saída do gerador óptico comb ............................81

Figura 3.17 - Transmissor óptico com cascata de moduladores Mach-Zehnder ......82

Figura 3.18 - Espectro gerado com cascata de moduladores Mach-Zehnder ...........83

Figura 3.19 - Transmissor óptico alimentado por uma onda senoidal ......................84

Figura 3.20 - Espectro de saída utilizando laser de modo discreto ..........................85

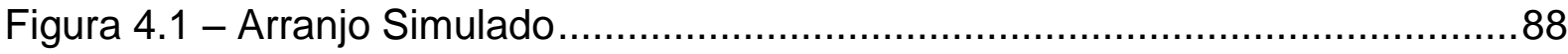

Figura 4.2 - Espectro de saída do comb generator: (a) Simulado, (b) Experimental [64] 
Figura 4.3 - Espectro após o modulador DP-QPSK: (a) Simulado,

(b)Experimental[64]

Figura 4.4 - BER VS OSNR em função no número de voltas do loop do meio de transmissão para os canais : (a) \#1, (b)\#5, (c)\#10

Figura 4.5 - Constelações simuladas para os modos de polarização ortogonais do canal 1 no eixos (a) $\mathrm{X}$ e (b) $\mathrm{Y}$ (No inset são apresentadas as constelações obtidas no experimento)

Figura 4.6 - Sistema DP-QPSK com $112 \mathrm{~Gb} / \mathrm{s}$

Figura 4.7 - BER x Número de voltas do filtro óptico para às três técnicas de geração de supercanal para os canais : (a) \#1, (b)\#5, (c)\#10

Figura 4.8 - BER x número de voltas da fibra óptica para às três técnicas de geração de supercanais ópticos para os canais: (a)\#1, (b)\#5 e (c)\#10 


\section{Lista de Tabelas}

Tabela 2.1 - Dados da simulação para OFDM com detecção direta e coerente ......56

Tabela 3.1 - Demonstrações experimentais de supercanais [52] ............................66

Tabela 4.1 - Parâmetros de simulação para OFDM óptico ......................................95 



\section{Introdução}

A utilização, em sistemas de comunicações ópticas, de diferentes formatos de modulação digital é vista atualmente como maneira promissora para aumentar a eficiência espectral dos sistemas, aproveitando a infraestrutura já implantada. Técnicas digitais de modulação podem ser classificadas em duas categorias: modulação com portadora única, em que os dados são transportados por uma única portadora, e modulação com múltiplas portadoras. A técnica WDM (wavelength division multiplexing) pode ser considerada um caso especial de transmissão por

multiportadoras espaçadas entre si de, pelo menos, $50 \mathrm{GHz}$, e onde, para cada comprimento de onda, o formato de modulação mais usado tem sido o OOK (on/off keying). Esta é uma forma mais simples de modulação em amplitude, e representa dados digitais com a presença ou ausência de uma onda portadora com codificação NRZ (non return to zero) ou RZ (return to zero) [1]. Entretanto, a necessidade de mais altas taxas de transmissão [2] e um melhor aproveitamento da eficiência espectral da banda utilizada conduziram à investigação de formatos de modulação alternativos com melhores desempenhos.

$\mathrm{Na}$ segunda categoria (modulação multiportadora) os dados são transportados através de múltiplas subportadoras estreitamente espaçadas e, em alguns casos, sobrepostas espectralmente (i.e. sem banda de guarda). A multiplexação por divisão de frequências ortogonais (OFDM) é uma classe especial de sistemas com multiportadoras que só recentemente ganhou a atenção na 
comunidade de comunicações ópticas, especialmente depois de ter sido proposta para transmissão por longa distância com detecção coerente [3] e direta [4], [5]. Experimentos com transmissão OFDM óptica coerente (CO-OFDM, CoherenteOFDM) em $100 \mathrm{~Gb} / \mathrm{s}$ realizados por vários grupos colocaram a técnica na corrida para a próxima geração de redes ópticas [6].

Historicamente, o OFDM surgiu como técnica de modulação no domínio elétrico (RF) e foi evoluindo rapidamente. O avanço tecnológico permitiu que, hoje, diferentes sistemas de comunicação ofereçam, constantemente, novos serviços aos seus usuários, com troca de informações realizada com maior facilidade, rapidez e comodidade. Nos sistemas de telefonia celular, por exemplo, já se pode transmitir pacotes multimídia em tempo real. Entretanto, para que isso seja possível, é necessário que o sistema tenha altas taxas de transmissão, grande eficiência espectral e qualidade de serviço garantida.

Com estes atributos, o OFDM é uma opção que vem sendo estudada e utilizada em quase todos os principais padrões de comunicação, incluindo aplicações em LAN (local area network) sem fio (IEEE 802.11, também conhecido como WiFi), vídeo digital e padrões de áudio (DAV, digital áudio/vídeo/ DAB, digital audio broadcast)), linha de assinante digital (DSL, digital subscriber line) e no sistema de telefonia celular [7].

O OFDM óptico tem semelhanças e diferenças com a contrapartida RF. Por um lado, o OFDM óptico sofre com dois problemas bem conhecidos no domínio elétrico, que são a alta razão entre a potência de pico e a potência média (PAPR, peak to average power ratio) e a sensibilidade a ruído de fase e frequência [1], [8]. Duas vantagens fundamentais do OFDM são a robustez do canal frente à dispersão cromática e a possibilidade de estimação de fase do sinal no domínio do tempo. 
Constitui, portanto uma solução eficaz para mitigar a interferência intersimbólica causada por um canal dispersivo [4]. Por outro lado, o canal óptico tem o seu próprio conjunto de problemas. Uma das principais diferenças no caso óptico é a existência de não linearidades do meio e da sua interação complexa com a dispersão de fibras, inexistente nos sistemas de RF [9].

\subsection{Revisão Histórica e Perspectivas Futuras}

A primeira proposta da técnica OFDM foi apresentada, em 1966, por Robert W. Chang e patenteada, em 1970, pelo Bell Labs [10]. Já em 1969, surgiu a proposta para gerar sinais multiplexados, usando a transformada inversa de Fourier (IFFT - Inverse Fast Fourier Transform) [11], permitindo-se que os sinais fossem processados com maior velocidade computacional.

Em 1980, foi proposto um aspecto importante da técnica, o prefixo cíclico (CP), e durante a década de 80 , o Bell Labs publicou algumas pesquisas sobre OFDM em comunicações móveis [12]. Em 1982, Lassalle e Alard [13] aplicaram a técnica OFDM em radiofusão e notaram a importância desta combinada à técnica de correção de erro (FEC - Forward error correction). Em 1995, Telatar e Foschini [14], [15] publicaram trabalhos sobre a possibilidade da técnica ser usada em sistemas com múltiplas entradas e múltiplas saídas, o que melhoraria, posteriormente, o desempenho das comunicações móveis com o uso de varias antenas de transmissão e recepção.

Por volta de 2001, a técnica começa a ser usada e implementada em redes locais sem fio [16] e a partir de 2005 começou a ser estudada para aplicações em comunicações por fibras ópticas [17]. No aspecto do espaçamento entre as portadoras é que o OFDM se diferencia do WDM, pois é uma técnica multiportadora 
com sobreposição de canais, na qual se prevê uma redução de aproximadamente $50 \%$ da largura de banda, quando comparada com a técnica multiportadora sem sobreposição [18].

Historicamente, apesar da perda por propagação na fibra ser extremamente baixa em comparação com a de sistemas de RF, onde ocorre propagação em multipercurso e a transmissão é mais susceptível a interferências, os primeiros sistemas ópticos ainda necessitavam de regeneração para distâncias superiores a $100 \mathrm{~km}$. No final dos anos 80 , a detecção coerente, por prover uma melhoria na sensibilidade do receptor, foi introduzida para aumentar a distância de transmissão [19], [20]. No entanto, este esforço desvaneceu após o desenvolvimento do amplificador óptico a fibra dopada com érbio, EDFA, no início da década de 90. Este advento marcou uma nova era das comunicações ópticas no qual com grande número de canais, multiplexados em comprimento de onda (WDM), os sinais puderam ser transmitidos ao longo de milhares de quilômetros, sem regeneração [1].

A Figura 1.1 resume os progressos em comunicações ópticas alcançados durante as últimas três décadas [1]. O crescimento da capacidade do sistema ocorreu devido ao avanço da taxa de bits e do número de canais de comprimento de onda que pode ser multiplexado em uma fibra. Em meados dos anos 90, a capacidade de transmissão por um canal atingiu $10 \mathrm{~Gb} / \mathrm{s}$ e, por volta de 2003 , sistemas WDM com $40 \mathrm{~Gb} / \mathrm{s}$ por canal já eram disponíveis comercialmente [21], [22]. 


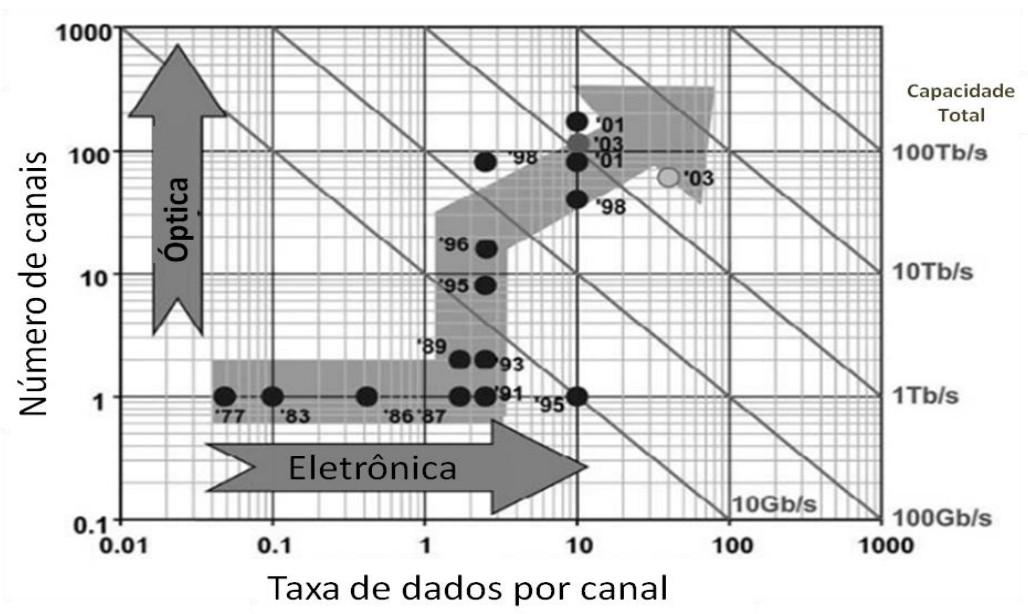

Figura 1.1 - Avanço dos sistemas de transmissão por fibras ópticas, em termos de números de canais WDM e taxa de dados por canal [1]

O advento da internet mudou a infraestrutura de comunicação de informações. O tráfego da internet, com novas aplicações, como YouTube, redes sociais e IPTV, tem aumentado continua e rapidamente e não aponta para uma desaceleração no futuro previsível [23]. A Figura 1.2 mostra uma projeção do tráfego de internet até 2012 [23], indicando o crescimento da largura de banda de um fator 2 a cada 2 anos. Esse crescimento coloca uma enorme pressão sobre a infraestrutura de informação subjacente a todos os níveis, a partir do núcleo para redes metropolitanas e de acesso. Segundo os dados da cisco de 2011, projetados para 2016, o tráfego mundial de dados móveis aumentará 18 vezes nesse período atingindo um total de 10,8 exabytes por mês - ou um volume de 130 exabytes por ano - até 2016. Para o Brasil é esperado um aumento de 19 vezes, alcançando um total de 0,26 exabytes por mês em 2016 . 


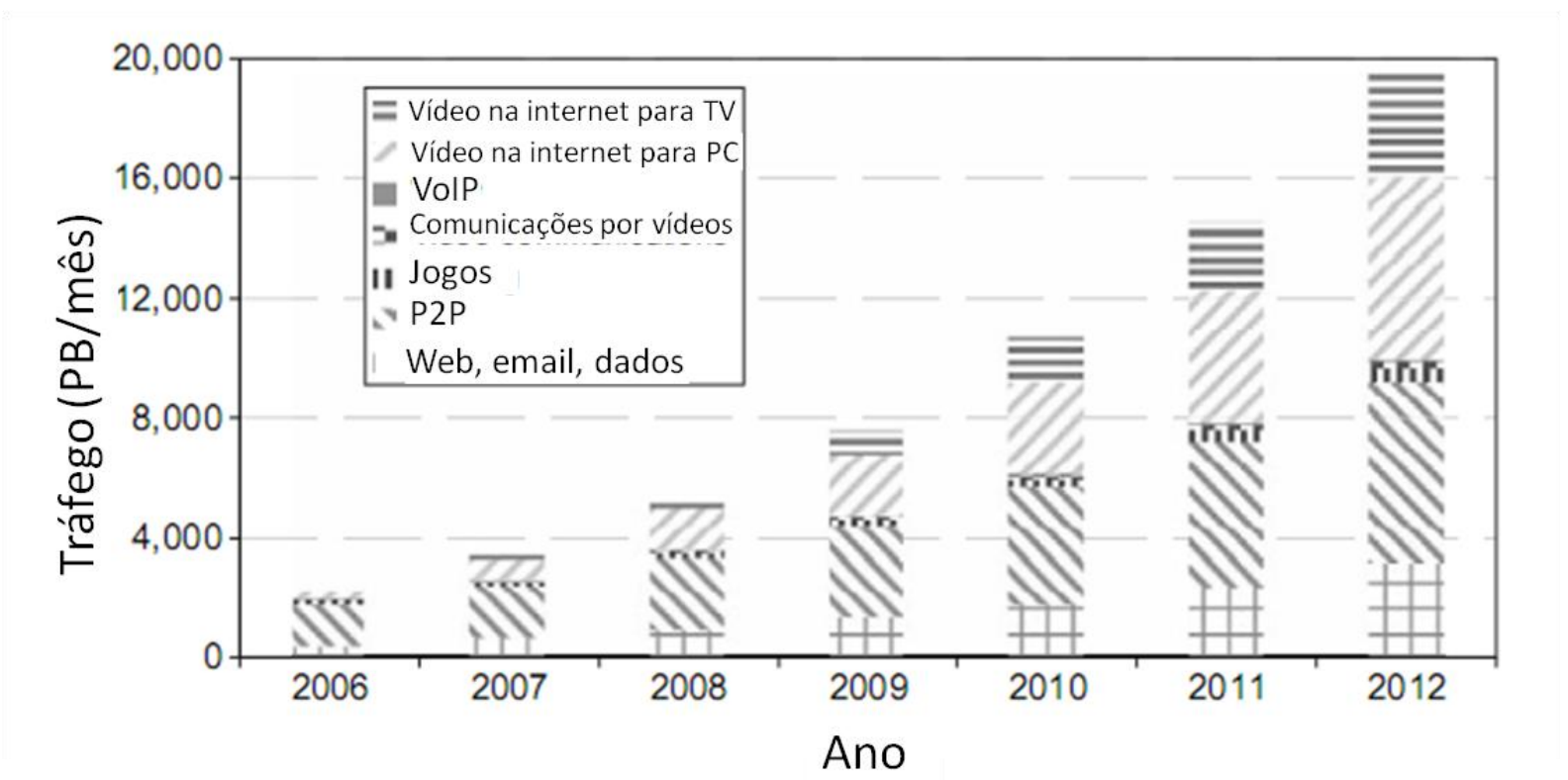

Figura 1.2 - Crescimento do Tráfego da Internet para 2012 [23]

O esperado aumento acentuado no tráfego móvel é devido, em parte, a um aumento projetado no número de dispositivos móveis conectados à Internet, que excederá a população do planeta. Segundo as estimativas das Nações Unidas, esta deve ser de 7,3 bilhões de habitantes até 2016. Entre 2011 e 2016, estima-se que o tráfego global de dados móveis superará em três vezes o tráfego global de dados fixos, como podemos observar na Figura 1.3.

A capacidade de uma fibra, equivalente a $100 \mathrm{~Tb} / \mathrm{s}$ [24], representa uma limitação ao atendimento da demanda continuamente crescente por banda e coloca novos desafios para a pesquisa em comunicação óptica, que se vê frente à necessidade de desenvolver sistemas inovadores com taxas de dados mais altas. 


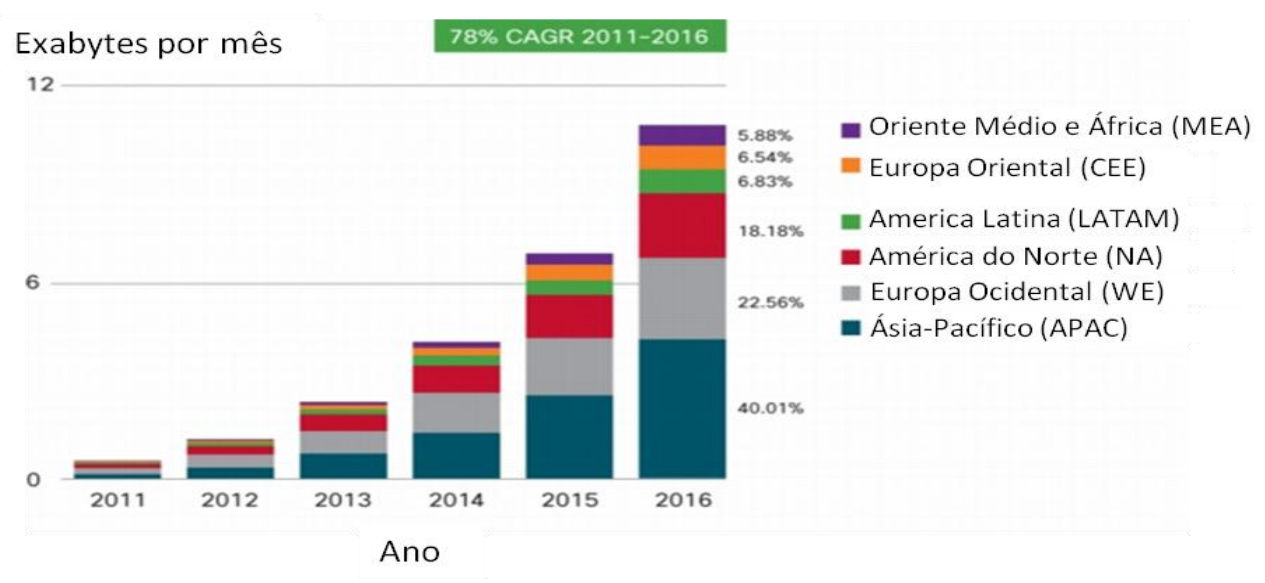

Figura 1.3 - Previsão do Tráfego Global de Dados por Região [23]

Para este cenário futuro, J. Armstrong [1] destaca a importância da técnica OFDM unida às técnicas de modulação já existentes, permitindo que os novos sistemas operem com robustez frente às limitações de camada física, por exemplo, evitando interferências intersimbólicas, causadas por efeitos dispersivos. O OFDM emprega sinais com portadoras ortogonais para transmitir, em paralelo, informações provenientes de diferentes fontes, durante um determinado período. Através de uma técnica de superposição do espectro de sinais, a técnica OFDM permite um aumento da eficiência espectral $(\mathrm{J})$ do sistema, que é definida como a razão entre a taxa de bit $\left(R_{b}\right)$ transmitida e a largura de banda $(W)$ utilizada [25].

$$
J=\frac{R_{b}}{W}
$$

Como dito anteriormente, no início dos anos 90, o amplificador de fibra dopada com érbio EDFA (erbium doped fiber amplifier) foi uma inovação na melhoria da transmissão de sinais ópticos [26]. O uso dos EDFAs permitiu que longas distâncias pudessem ser superadas sem conversões eletro-ópticas, porém atualmente necessita do apoio de novas tecnologias para suprir a demanda por banda. Assim, os formatos de modulação digital de alta ordem [27] têm sido estudados de modo a aumentar a eficiência espectral além de combater or efeitos de 
propagação como a dispersão cromática (CD - chromatic dispersion) e dos modos de polarização, PMD (polarization mode dispersion).

\subsection{Motivação do Trabalho}

As discussões sobre a evolução das redes ópticas [6] representam uma oportunidade para análise das opções tecnológicas que serão empregadas nos sistemas de telecomunicações de alta capacidade nos próximos 10 anos. O constante surgimento de aplicações de banda larga requer uma infraestrutura de rede que seja dinamicamente adaptável a novas configurações, mantendo boa relação custo-benefício. Os atuais sistemas ópticos de comunicação atendem a essa demanda operando a taxas de até $100 \mathrm{~Gb} / \mathrm{s}$ por canal, porém apresentam desafios quanto ao número de canais e sua pouca granularidade, ou seja é a extensão à qual um canal pode ser dividido em partes menores. O aumento de demanda estimada para os próximos anos é incompatível com o atual modelo, obrigando a investigação de novas tecnologias. Nesse contexto, a técnica de multiportadoras ortogonais tem assumido um papel importante e neste trabalho, em particular, investigamos geração de múltiplas portadoras ópticas coerentes para aplicação em sistemas de alta capacidade.

Ao longo desta dissertação, serão simuladas algumas implementações de transmissores e receptores de um sistema OFDM óptico, e seu desempenho será avaliado. Os objetivos gerais do trabalho consistem no estudo e implementação da técnica OFDM no domínio óptico. Já os objetivos específicos, podem ser definidos como:

1) Estudo das técnicas de OFDM gerado no domínio elétrico e transmitido no domínio óptico. 
2) Estudo comparativo entre tais sistemas elétrico-óptico com detecção direta e coerente.

3) Estudo das técnicas de OFDM gerado, transmitido e recebido no domínio óptico. Em particular serão avaliados três técnicas de geração de pentes ópticos que podem produzir um conjunto de sinais ópticos ortogonais entre si, denominados supercanais.

4) Estudo sistêmico da geração, recepção de supercanais ópticos com taxas superiores a $400 \mathrm{~Gb} / \mathrm{s}$.

\subsection{Organização}

O trabalho está organizado em cinco capítulos. Desta forma, o Capítulo 1, foi direcionado a introduzir o tema desta pesquisa, bem como apresentar as motivações e justificativas que levaram à realização da pesquisa.

O Capítulo 2 destina-se ao estudo dos conceitos ligados à multiplexação por divisão de frequência (FDM) e multiplexação por divisão de frequência ortogonal (OFDM), descreve o sistema OFDM elétrico/óptico, e por fim analisa o desempenho do sistema OFDM com detecção direta e coerente.

No Capítulo 3 são apresentadas as principais características de um sistema OFDM óptico e as três técnicas para geração de pentes ópticos. Ilustra-se também todo o processo de modelagem e simulação sistêmica estudada nessa dissertação.

No Capítulo 4 são apresentados os resultados das simulações computacionais para sistemas OFDM óptico com detecção coerente, e a comparação dos resultados referentes às três técnicas de geração de supercanais.

Por fim, cabe ao Capítulo 5 fornecer as discussões e conclusões obtidas e propor em linhas gerais alguns trabalhos futuros. 


\section{Sistema OFDM Elétrico/Óptico}

\subsection{Introdução}

Nos últimos anos, a tecnologia no campo das comunicações ópticas tem experimentado avanços sem precedentes, resultando em sistemas cada vez mais sofisticados e complexos. Em decorrência disso, a utilização, de diferentes formatos de modulação é vista, atualmente, como uma forma promissora de aumentar a eficiência espectral, frente aos diversos efeitos de degradação do sinal em fibra óptica, sem alterar a infraestrutura já implantada. É nesse contexto que surge a técnica OFDM (Orthogonal Frequency Division Multiplexing) que permite a sobreposição espectral das subportadoras. A descrição da técnica OFDM é abordada nas seções seguintes.

\subsection{Multiplexação por Divisão de Frequência (FDM - Frequency Division Multiplexing)}

Mesmo com a digitalização do sinal analógico, ainda é preciso maximizar a transmissão de dados, e isso pode ser feito através da multiplexação, que é uma importante operação em processamento de sinais. No domínio da frequência sempre que a largura de banda de um meio físico for maior ou igual à largura de banda de um determinado sinal, este meio poderá ser utilizado para transmitir este sinal [8]. Na prática, a banda passante necessária para a transmissão do sinal é, em geral, bem menor do que a banda passante disponível nos meios físicos. Portanto, dentro 
deste fundamento de aproveitar a banda passante maior para a transmissão simultânea de outros sinais se baseia o conceito de multiplexação espectral, ou seja, muitos sinais independentes podem ser combinados em um sinal composto para a transmissão dentro de um único canal utilizando o mesmo meio de transmissão. Quando os sinais são separados por bandas de frequências, de maneira que eles não se interfiram mutuamente, ou seja, de uma forma que os sinais não interfiram entre si, tem-se a técnica de multiplexação por divisão de frequência (FDM) [8].

Neste sistema, os espaçamentos entre as portadoras permitem uma recepção adequada utilizando-se filtros e demoduladores convencionais, como os detectores de envoltória. O FDM é classificado como uma técnica multiportadora sem sobreposição de canais e apresenta, como principal desvantagem, a necessidade das bandas de guarda, que reduzem a eficiência do uso do espectro como podemos observar na Figura 2.1 [18].

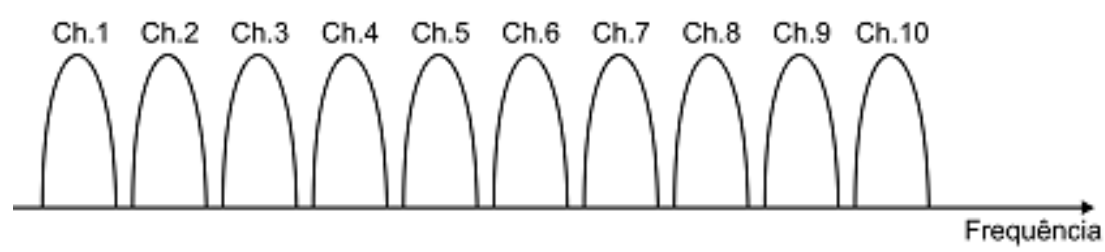

Figura 2.1 - Espectro de um sinal (FDM), modulação multiportadora sem sobreposição

\subsection{Multiplexação por Divisão de Frequência Ortogonal (OFDM - Orthogonal Frequency Division Multiplexing)}

A técnica OFDM de transmissão de dados surgiu como uma evolução do FDM e, ao invés de utilizar bandas de guarda para a separação das subportadoras na recepção do sinal, trabalha com sobreposição espectral das subportadoras. Esta técnica pertence a uma classe de modulação mais ampla (Multicarrier Modulation, 
$M C M$ na qual a informação é transportada por muitas subportadoras em taxas mais baixas [4].

O uso conjunto da técnica OFDM com técnicas de modulação como QAM (Quadrature Amplitude Modulation) e QPSK (Quadrature Phase Shift Keying) resulta em um sinal com robustez à interferência intersimbólica [1]. Uma das alternativas para o aumento da eficiência espectral é o uso da modulação multinível QAM que combina duas componentes de uma mesma frequência óptica, cujas amplitudes são moduladas independentemente e as fases são deslocadas entre si em um ângulo de 90 graus. No OFDM as portadoras são escolhidas de forma que os sinais sejam ortogonais durante um determinado período, logo o OFDM é classificado como uma técnica multiportadora com sobreposição [28], [29].

A Figura 2.2 ilustra o espectro de um pulso gerado, da forma sinc(fT), com cruzamentos de zeros em pontos múltiplos de 1/T, sendo $T$ a duração de um símbolo. O valor "0" no eixo horizontal corresponde à frequência da portadora.

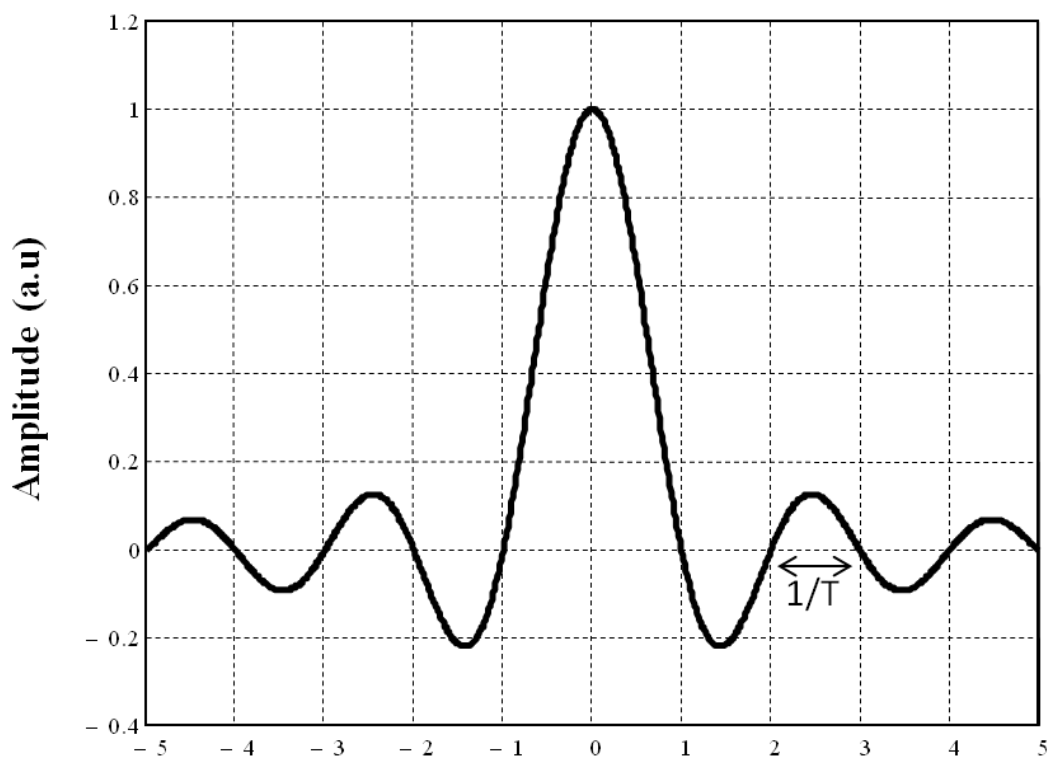

Frequência (a.u)

Figura 2.2 - Espectro do Sinal 
Conforme ilustrado na Figura 2.3, em um sistema OFDM o espaçamento entre as subportadoras é cuidadosamente selecionado de forma que cada subportadora seja alocada em pontos de cruzamento de zero do espectro das demais. Apesar de existir uma sobreposição espectral das subportadoras moduladas, a informação que cada subportadora irá conduzir poderá ser isolada das demais, ou seja, existe ortogonalidade entre elas, devida ao espaçamento de frequência empregado. Porém, para que se tenha ortogonalidade entre os subcanais na recepção é necessário que as subportadoras estejam centradas nas respectivas frequências dos subcanais OFDM, além de se ter a devida sincronização de relógio.

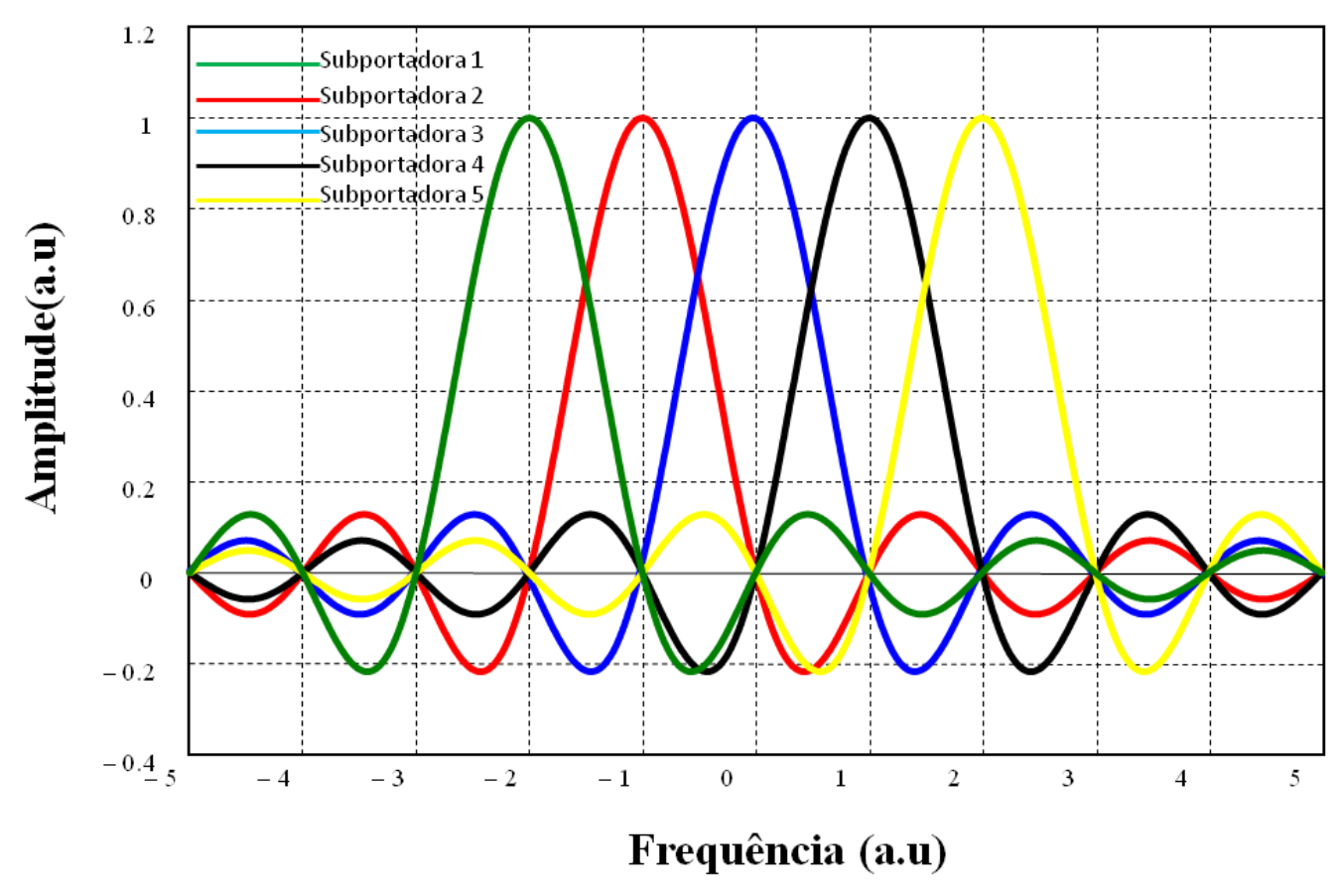

Figura 2.3 - Espectro de um sinal OFDM com 5 subportadoras

Nos sistemas de transmissão convencionais, os símbolos são enviados em sequência, em uma única portadora, onde o espectro irá ocupar toda a faixa de frequências disponíveis. Já a técnica OFDM consiste na transmissão paralela de dados por diversas subportadoras. Neste tipo de transmissão de dados a banda total do sinal é dividida em $\mathrm{N}$ subcanais sem sobreposição, onde cada canal será 
modulado com um símbolo em separado formando $\mathrm{N}$ subcanais multiplexados em frequência. A taxa de transmissão por subportadora será mais baixa quanto maior for o número delas [1]. Como podemos observar na Figura 2.4, utilizando uma modulação com sobreposição temos uma redução significativa na largura de banda do canal.

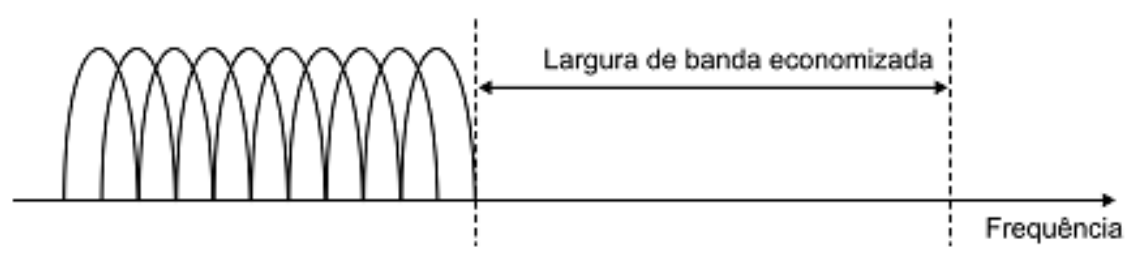

Figura 2.4 - Espectro de um sinal OFDM, modulação multiportadora com sobreposição

No exemplo da Figura 2.4 a sobreposição das subportadoras reduz em quase $50 \%$ a largura de banda a ser utilizada comparada com o espectro FDM com modulação multiportadora sem sobreposição como ilustrado na Figura 2.1. A economia na largura de banda proporcionada pela técnica a torna boa candidata para redes ópticas, que requerem melhor eficiência espectral [30].

\subsection{Detecção Direta}

A maioria dos sistemas ópticos implantados atualmente é baseada em um esquema de modulação digital em que uma corrente de bits elétrica modula a intensidade de uma portadora óptica no transmissor óptico. O sinal óptico transmitido pela fibra incide diretamente sobre um receptor óptico, que irá convertê-lo para o sinal digital original no domínio elétrico. Esse esquema é conhecido como modulação de intensidade com detecção direta [31].

A finalidade do receptor óptico é converter o sinal óptico para o domínio elétrico e recuperar os dados transmitidos, e sua configuração depende do formato de modulação utilizado pelo transmissor. A maioria dos sistemas emprega a 
modulação de intensidade binária e, neste contexto, iremos descrever um receptor óptico digital convencional, cujo diagrama de blocos é visto na Figura 2.5. Os seus principais componentes podem ser dispostos em 3 grupos: front end, canal linear e circuito de decisão.

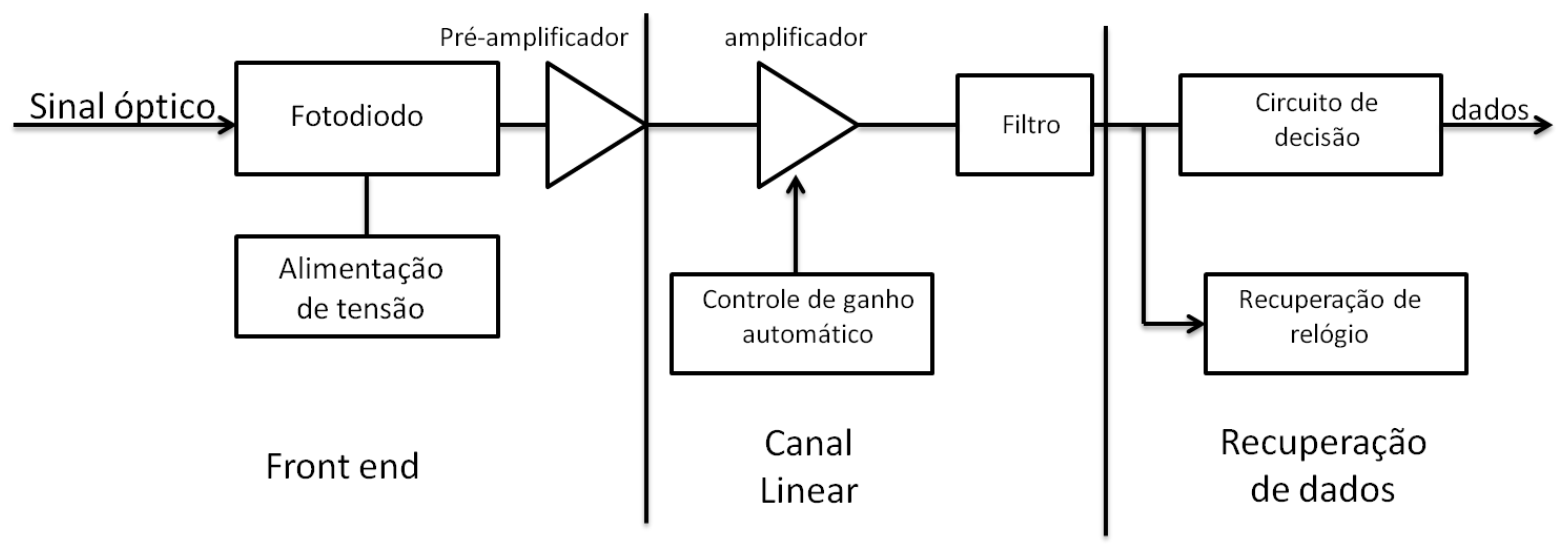

Figura 2.5 - Diagrama de um receptor Digital

\subsubsection{Front End}

O front end de um receptor é constituído por um fotodiodo seguido por um pré-amplificador elétrico. O sinal óptico incide no fotodiodo, que irá converter o fluxo de bits ópticos em um sinal elétrico. O papel do pré-amplificador é amplificar o sinal elétrico para a realização do processamento adicional [31].

\subsubsection{Canal Linear}

O canal linear em receptores consiste de um amplificador de alto ganho (o amplificador principal) e um filtro passa-baixa. Um equalizador às vezes é incluído antes do amplificador para corrigir a largura de banda limitada do front end. O ganho do amplificador é controlado automaticamente para limitar a tensão média de saída a um nível fixo independentemente da potência óptica incidente no receptor. A função 
do filtro passa-baixas é reduzir o ruído sem introduzir muita interferência intersimbólica [31].

\subsubsection{Circuito de Decisão}

A seção de recuperação de dados dos receptores ópticos consiste de um circuito de decisão e um circuito de recuperação de relógio. A finalidade deste último é isolar um componente espectral a partir do sinal recebido. Este componente fornece informação sobre o slot de bits para o circuito de decisão e fornece informações para o processo de decisão [31].

O circuito de decisão compara a saída do canal linear com um limiar plano. Os tempos de amostragem são determinados pelo circuito de recuperação de relógio que decide se o sinal de bit corresponde a um bit 1 ou a um bit 0 . 0 melhor instante de amostragem corresponde à situação em que a diferença de nível de sinal entre 1 e 0 bits é máxima.

A detecção direta não utiliza valores de referência, mas pode utilizar modulação diferencial, onde a informação é transmitida pela diferença entre dois símbolos sucessivos [32]. Apesar da detecção direta ter sido a pioneira nas comunicações ópticas, as transmissões ópticas futuras se basearão, na maioria, na detecção coerente devido a fatores como a melhoria na sensibilidade do receptor e o melhor aproveitamento da largura de banda disponível [7].

\subsection{Detecção Coerente}

Em sistemas com detecção coerente a coerência de fase da portadora óptica desempenha um papel importante e o oscilador local LO (local oscillator), situado no receptor, deve ser sintonizado na mesma frequência, ou muito próximo à 
frequência da portadora. Técnicas de transmissão coerentes foram estudadas extensivamente durante a década de 1980 [33] em função das características de aumento de sensibilidade e robustez do receptor. Mas sua implantação, no entanto, foi adiada devido à sua complexidade e ao custo elevado, além de ser suplantada pelos amplificadores ópticos [34].

Nos sistemas ópticos coerentes digitais atuais o sinal da portadora é gerado por um laser de onda contínua e modulado por um modulador em fase e quadratura (in-fase/quadrature modulator - IQM), normalmente utilizado na transmissão [27]. Moduladores IQM são construídos aliando moduladores de Mach-Zehnder (MachZehnder Modulator - MZM) e moduladores de fase (phase modulator - PM), como ilustrado na Figura 2.6 Nessa configuração, os moduladores MZM atuam como moduladores de amplitude, enquanto o modulador PM é utilizado para defasar o sinal em $90^{\circ}$.

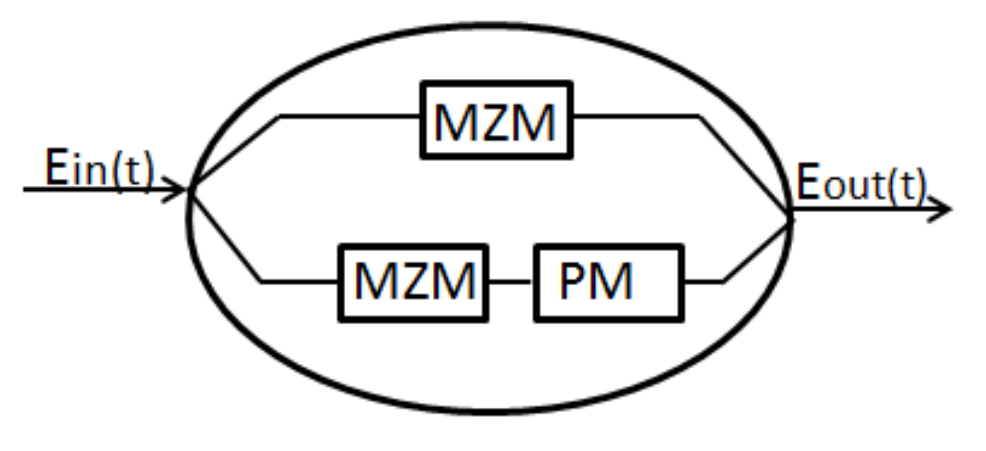

Figura 2.6 - Modulador de fase e quadratura (IQM)

No transmissor, pode-se considerar o laser como uma fonte de luz contínua e com isso pode-se modelar o campo elétrico, de acordo com [31] e [27], como:

$$
E_{c w}(t)=\sqrt{P_{s}} e^{j\left(\omega_{s} t+\varphi_{s}\right)} e_{s}
$$


No qual $\sqrt{P_{s}}$ é a amplitude do campo, $\omega_{s}$ é a frequência da portadora, $\varphi_{s}$ é a fase inicial e $e_{s}$ é a polarização do campo. O índice "s" é apenas para indicar que é o laser de transmissão ou de sinal.

As modulações são habitualmente representadas por um diagrama de amplitude e fases designado por constelação, onde é comum fazer a representação dos eixos I e $Q$ do sinal, assim como ilustra a Figura 2.7. Esse tipo de modulador permite a transmissão de diferentes constelações. Sistemas coerentes possuem uma grande vantagem na transmissão usando formatos de modulação de altas ordens, pois todos os parâmetros do campo óptico (amplitude e fase) são transferidos para o domínio elétrico na detecção coerente, permitindo a aplicação de técnicas de processamento digital de sinais na recepção [27].

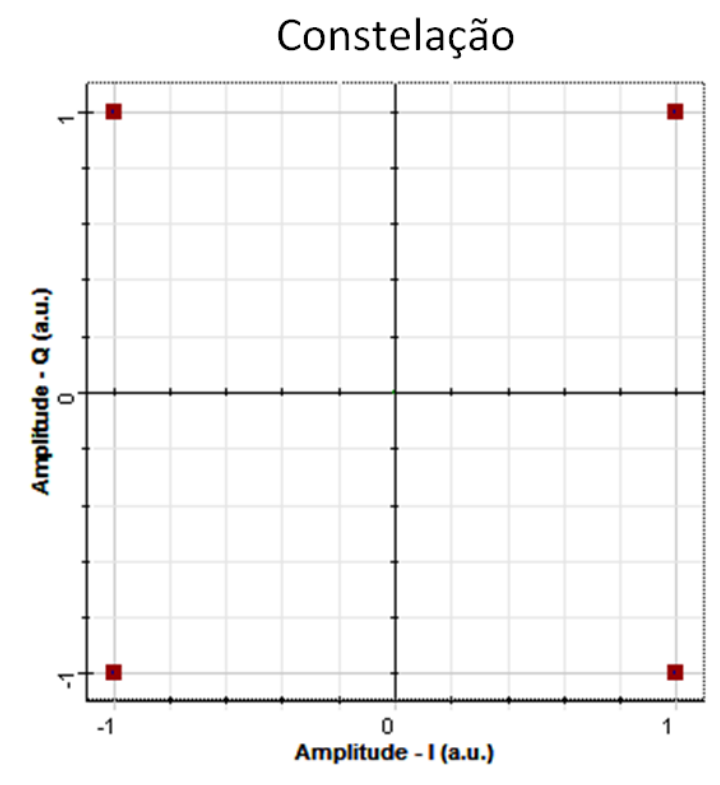

Figura 2.7- Diagrama de constelação

Há três categorias de recepção coerente quanto à fase e a frequência do sinal: homódino, heteródino e intradino. No receptor homódino, o laser LO e o laser de sinal têm a mesma frequência e a diferença de fase entre os dois é zero. A vantagem do receptor homódino é ter a melhor sensibilidade; sendo até $3 \mathrm{~dB}$ 
superior ao heteródino. Entretanto, a realização prática para o travamento de fase e frequência nesse receptor é complexa e de alto custo. No receptor heteródino, o laser de sinal e o laser oscilador local têm frequências distintas e isso é mais simples de ser implementado, não há necessidade de travamento de frequência e fase entre os lasers; entretanto sua sensibilidade é inferior. Outra desvantagem para esse tipo de receptor é que os componentes necessitam de uma maior largura de banda, pois o sinal não está em banda base. No receptor intradino, a diferença de frequência entre os lasers não é zero, mas é muito próxima disso, com um desvio máximo podendo ser compensado digitalmente. Esse tipo de receptor é o mais estudado e desenvolvido para os novos sistemas coerentes e, por isso, iremos utilizar, nos nossos sistemas, o conceito e a estrutura do receptor intradino, considerando os subsistemas para recuperação de sinal no domínio digital [35].

De forma similar à equação (2.1), o campo elétrico do oscilador local (LO) pode ser definido como:

$$
E_{l o}(t)=\sqrt{P_{l o}} e^{j\left(\omega_{l o} t+\varphi s_{l o}\right)} e_{l o}
$$

De acordo com [26] o campo elétrico na saída de um modulador IQ, ou até mesmo no modulador $\mathrm{PM}-\mathrm{Q}$ para o campo elétrico em cada polarização, pode ser representado como:

$$
E_{s}(t)=\sqrt{P_{s}} e^{j\left(\omega_{s} t+\varphi_{s}\right)} a(t) e^{j \varphi(t)} e_{s}
$$

Onde $a(t)$ indica a componente de modulação em amplitude e $\varphi(t)$ a componente de modulação de fase do laser.

O princípio da detecção coerente é a combinação do sinal gerado no laser com o sinal gerado no oscilador local, que pode ser realizado através de um acoplador 3dB. Como ilustra a Figura 2.8, a combinação entre esses campos ópticos 
ocorre no acoplador, resultando nos campos elétricos $E_{1}$ e $E_{2}$, que servem de entrada para o fotodetector.

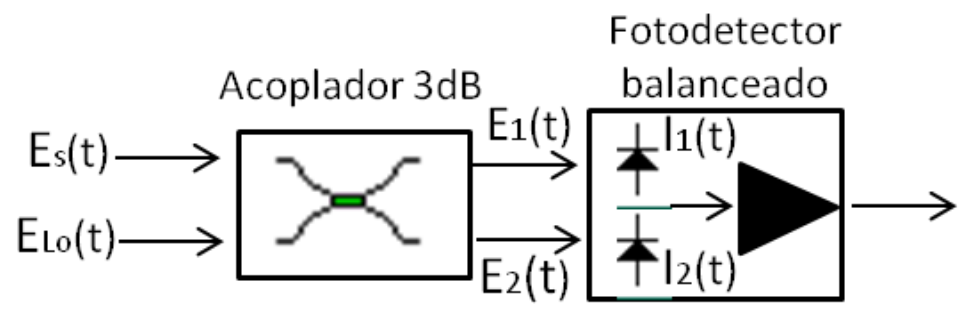

Figura 2.8 - Detecção Coerente

A mistura do sinal óptico do oscilador local com o sinal recebido é realizada da seguinte maneira: na saída do acoplador os campos ópticos da combinação entre o sinal do laser e o sinal do oscilador local, $E_{1}$ e $E_{2}$, têm diferença de fase de $180^{\circ}$, que é uma característica do acoplador de $3 \mathrm{~dB}$. Os dois sinais são fotodetectados por fotodetectores balanceados, o que significa que o resultado à saída deste circuito de fotodetecção é a diferença dos dois sinais. Esta é uma solução para o problema de ruído de intensidade. Assim, com o uso de dois fotodetectores as correntes resultantes do batimento são proporcionais à responsividade do fotodetector e ao quadrado do campo elétrico incidente [27]:

$$
\begin{aligned}
& I_{1}(t)=\frac{1}{2} R\left[E_{s}(t)+j E_{l o}(t)\right]\left[E_{s}(t)+j E_{l o}(t)\right]^{*} \\
& I_{2}(t)=\frac{1}{2} R\left[j E_{s}(t)+E_{l o}(t)\right]\left[j E_{s}(t)+E_{l o}(t)\right]^{*}
\end{aligned}
$$

Onde $R(A / W)$ é a responsividade dos fotodetectores, e o * é o complexo conjugado. Com isso pode-se substituir (2.2) e (2.3) em (2.4), obtendo-se:

$$
\begin{aligned}
& I_{1}(t)=\frac{1}{2} R P_{s} a^{2}(t)+\frac{1}{2} R P_{l o}+R \sqrt{P_{s} P_{l o}} a(t) e_{s} e_{l o} \sin [\Delta \omega t+\varphi(t)] \\
& I_{2}(t)=\frac{1}{2} R P_{s} a^{2}(t)+\frac{1}{2} R P_{l o}-R \sqrt{P_{s} P_{l o}} a(t) e_{s} e_{l o} \sin [\Delta \omega t+\varphi(t)]
\end{aligned}
$$


Considerando $I_{1}(t)$ e $I_{2}(t)$, observa-se que o primeiro termo da equação é proporcional à potência do laser de sinal e à componente de amplitude de modulação ao quadrado. Geralmente, nesse termo é esperado que $P_{s}<P_{l o}$. O segundo termo é um nível DC, proporcional à potência do oscilador local. Já o terceiro termo é o termo de interesse, pois nos mostra as características de modulação e batimento: $\sqrt{P_{s} P_{l o}}$, denominado ganho coerente, $a(t)$ é a modulação de amplitude, $\varphi(t)$ a modulação em fase, $\Delta \omega t$ é o desvio de frequência (FO Frequency Offset) entre os lasers, e $e_{s}$ e $e_{l o}$, os termos proporcionais ao eixo de polarização dos lasers.

Voltando à Figura 2.8 que ilustra um diagrama de blocos de um receptor coerente, o acoplador de 3dB combina o sinal óptico com o oscilador local e divide o sinal óptico combinado em duas partes iguais, com um deslocamento de fase de $180^{\circ}$. Com base na equação 2.5 e no circuito, a subtração das correntes proporciona o sinal heteródino. A corrente gera uma fotocorrente que possui informações sobre amplitude, frequência e fase do campo do sinal óptico. Essas informações são extraídas por processamento eletrônico [36].

Os receptores coerentes são mais sensíveis que os receptores com detecção direta, devido a dois efeitos distintos:

Primeiro, a mistura óptica melhora a relação sinal-ruído (SNR) na saída do pré-amplificador do receptor porque a potência do sinal recebido é aumentada através da mistura com o sinal gerado localmente que possui uma potência maior do que a potência óptica transmitida, ou seja, o oscilador local age como um tipo de amplificador no domínio óptico, amplificando o sinal que o fotodiodo irá receber, melhorando assim a SNR, que é definida como a razão entre o nível de potência do sinal transmitido e o nível de potência de ruído na banda de transmissão. Quanto 
menor for a SNR, maior é o efeito do ruído no sistema e, consequentemente, maior o erro inserido nos símbolos transmitidos, comprometendo assim a informação transmitida [36], [37].

Segundo, a melhora na taxa de erro de bits (BER) para uma dada SNR, devido ao uso de diferentes formatos de modulação e demodulação. O campo do sinal óptico incidente e o campo do oscilador local são combinados pelo acoplador óptico e o campo total incidente sobre o fotodiodo é a soma dos dois campos. Com isso, o sinal modulado em fase torna mais fácil a detecção dos bits, diminuindo assim os erros na detecção [33].

$\mathrm{Na}$ arquitetura dos fotodetectores balanceados, a corrente resultante total é $I(t)=I_{1}(t)-I_{2}(t)$, obtendo-se assim:

$$
I(t)=2 R \sqrt{P_{s} P_{l o}} a(t) e_{s} e_{l o} \sin [\Delta \omega t+\varphi(t)]
$$

Ainda assim, o acoplador de $3 \mathrm{~dB}$, em sistemas com modulação em fase, não fornece combinações de sinal suficiente para recuperar as duas componentes I e Q, portanto, para tais sistemas, o acoplador de 3dB deve ser substituído por híbridas de $90^{\circ}$, que possibilitam a combinação do laser com o oscilador local, preservando as componentes de fase e quadratura nas saídas dos fotodetectores balanceados. Com a híbrida de $90^{\circ}$, localizada nesse receptor, deve-se possuir duas entradas, ou seja, uma para o sinal e outra para o oscilador local, conforme o acoplador de $3 \mathrm{~dB}$, e quatro saídas com defasagens de $90^{\circ}$ uma em relação à outra, como descrito pelas equações a seguir. 


$$
\begin{aligned}
& E_{\text {out } 1}(t)=\frac{1}{2} E_{s}(t)+E_{\text {lo }}(t) \\
& E_{\text {out } 2}(t)=\frac{1}{2} E_{s}(t)+j E_{l o}(t) \\
& E_{\text {out } 3}(t)=\frac{1}{2} E_{s}(t)-E_{l o}(t) \\
& E_{\text {out } 4}(t)=\frac{1}{2} E_{s}(t)-j E_{\text {lo }}(t)
\end{aligned}
$$

A detecção coerente utilizando-se a híbrida de $90^{\circ} \mathrm{com}$ as componentes de fase e quadratura é ilustrada na Figura 2.8.

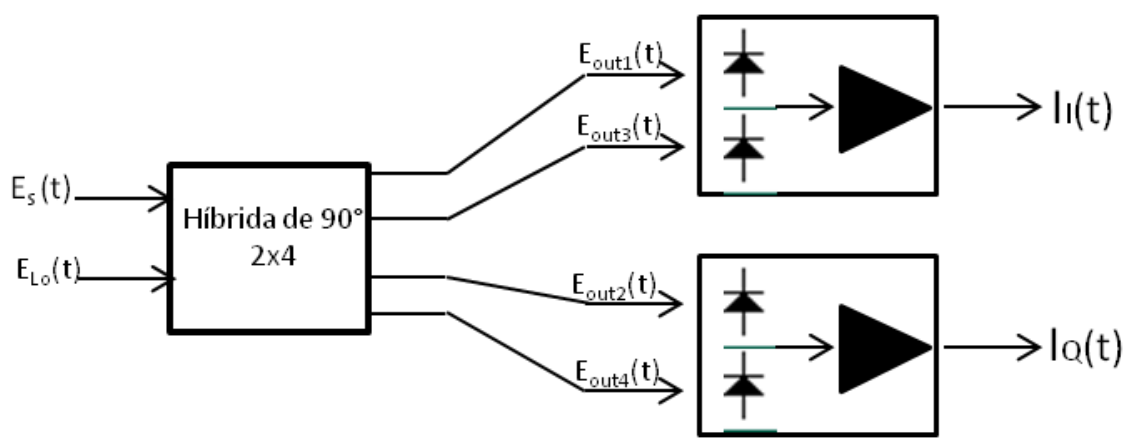

Figura 2.9 - Detecção coerente utilizando híbrida de $90^{\circ}$

Considerando a Figura 2.9, as correntes das componentes em fase e quadratura podem ser escritas como em (2.7). Como pode ser visto para recuperar a componente em fase são utilizados os sinais de saída $E_{\text {out } 1}$ e $E_{\text {out } 3}$, e a componente em quadratura utiliza os sinais, $E_{\text {out } 2}$ e $E_{\text {out } 4}$, devido à diferença de fase de $180^{\circ}$ entre si.

$$
\begin{aligned}
& I_{I}(t)=R E_{\text {out } 1}(t) E_{\text {out } 1}^{*}(t)-R E_{\text {out } 3}(t) E_{\text {out } 3}^{*}(t) \\
& I_{Q}(t)=R E_{\text {out } 2}(t) E_{\text {out } 2}^{*}(t)-R E_{\text {out } 4}(t) E_{\text {out } 4}^{*}(t)
\end{aligned}
$$

Substituindo-se (2.2), (2.3) e (2.7) em (2.8), tem-se que as correntes $\mathrm{I}_{\mathrm{I}}(\mathrm{t})$ e $\mathrm{I}_{\mathrm{Q}}(\mathrm{t})$ podem ser descritas como:

$$
\begin{aligned}
& I_{I}(t)=2 R \sqrt{P_{s} P_{l o}} a(t) e_{s} e_{l o} \cos [\Delta \omega t+\varphi(t)] \\
& I_{Q}(t)=2 R \sqrt{P_{s} P_{l o}} a(t) e_{s} e_{l o} \operatorname{sen}[\Delta \omega t+\varphi(t)]
\end{aligned}
$$


De (2.9) observa-se, como esperado, que as componentes em fase e quadratura estão defasadas de $90^{\circ}$.

\subsubsection{Sistema OFDM elétrico/óptico}

Os sistemas OFDM são implementados pela aplicação no transmissor da transformada inversa de Fourier na sequência de bits de informação, gerando um conjunto de portadoras ortogonais no domínio da frequência. Na recepção é feito o processo inverso para a recuperação dos dados pelo uso da transformada direta de Fourier. Os sistemas ópticos OFDM podem ser classificados em três grupos:

1) Geração de múltiplas portadoras no domínio elétrico, onde o sinal OFDM elétrico é convertido para analógico antes de modular a portadora óptica [38].

2) Geração de múltiplas portadoras no domínio óptico, onde cada umas das portadoras ópticas, que compõem o sinal OFDM, é modulada individualmente e separadas em frequência com o mesmo valor da taxa de dados da modulação [37].

3) Geração de múltiplas portadoras no domínio elétrico e óptico, que é uma combinação das técnicas dos dois sistemas anteriores [37].

O gerador utilizado nesse capítulo é um dos componentes do sistema pertencente ao grupo da geração de múltiplas portadoras no domínio elétrico. Estes sistemas OFDM podem ser divididos em cinco blocos funcionais, como ilustrado na Figura 2.10. 
Transmissor OFDM
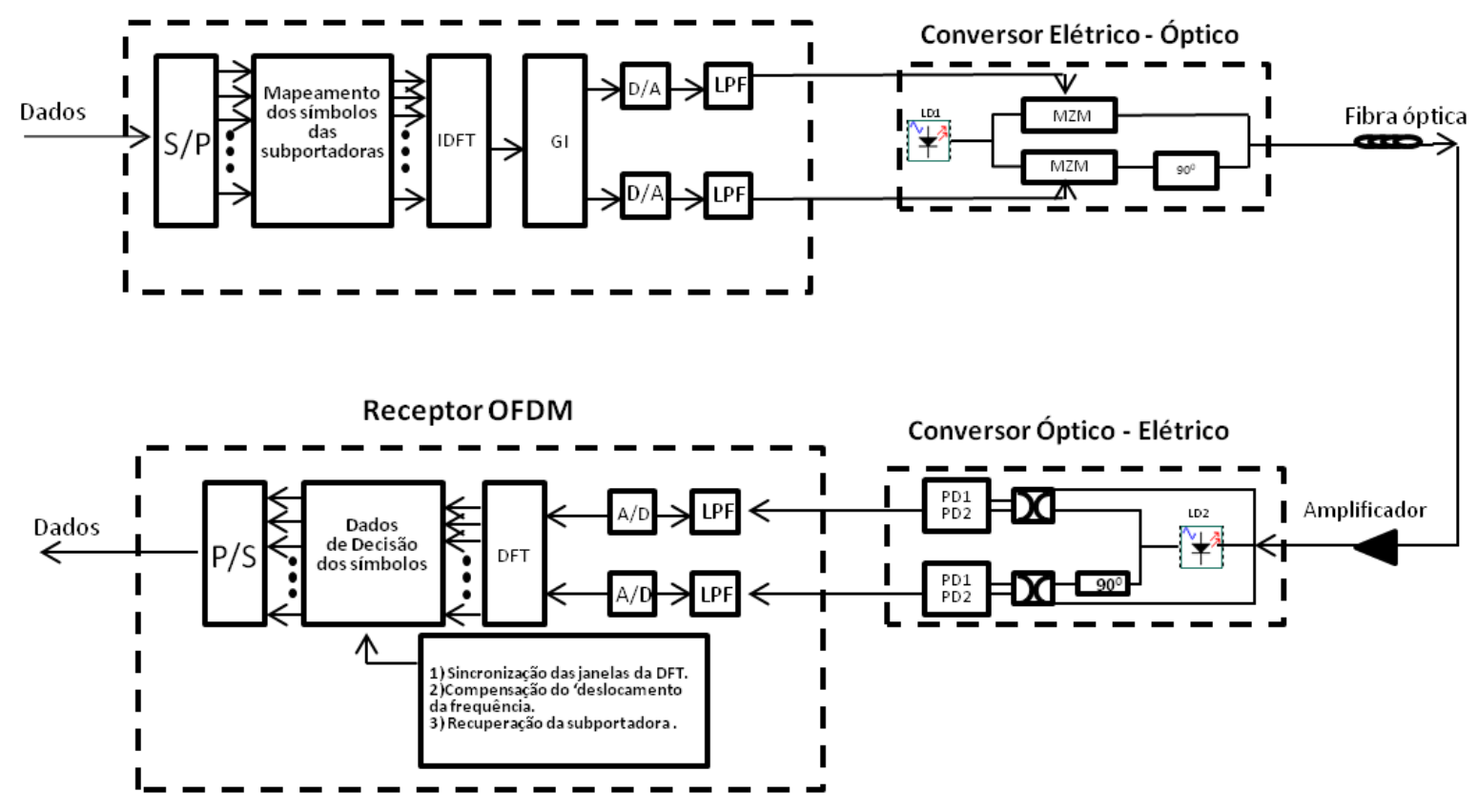

Figura 2.10 - Diagrama de um sistema OFDM elétrico-Óptico

Na figura, o termo "RF" representa o sinal elétrico. O diagrama está divido em 5 blocos sendo eles o transmissor OFDM, conversor do domínio elétrico para o óptico, o enlace de fibra, o conversor do domínio óptico para o domínio elétrico e por fim o receptor OFDM. No transmissor OFDM, os dados digitais de entrada são primeiro convertidos de serial para paralelo em um "bloco" com $\mathrm{N}$ símbolos de informação, cada um dos quais pode conter vários bits para codificação.

Os dados de entrada do modulador OFDM podem estar em diferentes formatos de modulação, por exemplo, BPSK (binary phase shift keying), QPSK (quadrature phase shift keying), QAM (quadrature amplitude modulation). Este fluxo de entrada de símbolos em serial é transformado em paralelo, em seguida, os dados são transmitidos em paralelo através da atribuição de cada símbolo para uma subportadora na transmissão.

Após o mapeamento do espectro, o sinal digital no domínio do tempo é obtido usando-se um bloco IDFT (Inverse Discrete Fourier Transform). A 
transformada de Fourier transforma o sinal no domínio do tempo (onde cada uma das amostras do sinal está associada com um determinado tempo) e o mapeia, com pouca perda de informação, no domínio da frequência. A transformada inversa de Fourier mapeia o sinal de volta a partir do domínio da frequência para o domínio do tempo.

Subsequentemente, um intervalo de guarda pode então ser adicionado ao início de cada símbolo, tornando-se o tempo de símbolo muito maior do que a dispersão temporal do canal, aumentando mais ainda a robustez contra interferência entre as subportadoras e, a seguir, o sinal digital é convertido para uma forma analógica por meio de um DAC (Digital to Analog Converter) e filtrado por um filtro passa-baixas para remoção do ruído do sinal. O intervalo de guarda é inserido para impedir a interferência intersimbólica (ISI, intersymbol interference), devido à dispersão de canal [7]. A Figura 2.11 apresenta um exemplo do bloco transmissor OFDM implementado no software Optisystem 9.0, usando um transmissor OFDM com codificação de dados em $10 \mathrm{~Gb} / \mathrm{s}$ para símbolos no formato 4-QAM. Os símbolos QAM são mapeados em 4 subportadoras definidas no modulador OFDM. Seguindo o modelo em [4] para uma taxa de $10 \mathrm{~Gb} / \mathrm{s}$, utiliza-se um número de subportadoras de 512, mas nesse exemplo foi utilizado apenas 4 subportadoras, pois quanto mais subportadoras alocadas menor o espaço entre elas. Assim, para uma melhor visualização das subportadoras no domínio da frequência utilizamos apenas 4 subportadoras, na configuração ilustrada na Figura 2.11. A Figura 2.12, mostra o espectro do sinal após o modulador OFDM aplicar a FFT com as 4 subportadoras alocadas. 


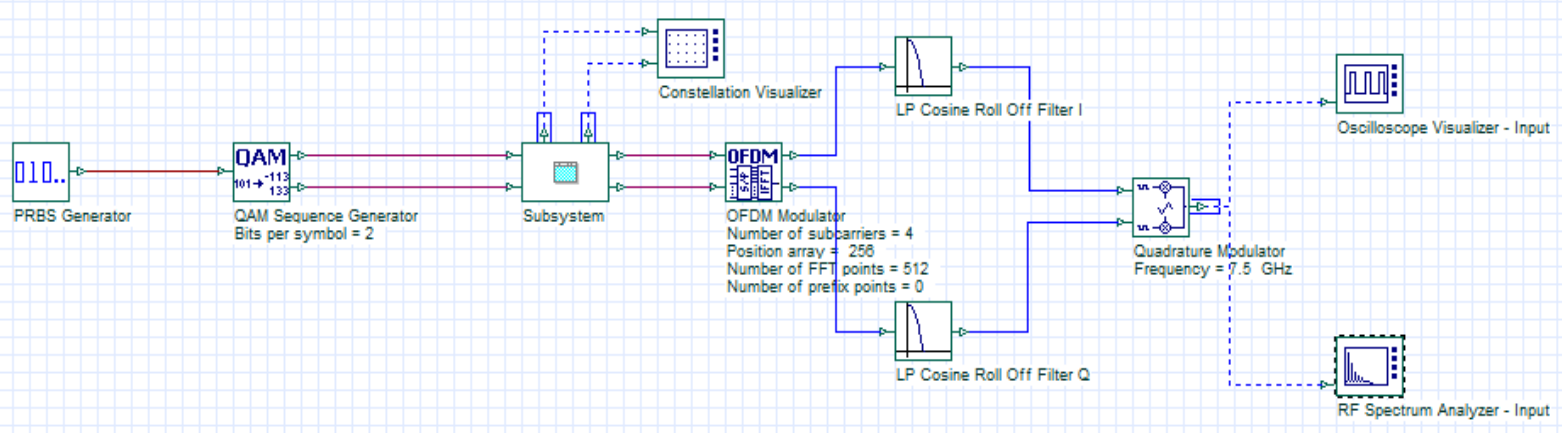

Figura 2.11 - Transmissor OFDM no software Optisystem

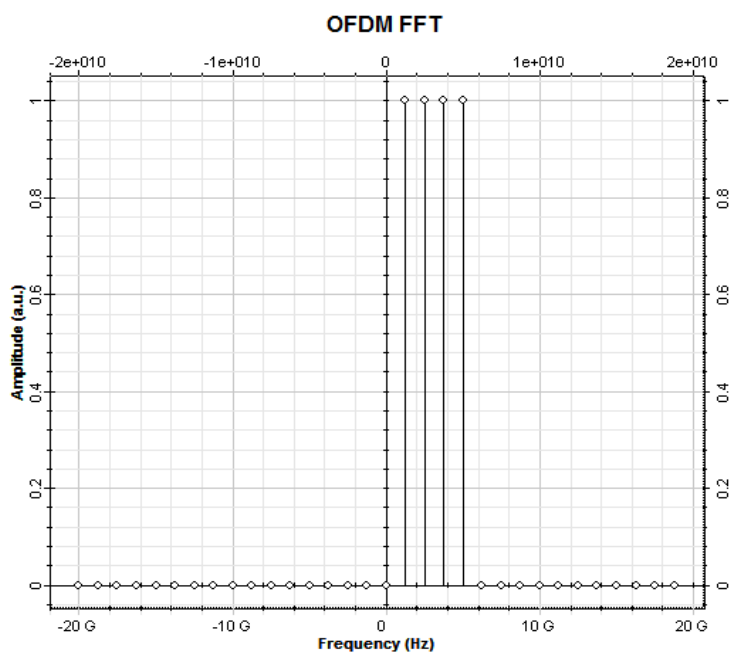

Figura 2.12 - Espectro das subportadoras no domínio da frequência

O bloco do conversor elétrico-óptico subsequente converte o sinal de banda base, ou seja, o sinal modulado para o domínio óptico utilizando um par de moduladores ópticos Mach-Zehnder com offset de fase de 90 graus. No receptor OFDM, o conversor óptico-elétrico recebe o sinal óptico que será amostrado por um conversor ADC (Analog to Digital Converter). Em seguida o sinal precisa passar por 3 níveis de processamento [40] : 
1) Sincronização das janelas da DFT, em que os símbolos OFDM são adequadamente alinhados para evitar interferência intersimbólica.

2) Sincronização da frequência, ou seja, o deslocamento de frequência será estimado, compensado e, de preferência, ajustado para o menor valor do início.

3) Recuperação da subportadora, onde cada canal de subportadora é estimado e compensado.

\subsection{Resultados OFDM elétrico/óptico}

Nesta seção os sistemas OFDM elétrico/óptico são avaliados através de simulações realizadas no software Optisystem 9.0.

\subsubsection{Projeto do sistema OFDM elétrico/óptico com detecção Direta}

Apesar deste estudo colocar maior ênfase na detecção coerente, a detecção direta também será estudada para efeito de comparação de desempenho. O layout do primeiro sistema OFDM óptico com detecção direta é ilustrado na Figura 2.13.

Conforme a seção 2.4 , na detecção direta o fotodetector do receptor óptico irá gerar uma corrente proporcional à potência óptica recebida pela fibra óptica e as informações serão codificadas na intensidade do sinal. 


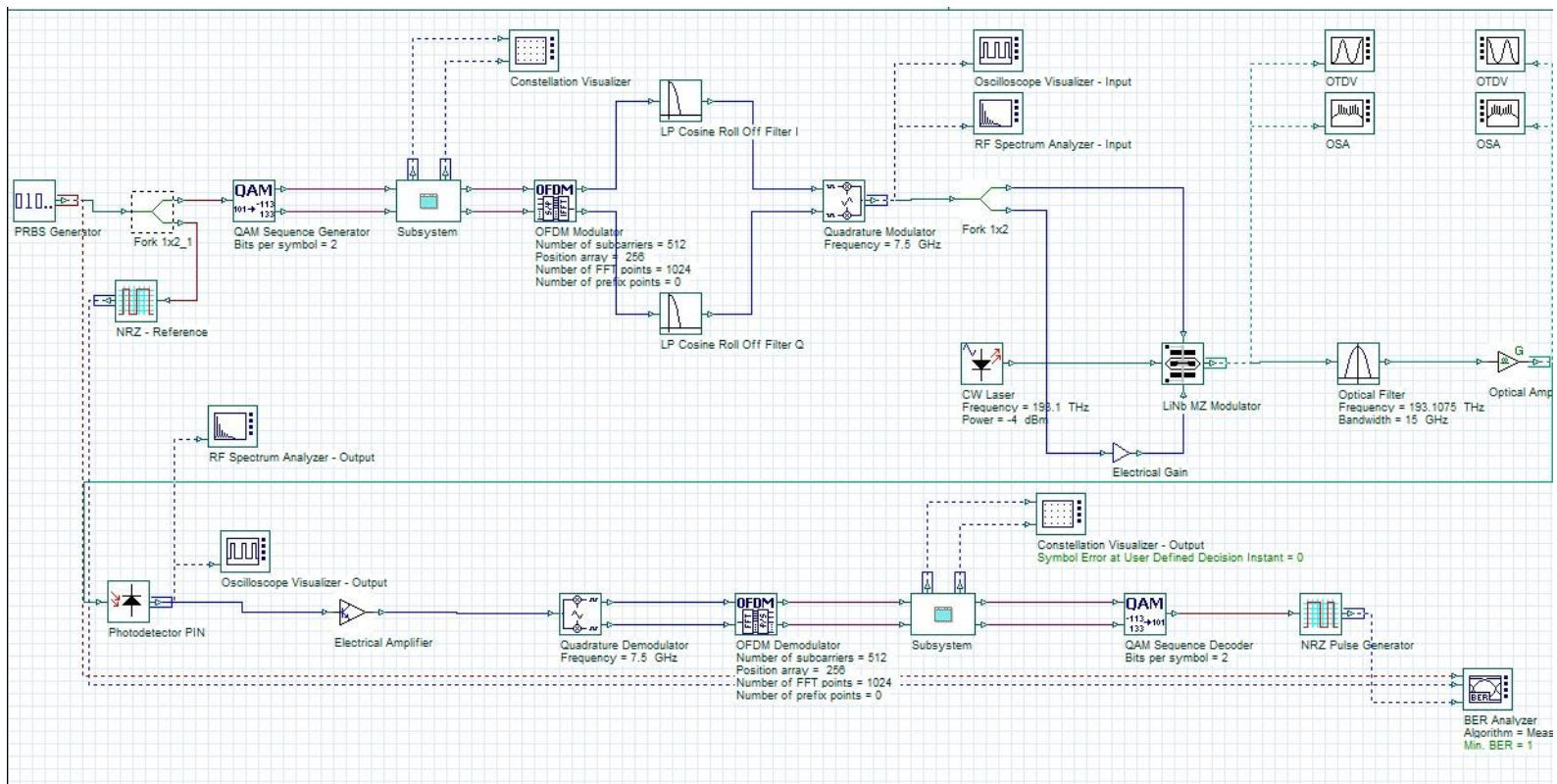

Figura 2.13 - Sistema OFDM com detecção direta

O primeiro relato sobre OFDM elétrico/óptico com detecção direta foi para a aplicação de óptica de espaço livre para antena de televisão comunitária, no qual o OFDM apresentou uma robustez ao ruído gerado pelo laser [7]. Pesquisas foram feitas e demonstraram a viabilidade de implementação da modulação com banda lateral única (SSB - OFDM - single sideband) em OFDM com detecção direta para obter um melhor aproveitamento da eficiência espectral do sistema [41].

Na Figura 2.14a é ilustrado o sinal elétrico de banda base do multiplexador OFDM, visto no analisador de espectro após o modulador de quadratura, (responsável por modular um sinal em amplitude e fase (quadratura)). A banda base é a faixa de frequências de um determinado sinal modulante. A Figura 2.14b mostra a portadora óptica principal, centrada no comprimento de onda de $1552,52 \mathrm{~nm}$ (193,1THz), visualizado no analisador de espectro óptico após o modulador MachZehnder antes da filtragem, onde essa portadora óptica é modulada pela banda base. 


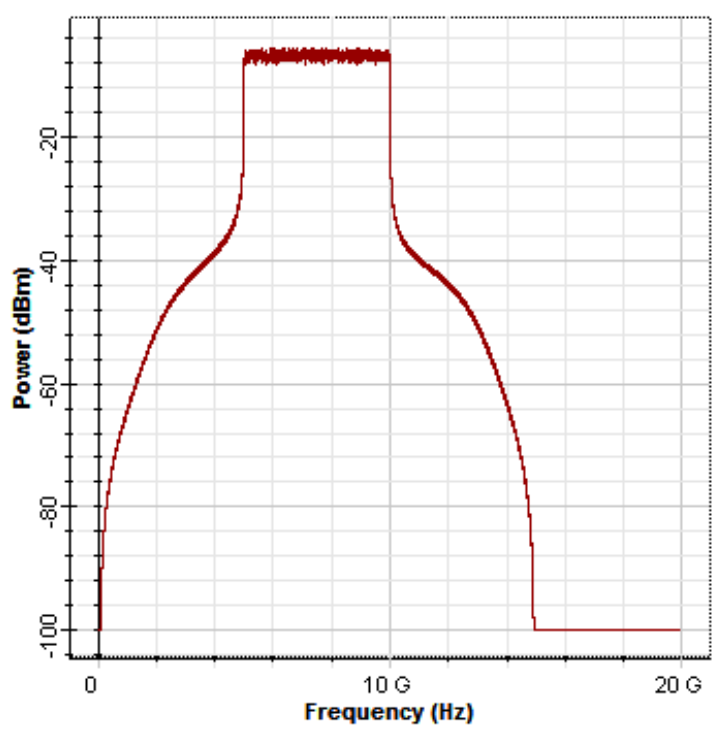

(a)

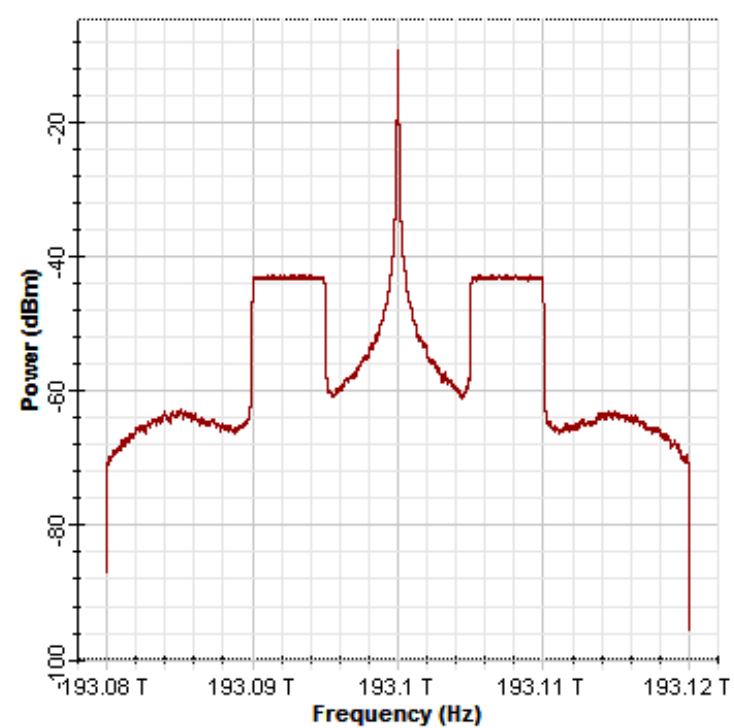

(b)

Figura 2.14 - (a) Espectro do sinal em banda base(domínio elétrico), (b) Espectro do sinal no domínio óptico com banda lateral dupla

O espectro do sinal óptico visto na Figura 2.14b, apresenta uma desvantagem frente ao de banda lateral única, devido aos efeitos dispersivos da fibra óptica, onde as bandas laterais podem sofrer desvios de fase diferentes, dependendo da distância percorrida na fibra. Estes desvios na fase podem ocasionar interferências construtivas ou destrutivas no sinal. Isso justifica a adição do filtro óptico após o modulador Mach-Zehnder para suprimir uma banda lateral. Este método é, conceitualmente, a maneira mais simples para suprimir a banda lateral, assim como ilustrado na Figura 2.15a [42]. Outra vantagem de suprimir a banda lateral é o aumento da eficiência espectral, possibilitando a inserção de um número maior de canais. A Figura 2.15 ilustra o espectro do sinal óptico após o filtro óptico ter suprimido a banda lateral esquerda (2.15a), e o espectro do sinal após percorrer $100 \mathrm{~km}$ de fibra (2.15b). 


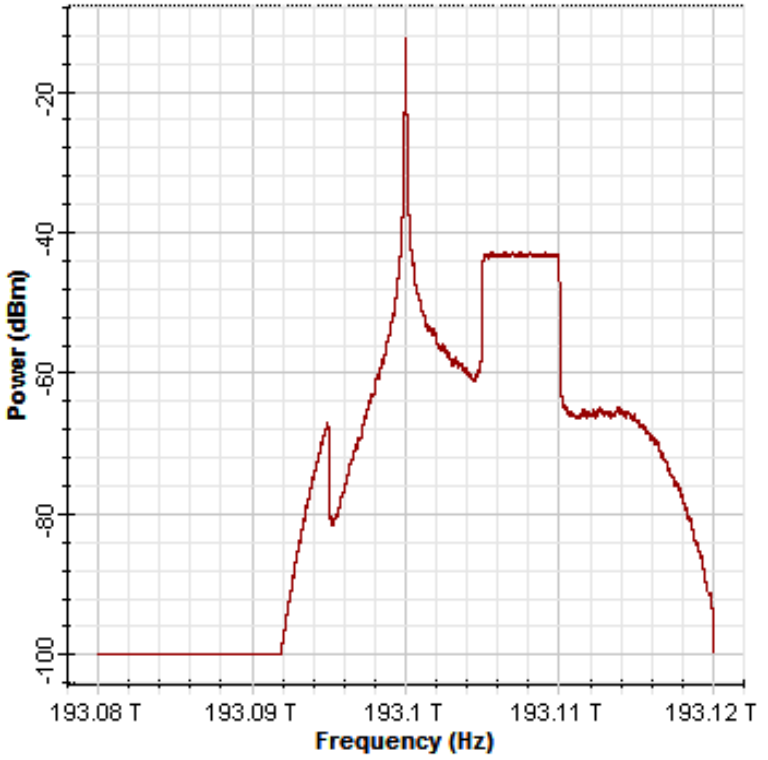

(a)

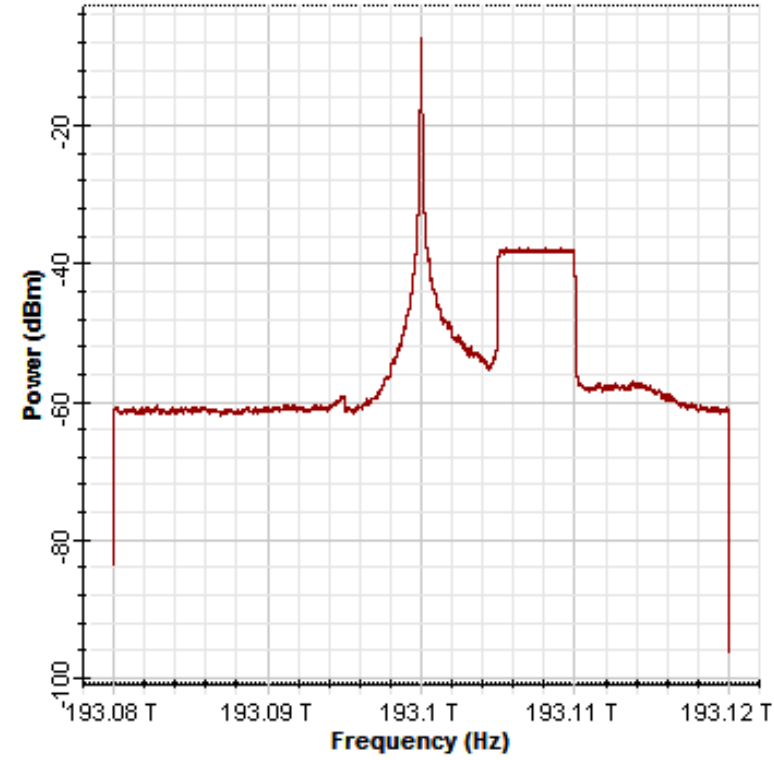

(b)

Figura 2.15 - (a) Espectro do sinal no domínio óptico após o filtro suprimir a banda lateral, (b) espectro do sinal após percorrer $100 \mathrm{~km}$ de fibra

São apresentadas na Figura 2.16 as curvas da BER x OSNR para o sistema OFDM com detecção direta em back to back, ilustrado na Figura 2.11. A expressão para o cálculo da OSNR é:

$$
\operatorname{OSNR}(d B)=10 \log \left(\frac{P_{\text {sinal }}}{\mathrm{P}_{\text {ruido }}}\right)
$$

no qual $P_{\text {sinal }}, \mathrm{P}_{\text {ruido }}$ são as potências em watt. 


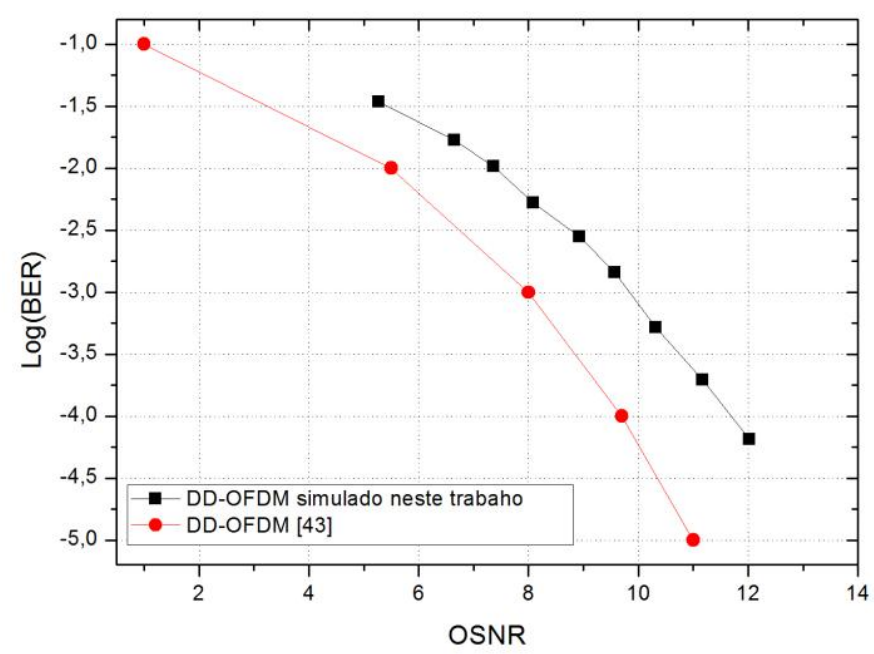

Figura 2.16-BER x OSNR do sistema DD-OFDM

Alguns parâmetros utilizados no programa para o transmissor, receptor e amplificadores foram configurados baseados na referência [43] a fim de aferir os resultados obtidos e, a partir da validação, ser possível realizar novas simulações. $A$ tabela 2.1 sumariza os parâmetros utilizados nesta simulação.

Ao compararmos as curvas da Figura 2.16, observamos um aumento na OSNR, consistente, de cerca de $1 \mathrm{~dB}$, em relação aos resultados da referência [43]. Este deslocamento pode ser atribuído a parâmetros de dispositivos utilizados na simulação que não foram declarados no artigo. Porém, para efeito de validação dos resultados aqui obtidos, a concordância entre as duas curvas pode ser considerada aceitável. 
Tabela 2.1 - Dados da simulação para OFDM com detecção direta e coerente

$\left.\begin{array}{|c|c|}\hline \text { Parâmetros Utilizados } & \text { Valor } \\ \hline \text { Taxa de bits (Gb/s) } & 10 \\ \hline \text { Modulação } & \text { QAM } \\ \hline \text { Número de subportadoras } & 512 \\ \hline \text { Número de pontos da transformada de } \\ \text { Fourier }\end{array}\right)$

A Figura 2.17 mostra os diagramas de constelação obtidos no receptor em back to back e após percorrer um enlace de fibra de $100 \mathrm{~km}$ de fibra convencional de extensão, onde o sinal está indicado na cor azul e o ruído na cor vermelha, considerando-se os efeitos não lineares. 


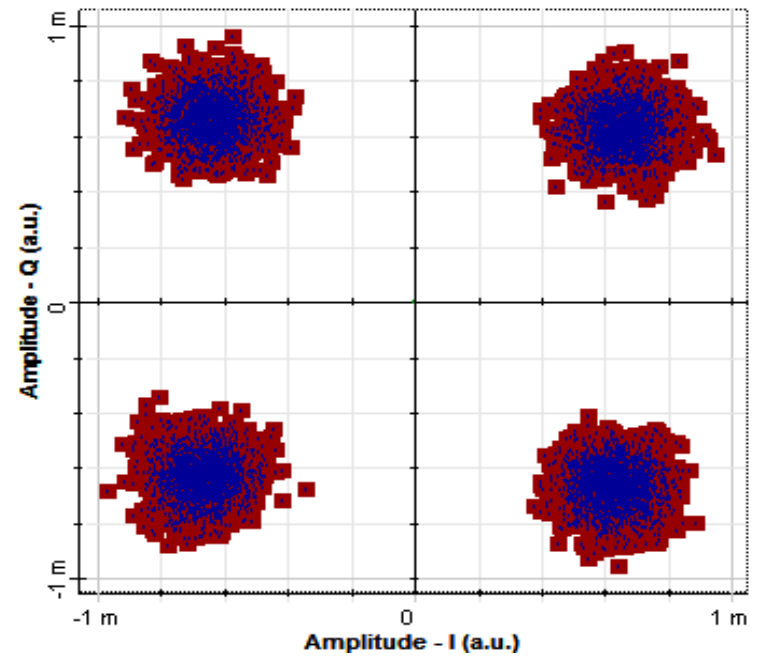

(a)

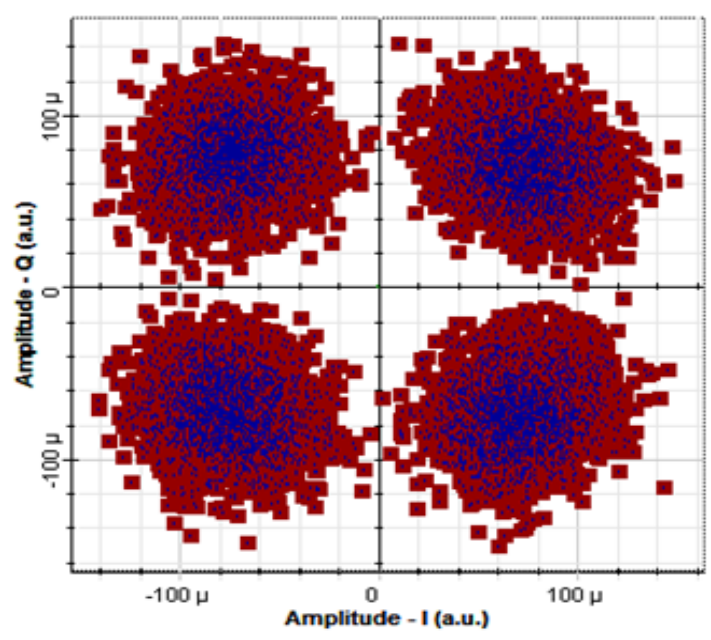

(b)

Figura 2.17- (a) Constelação do sinal recebido em back to back, (b) Constelação do sinal recebido após percorrer uma fibra de $100 \mathrm{~km}$

\subsubsection{Projeto do sistema OFDM elétrico/óptico com detecção coerente}

Nesta seção são apresentados os componentes utilizados na montagem dos sistemas OFDM elétrico/óptico coerente digital, configurado como ilustrado na Figura 2.18. Serão apresentados os resultados obtidos por meio das simulações do Optsystem 9.0 com a detecção coerente CO-OFDM. 


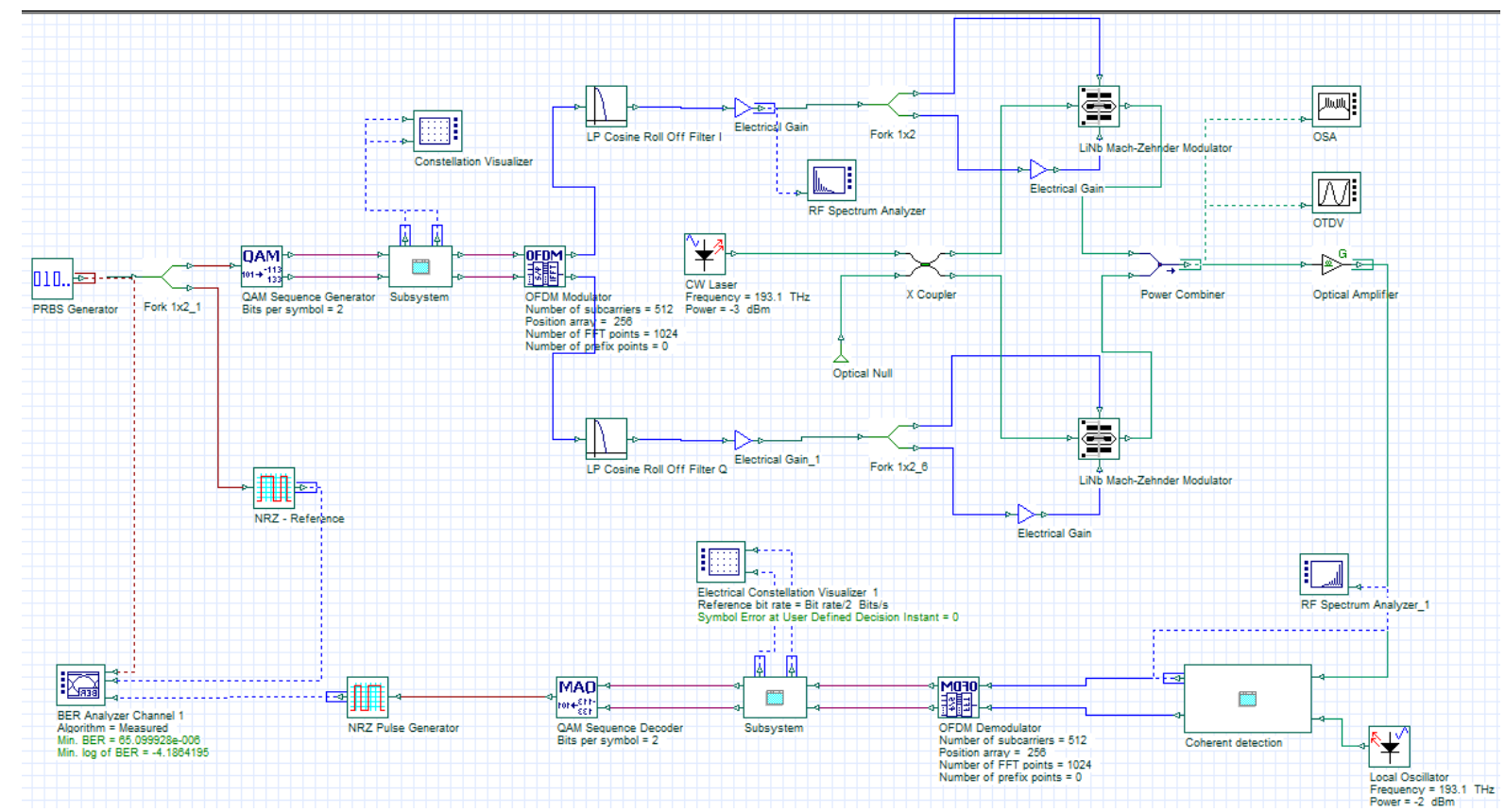

Figura 2.18 - Sistema OFDM óptico coerente

Utilizou-se modulação elétrica 4-QAM em back to back e transmissão por um enlace de até 200 km de fibra monomodo G.652 (padrão convencional), pois como vamos perceber nos resultados posteriores, para distâncias maiores que essa nesse sistema, o uso de processamento de sinal é indispensável para que este não chegue ao receptor muito degradado. Foi utilizado um amplificador após a modulação da portadora óptica no cenário em back to back, e um atenuador antes da entrada do receptor óptico coerente a fim de ir variando a atenuação para obtenção das curvas da Figura 2.19. 


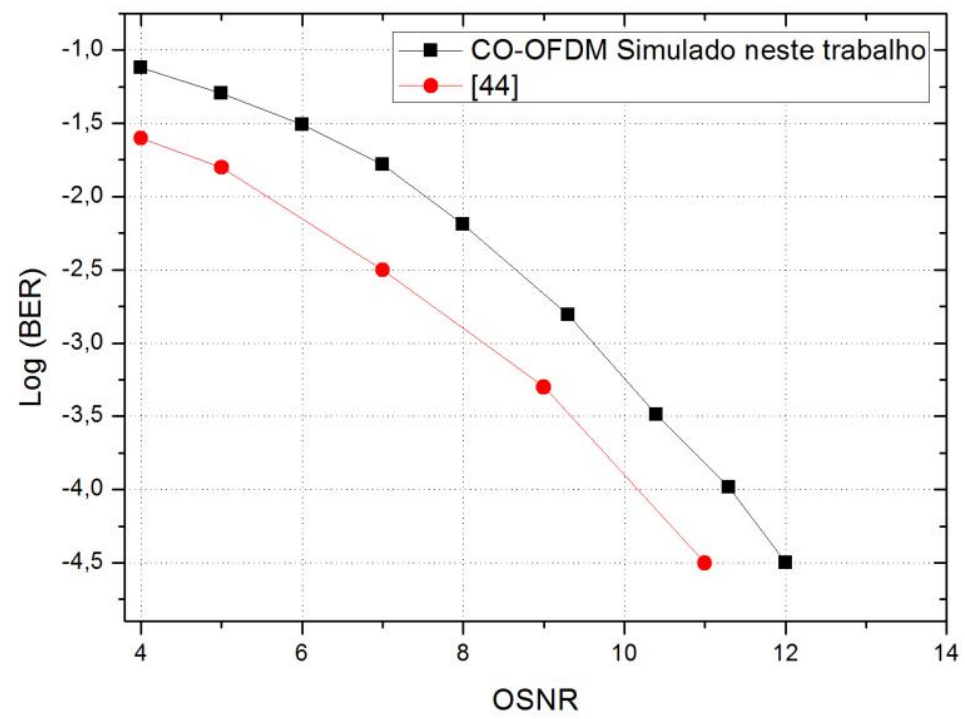

Figura 2.19-BER x OSNR do sistema Co-OFDM

Os resultados com detecção coerente Co-OFDM são ilustrados na Figura 2.19 e os parâmetros utilizados de acordo com Tabela 2.1 baseado na referência [44].

Uma vez validadas as paletas de simulação, em back to back, na Figura 2.20, foram utilizados amplificadores ópticos, sendo eles um booster e um préamplificador para se obter a variação da BER em função da distância percorrida na fibra convencional. As curvas foram obtidas variando-se o comprimento da fibra óptica em função da BER, considerando-se os efeitos não lineares. Como podemos observar na Figura 2.20 o sistema Co-OFDM consegue um alcance maior devido à detecção coerente. 


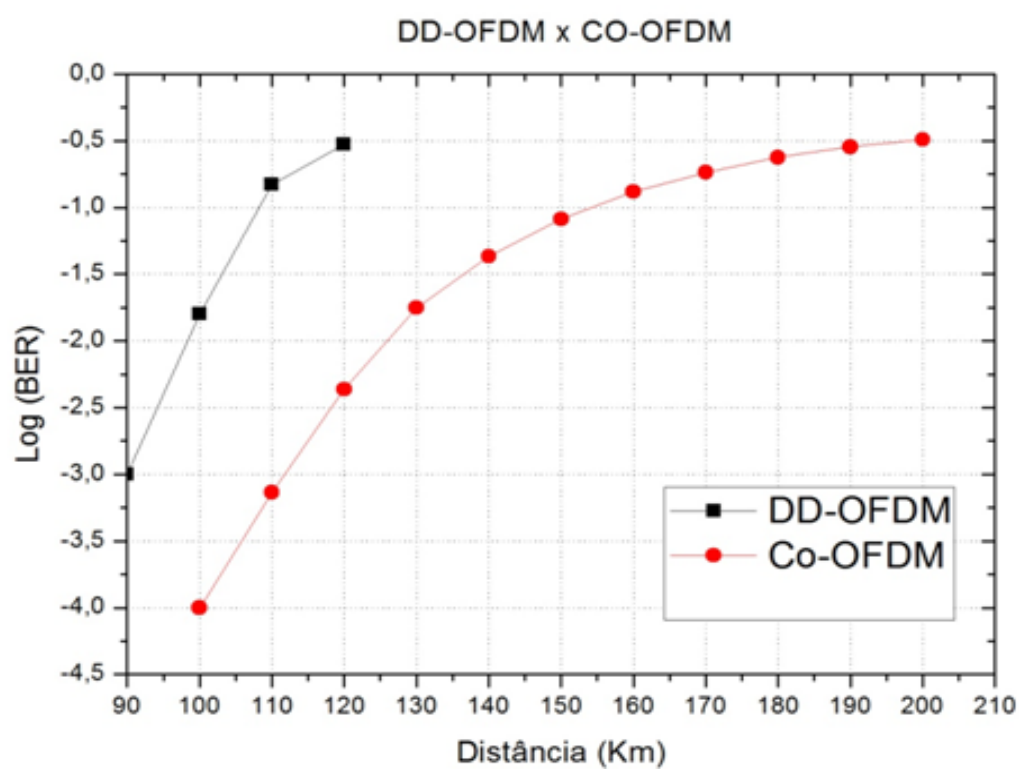

Figura 2.20 - BER em função da distância percorrida na fibra.

São apresentadas na Figura 2.21 as constelações obtidas no sistema CoOFDM em back to back e com um enlace de fibra de $100 \mathrm{~km}$. O sinal está indicado na cor azul e o ruído na cor vermelha. Essa rotação nos símbolos na constelação do back to back é devido ao ruído de fase do laser, pois após zerar o parâmetro ruído de fase do laser (equivale a zerar a largura de linha do laser), a rotação dos símbolos desaparece.

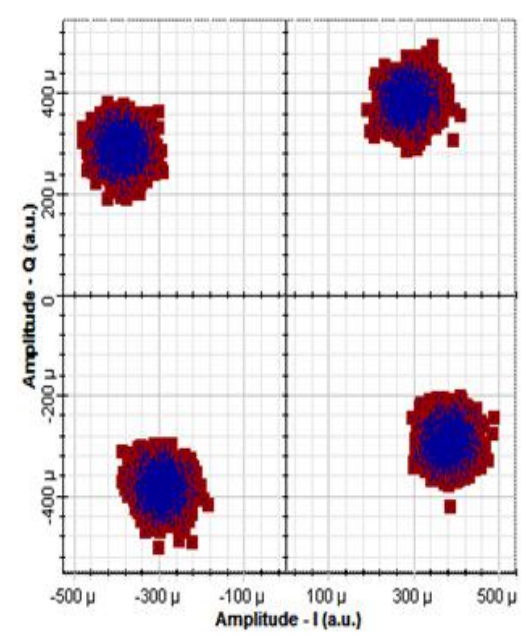

(a)

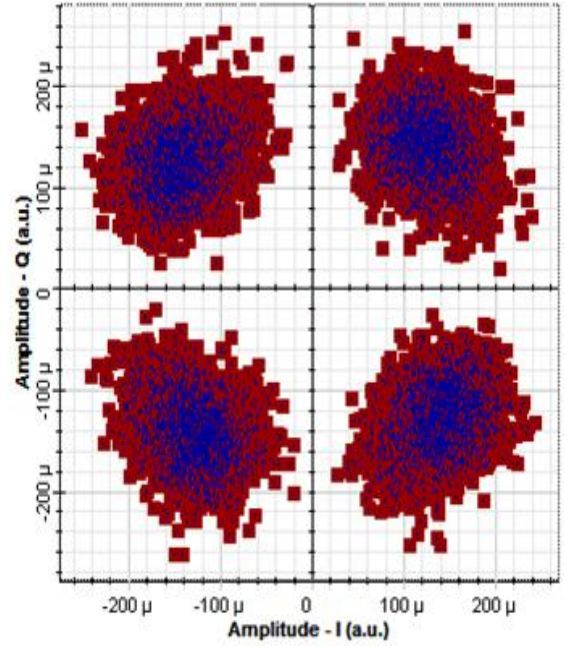

(b)

Figura 2.21 - (a) Constelação do sinal recebido em back to back, (b) Constelação do sinal recebido após percorrer uma fibra de $100 \mathrm{~km}$. 


\subsection{Conclusão}

Neste capítulo foi apresentado a técnica OFDM aplicada no domínio elétrico e após modulada em uma portadora óptica. Foram apresentados resultados, gráficos e figuras, de forma a analisar qual arquitetura de rede óptica simulada é mais indicada, de acordo com a taxa de erro de bit, a constelação dos sinais, a relação sinal ruído óptica e a distância obtida por cada arquitetura. A arquitetura Co-OFDM apresentou o melhor desempenho. Como esperado, os resultados confirmam que a detecção coerente como a mais indicada para as redes ópticas de próxima geração. 


\section{Sistema OFDM óptico Coerente}

\subsection{Introdução}

Com o crescimento do tráfego nas redes de dados em torno de $50 \%$ ao ano, as operadoras projetam um aumento significativo da capacidade de suas redes atuais, em torno de 10 vezes, se os sistemas migrarem para 100G DWDM [45]. Isso deve ser aplicado mantendo-se a compatibilidade com a grade de canais existentes e com poucas alterações na infraestrutura da rede. Para fomentar o interesse neste mercado e também garantir que os sistemas sejam dinamicamente adaptáveis às novas configurações, o Optical Internetworking Forum (OIF) definiu alguns padrões de implementação para nova geração de sistemas de transmissão, tais como o formato de modulação a ser usado e as características dos módulos transmissor e receptor visando redução de custo e tamanho pelos fabricantes [35]. Tendo isso em vista esta dissertação é voltada ao estudo de sistemas com taxas iguais ou superiores a $100 \mathrm{~Gb} / \mathrm{s} /$ canal baseados na geração de supercanais ópticos para sistemas de transmissão.

Como visto no capítulo anterior estudamos OFDM no domínio elétrico, neste capítulo iremos estudar primeiramente os princípios básicos do OFDM e suas aplicações no campo da comunicação óptica. Pois em sistemas RF fixos, o OFDM tem sido bastante utilizado em acesso banda larga ADSL (Asymmetric Digital Subcriber Line) e VDSL (Very-high bit-rate Digital Subscriber Line) via par trançado ou rede de distribuição elétrica. Apesar de possuir uma grande flexibilidade, foi 
preciso que as tecnologias de processamento de sinal alcançassem o grau de sofisticação necessário para a aplicação do OFDM em comunicações ópticas, e isso ocorreu por volta de 2005 [4], [7].

Uma das características do OFDM que mais o distinguem da modulação monoportadora é sua particularidade no processamento de sinal. Em sistemas com monoportadoras convencionais, o aumento da velocidade de transmissão acarreta na necessidade de uma maior precisão para o tempo de amostragem ótimo, tornando-o um parâmetro crítico, pois dele pode originar penalidades sistêmicas severas. Para enfrentar esse problema em OFDM óptico, um tempo de amostragem preciso não é importante, desde que a janela de amostragem seja apropriadamente selecionada de modo a não conter símbolos OFDM "contaminados" pela interferência intersimbólica. Contudo, essa tolerância à imprecisão do ponto de amostragem tem um compromisso com o deslocamento de frequência e ruído de fase [46].

O deslocamento da frequência central das subportadoras e sensibilidade a ruído de fase são dois problemas críticos na técnica OFDM. Pois ambos podem causar o efeito ICl (Interferência Interportadoras) [47], [48]. A Figura 3.1 mostra a resposta em frequência de 4 subportadoras ortogonais onde fora do pico de cada uma delas, todas as outras se anulam. Isto significa que elas não interferem entre si se forem amostradas exatamente nesse ponto (no valor de pico). A Figura 3.1 mostra também um dos problemas dos sistemas OFDM, a sensibilidade à interferência interportadoras. 


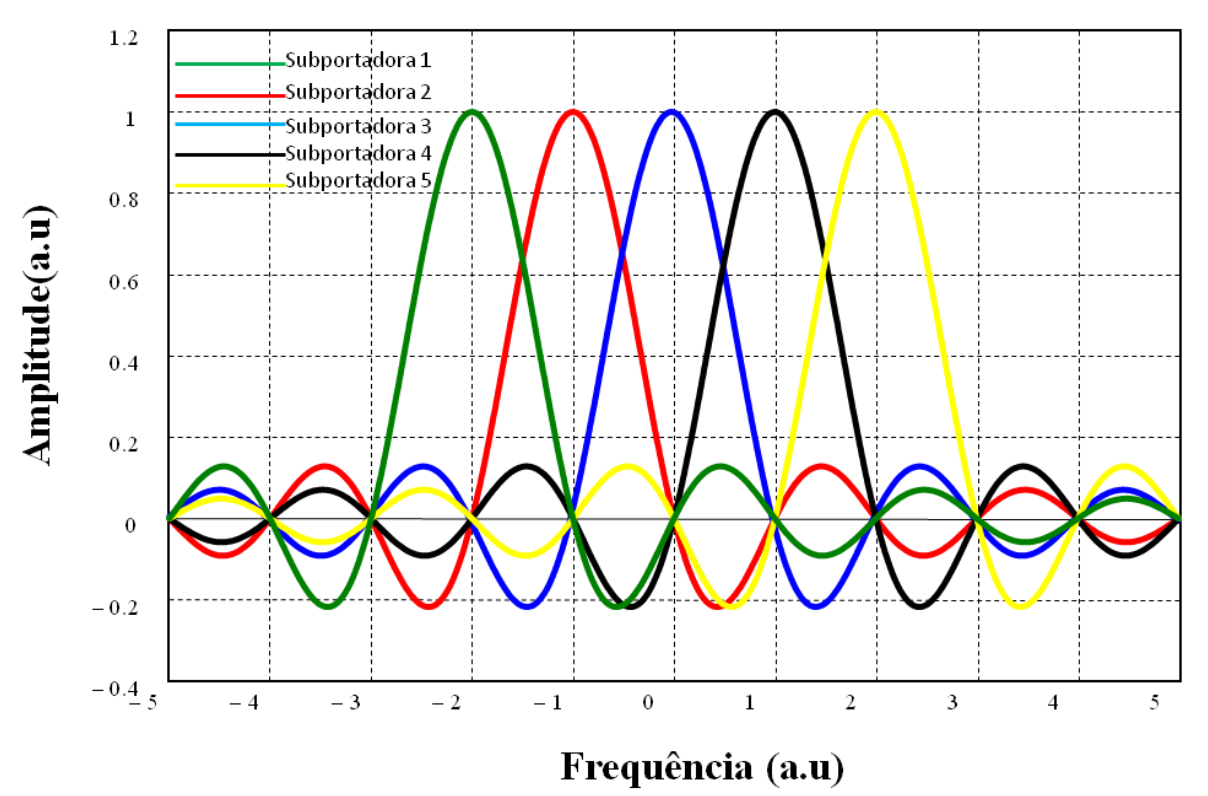

Figura 3.1 - Subportadoras Ortogonais no Domínio da Frequência

Como ilustrado na Figura 3.1 não ocorre $\mathrm{ICl}$ unicamente no ponto de máximo de cada uma das subportadoras. Deslocando-se o mínimo que seja para qualquer um dos lados a $\mathrm{ICI}$ pode alcançar níveis intoleráveis para o sistema. Esta sensibilidade apresentada obriga que neste tipo de sistema de comunicação seja conhecida a fase exata do sinal, além de exigir o sincronismo entre transmissor e receptor.

\subsection{Trabalhos Relacionados}

A tabela 1 mostra alguns resultados de arranjos experimentais recentes utilizando sistemas com multiportadoras ópticas (também denominados supercanais), obtidos por diversos grupos de pesquisa, com várias taxas de transmissão desde $100 \mathrm{~Gb} / \mathrm{s}$ a 1,2 Tb/s [46]. Para uma melhor compreensão dos desafios relacionados à geração e transmissão dessas tecnologias que estão sendo pesquisadas, neste capítulo serão descritos alguns subtópicos relacionados à 
geração, detecção, formatos de modulação e transmissão dos sistemas OFDM ópticos com altas taxas de transmissão (em torno de $400 \mathrm{~Gb} / \mathrm{s}$ até 1Tb/s [47]).

Tabela 3.1 - Demonstrações experimentais de supercanais [52]

\begin{tabular}{|c|c|c|c|c|}
\hline Formato & $\begin{array}{c}\text { Taxa } \\
(\mathbf{G b / s})\end{array}$ & $\begin{array}{c}\text { Composição } \\
(\mathbf{G b} / \mathbf{s})\end{array}$ & $\begin{array}{c}\mathbf{E S} \\
(\mathbf{b} / \mathbf{s} / \mathbf{H z})\end{array}$ & Alcance $(\mathbf{K m})$ \\
\hline NRZ-OOK (DD) & 288 & $7 \times 41,3$ & 0,93 & 1200 \\
\hline DQPSK (DD) & 100 & $2 \times 25$ & 1,87 & 1300 \\
\hline Duobinário (DD) & 100 & $4 \times 25$ & 0,93 & 100 \\
\hline NGI-CO-OFDM PDM-QPSK & 112 & $2 \times 56$ & 3,74 & 10093 \\
\hline NGI-CO-OFDM PDM-QPSK & 1200 & $24 \times 50$ & 3,74 & 7200 \\
\hline GI-CO-OFDM PDM-QPSK & 1080 & $36 \times 30$ & 3,15 & 600 \\
\hline GI-CO-OFDM PDM-QPSK & 1210 & $50 \times 24,2$ & 3,33 & 400 \\
\hline RGI-CO-OFDM PDM-16QAM & 448 & $10 \times 45$ & 7,00 & 2000 \\
\hline
\end{tabular}

Sendo: DD: Detecção Direta; NGI: Sem Intervalo de Guarda; RGI: Intervalo de Guarda Reduzido;

GI: Intervalo de Guarda; PDM: Multiplexação por Divisão de Polarização; SE: Eficiência Espectral; DQPSK: Differential Quadrature Phase Shift Keying.

\subsection{Transmissor}

O conceito de supercanal está associado à geração de um pente de portadoras amarradas em frequência, e algumas das técnicas de formação serão descritas de modo mais detalhado, na seção 3.6. Em sua configuração, um parâmetro útil, conhecido como ISE (Intrachannel Spectral Efficiency), especifica a eficiência espectral de um supercanal. [46].

Um transmissor típico é ilustrado na Figura 3.2 onde as multiportadoras são geradas através de um laser semente que irá gerar um sinal que incide no bloco gerador óptico comb também conhecido como OCG (Gerador Óptico Comb) Uma vez que o pente tenha sido gerado, a próxima etapa é a modulação de todos esses canais ópticos, por exemplo, através da modulação DP-QPSK (Dual polarization 
quadrature phase-shift Keying). Neste estágio, para que a mútua ortogonalidade entre as subportadoras seja bem estabelecida, todas as subportadoras devem ser espaçadas em um valor igual à taxa de símbolos. Uma vez obtida a ortogonalidade entre as subportadoras, a necessidade de banda de guarda entre as subportadoras adjacentes torna-se dispensável. $\mathrm{Na}$ saída do modulador DP-QPSK as subportadoras moduladas estão prontas para serem transmitidas. O transmissor óptico utilizado nas simulações está ilustrado na Figura 3.2.

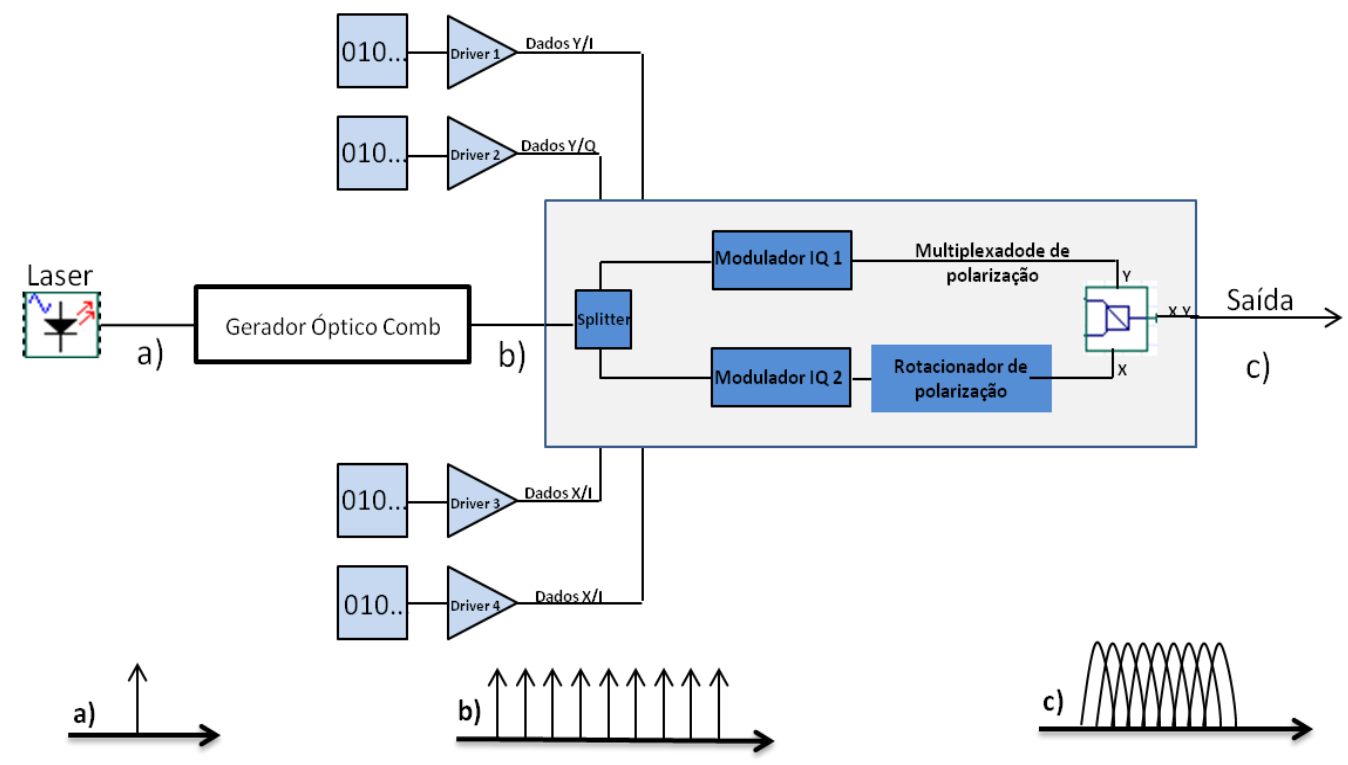

Figura 3.2 - Transmissor OFDM com portadoras amarradas em frequência. Os espectros (a), (b), (c) são ilustrados conforme cada etapa

A modulação DP-QPSK, ou seja, uma modulação por chaveamento de fase e quadratura e dupla polarização foi determinada pela OIF como padrão para sistemas 100G. Nesse tipo de modulação, dois sinais distintos, com polarizações ortogonais e mesmas frequências, são combinados para obter uma melhor eficiência espectral. Assim, como mostra a Figura 3.3, cada polarização é modulada em fase e quadratura, preservando-se o módulo do sinal constante e a fase variando entre $45^{\circ}$, $135^{\circ}, 225^{\circ}$ e $315^{\circ}$. Com isso, cada símbolo de cada polarização carrega dois bits de 
informação, resultando em 4 bits por símbolo e viabilizando uma transmissão de 100 $\mathrm{Gb} / \mathrm{s}$ no espaço de um canal DWDM.
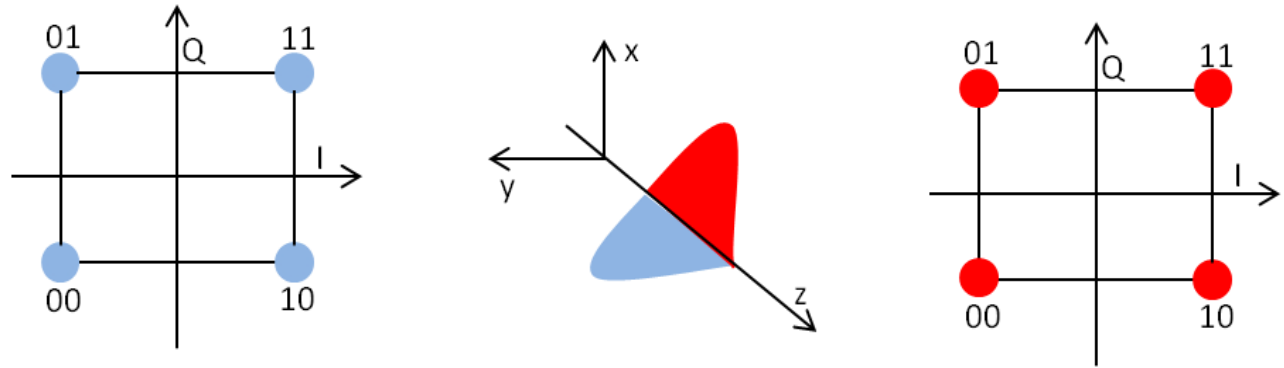

Figura 3.3 - Polarizações Ortogonais e constelações da Polarização X e Y da modulação $D P-Q P S K$

\subsection{Receptor}

$\mathrm{Na}$ recepção será utilizado um receptor óptico coerente, que recupera as informações de fase e amplitude do sinal transmitido, viabilizando o seu tratamento pelo processamento digital de sinais. Técnicas como a recepção coerente permitem o uso de um receptor único para diversos formatos de modulação, movendo a complexidade do processamento óptico da fase e polarização do sinal para o domínio elétrico, através do processamento digital de sinal [50].

No receptor óptico coerente com divisão de polarização, se faz necessário separar a informação nas componentes de polarização ortogonais $X$ e $Y$ de uma forma apropriada. Tendo isso em vista, faz-se o uso de um divisor de feixe de polarização, o PBS (Polarization beam splitter), um componente óptico passivo capaz de separar as componentes ortogonais de polarização de forma eficaz, assim como poder ser observado na Figura 3.4. Este componente divide o sinal de entrada para as duas portas de saída [53]. O PBS seleciona o componente de polarização apropriado do sinal na porta de entrada e cada componente de polarização para uma das portas de saída. 


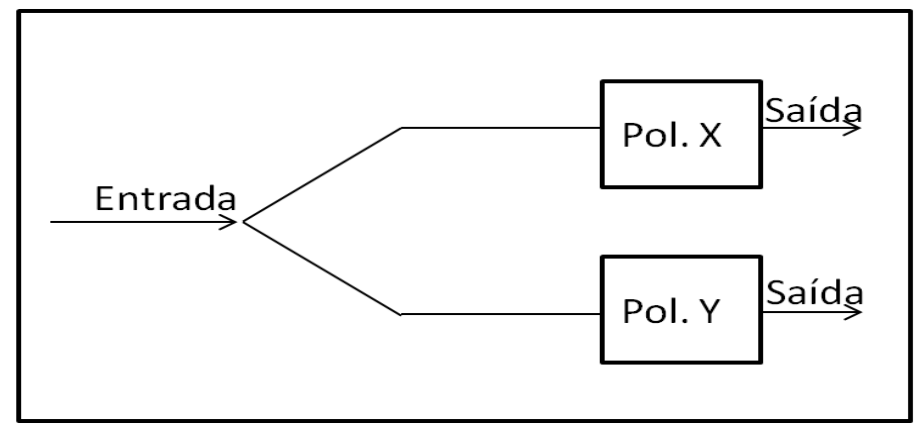

Figura 3.4 - Polarization Beam Splitter

Desta forma, conectando dois PBS e duas híbridas de $90^{\circ} \mathrm{com}$ a fotodetecção balanceada, pode-se utilizar o receptor coerente com diversidade de polarização e fase [51]. Com isso, podemos analisar o receptor óptico coerente utilizado nas simulações de acordo com a Figura 3.5.

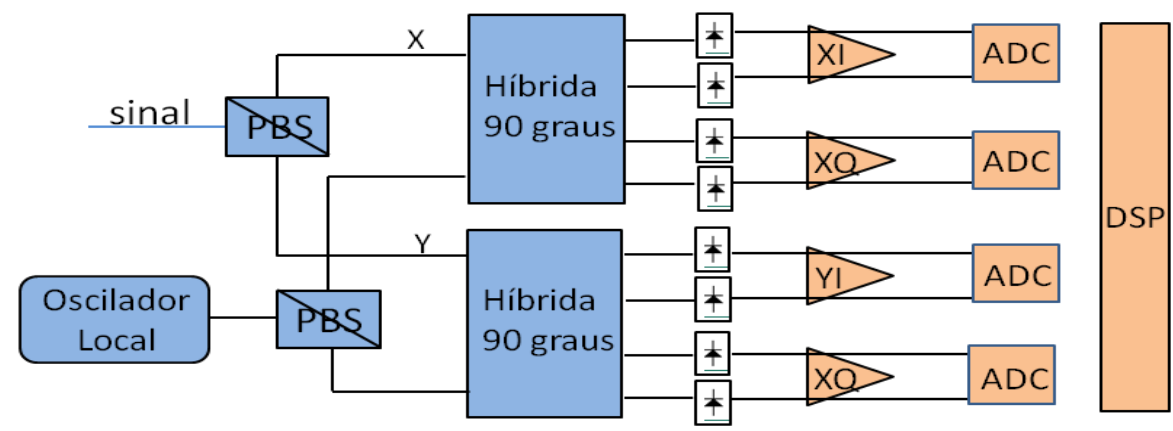

Figura 3.5 - Receptor óptico coerente com fase e polarização

No receptor óptico coerente com dupla polarização, como ilustrado na Figura 3.5, a parte de entrada óptica até a conversão optico-elétrica é representada em cor azul e a parte da eletrônica do receptor está representada em cor creme. O sinal óptico que incide no receptor coerente tem suas componentes de polarização de forma ortogonal separadas pelo PBS, e é então divido em duas polarizações ortogonais, as quais sofrem a combinação com o oscilador local ECL (External Cavity Laser) contendo as mesmas componentes de polarização através do laser do oscilador local que será inserida nas híbridas de $90^{\circ}$. Após essa combinação com o oscilador local os sinais de saída das híbridas de 90 graus, em fase e quadratura 
para cada polarização, serão então fotodetectados por 4 pares de fotodetectores balanceados, onde cada par é dedicado a uma das sequências de dados. As 4 sequências de dados elétricos geradas pelos fotodetectores, após a fotodeteção serão então amplificadas por amplificadores elétricos e por fim esses sinais elétricos serão digitalizados por conversores analógicos - digitais, obtendo-se as sequências de dados transmitida que serão processadas offline por algoritmos de processamento digital de sinais para a recuperação do sinal, conforme ilustrado na Figura 3.6.

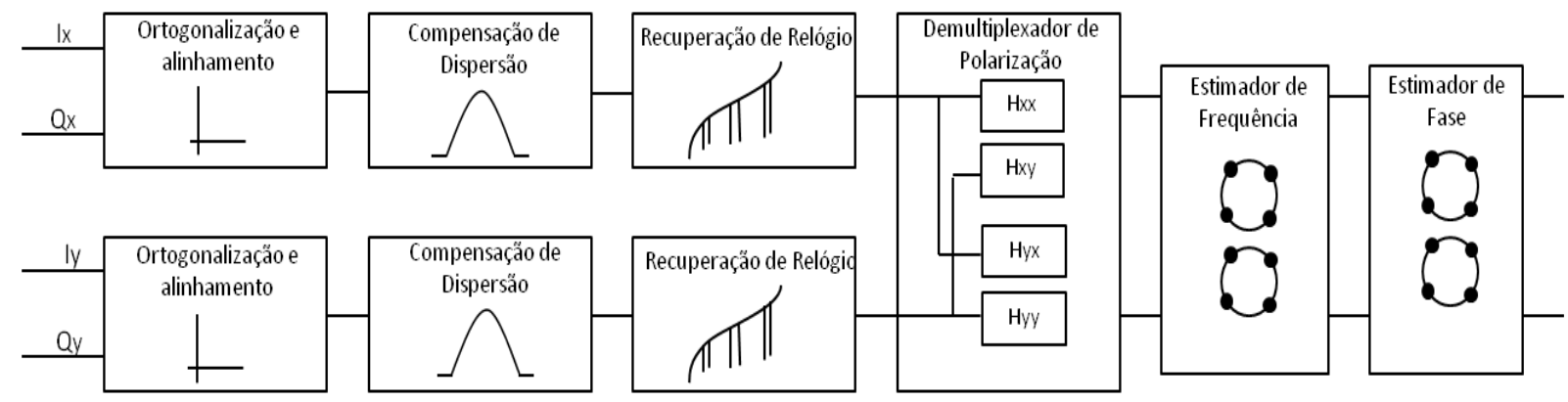

Figura 3.6 - Diagrama de blocos do algoritmo de processamento digital de sinais [52]

A Figura 3.6 ilustra a sequência de algoritmos usualmente empregada em unidades de PDS e que também foi utilizada neste trabalho. Na Figura 3.6, os algoritmos estão divididos em blocos que representam as principais funcionalidades. O bloco - Normalização, Equalizador Estático, Recuperação de Tempo, Equalizador Dinâmico, Estimador de Frequência, Estimador de Fase. Logo em seguida após todos esses algoritmos, o executável abre a janela de Análise de Constelação.

$\mathrm{Na}$ Figura 3.7, ilustra as constelações do sinal recebido após o receptor coerente, visto no analisador de constelação do simulador e no algoritmo de PDS, para os dois eixos de polarização, $\mathrm{X}$ e $\mathrm{Y}$. 
ontions
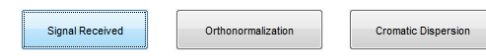

Time Recovery

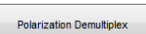

Frequency Estimator

Phase Estimator

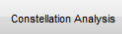

Signal Received

Received Signal X

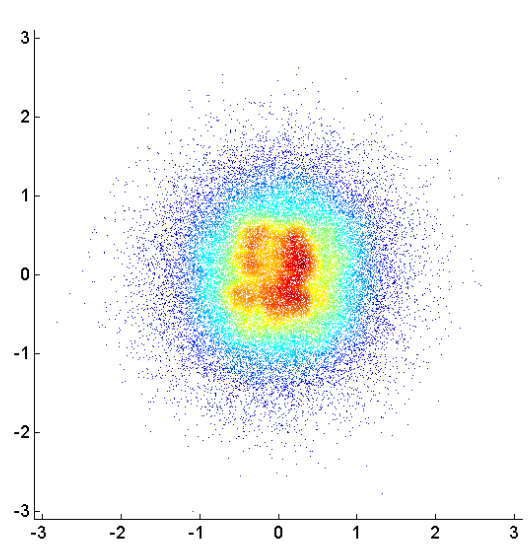

Received Signal Y

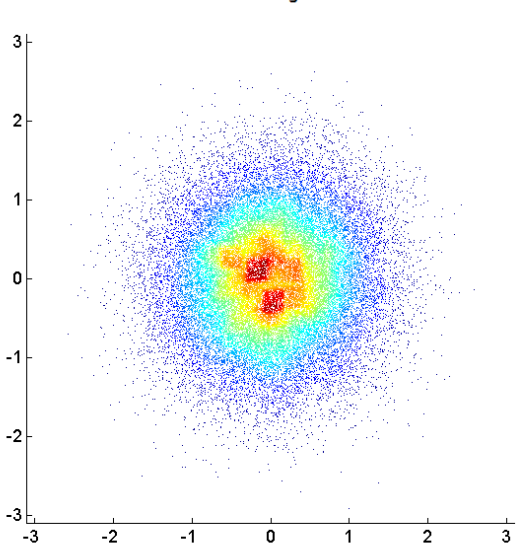

Figura 3.7 - Diagrama de constelação do sinal recebido

A Figura 3.8 ilustra o bloco - Normalização e Ortogonalização que compensa distorções na híbrida de $90^{\circ}$ e diferenças de potência entre as componentes em fase e quadratura.
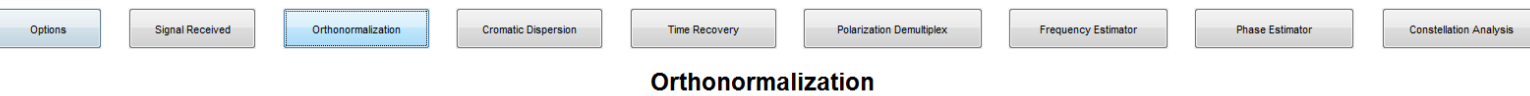

Orthonorm. X

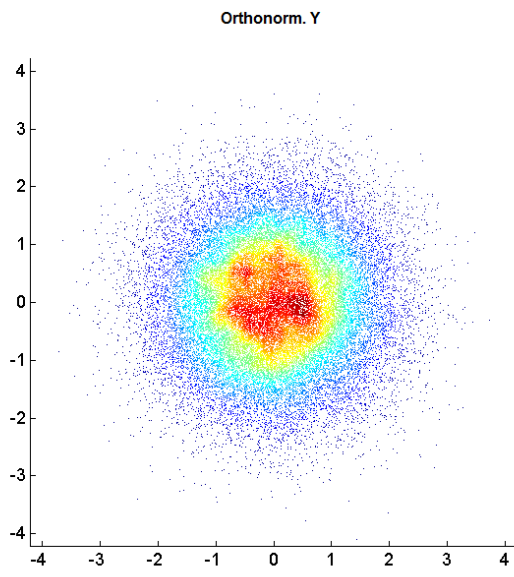

Figura 3.8 - Bloco de normalização e ortogonalização 
O bloco - Equalizador Estático faz a compensação da dispersão cromática (CD - chromatic dispersion) acumulada durante a transmissão, seja no domínio do tempo ou no domínio da frequência.

A Figura 3.9 ilustra o bloco - Recuperação de Tempo usa o algoritmo de Gardner para recuperar o tempo de símbolo.
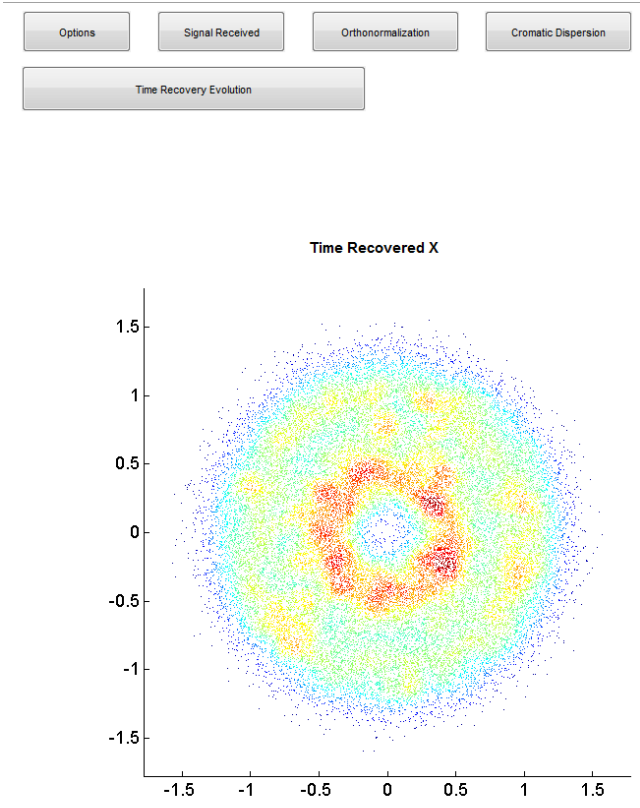
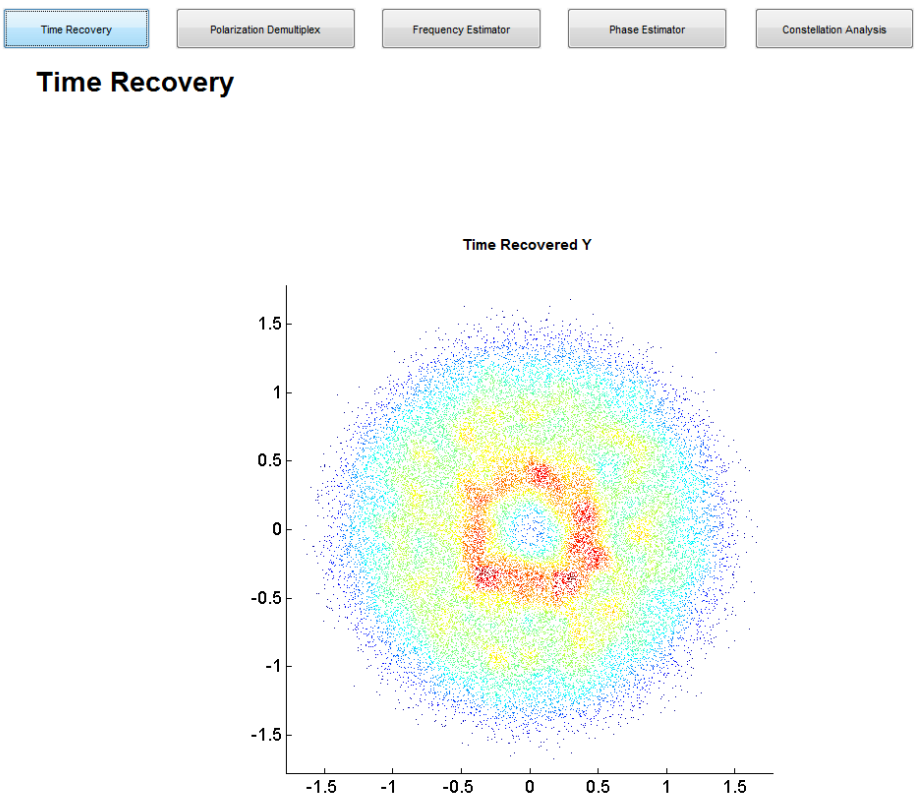

Figura 3.9- Bloco equalizador estático

O bloco - Equalizador Dinâmico é responsável por separar os eixos de polarização, bem como equalizar e acompanhar possíveis variações no estado do canal. Os algoritmos normalmente utilizados nesse bloco são o Constant Modulus Algorithm, o Least Mean Square (LMS) ou o Decision Directed LMS (DD-LMS); todos na configuração MIMO 2x2 (Multiple Input Multiple Output) usando quatro filtros de resposta finita ao impulso (Finite Impulse Response - FIR), como mostrado na Figura 3.10. 

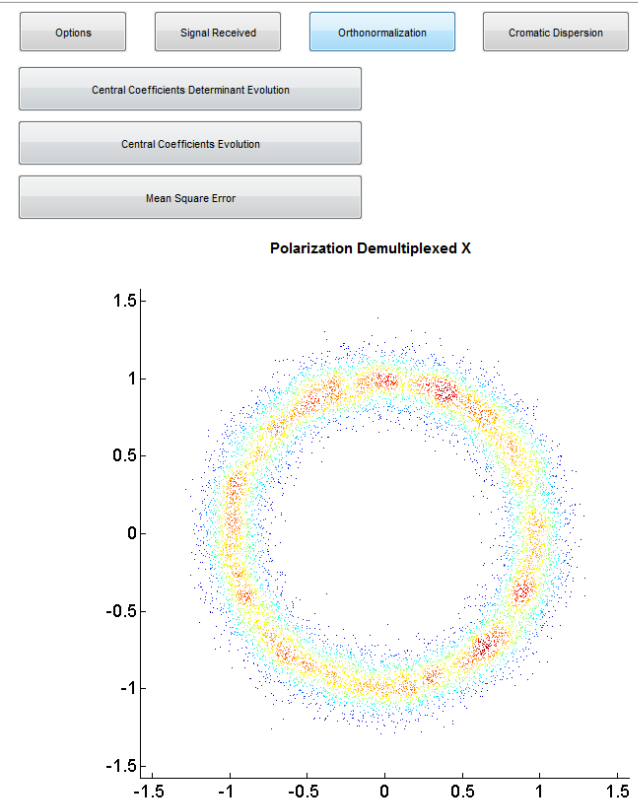

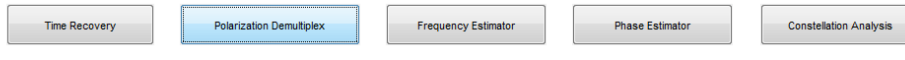

Polarization Demultiplex

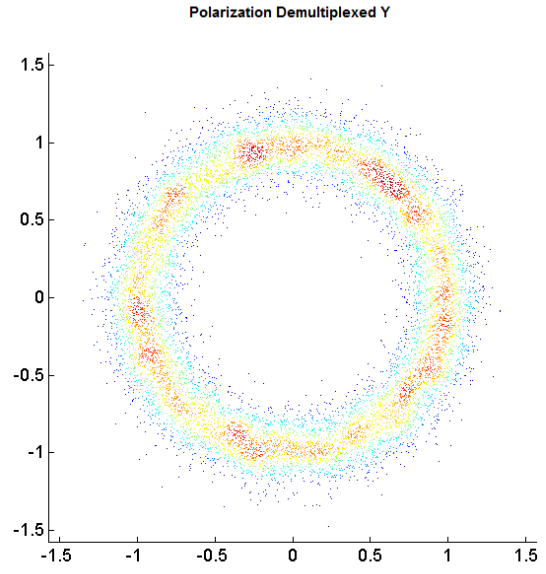

Figura 3.10 - Bloco equalizador dinâmico

Após a equalização dinâmica, o bloco - Estimador de Frequência realiza a estimação do desvio de frequência entre o laser de sinal e o laser oscilador local, seja no domínio do tempo ou no domínio da frequência, conforme a Figura 3.11.
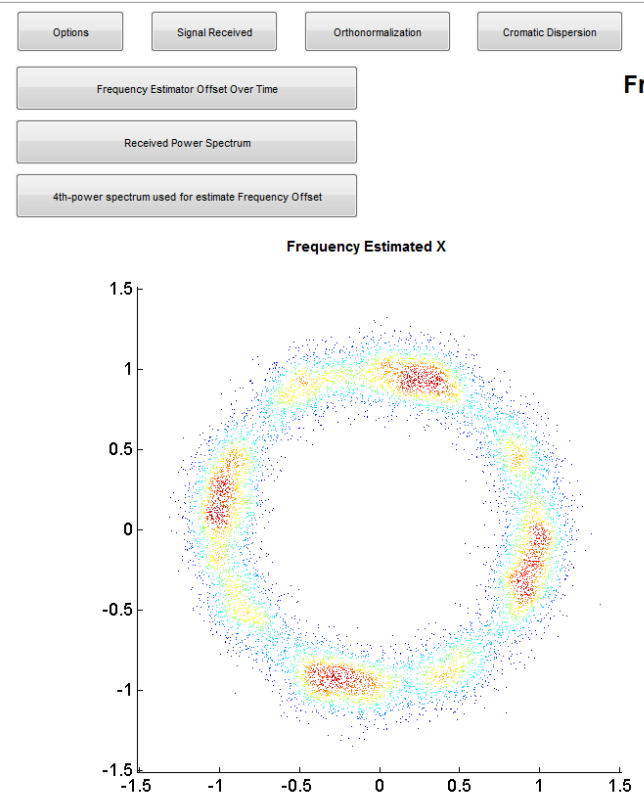

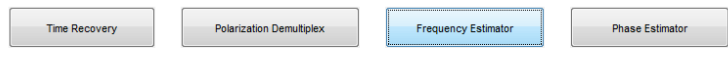

Frequency Offset Estimator

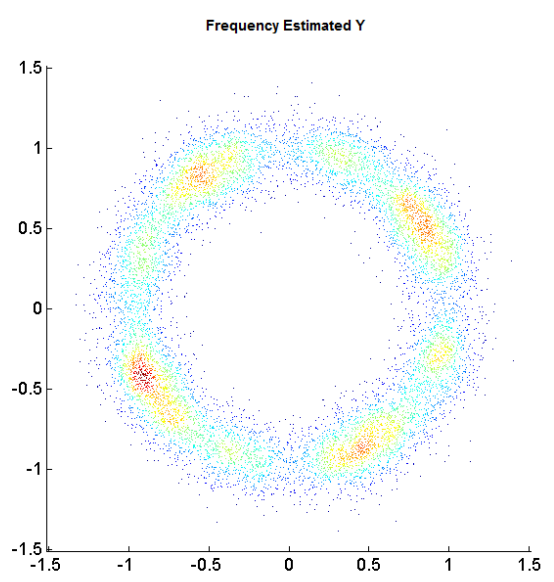

Figura 3.11 - Bloco estimador de frequência 
Já no bloco Estimador de Fase, a estimação de fase é realizada por meio do algoritmo de recuperação de fase por alimentação adiante (FFPE - feed-forward phase recovery), como pode ser visto na Figura 3.12.
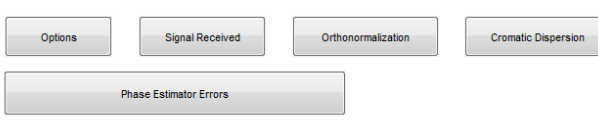

Phase Estimated X

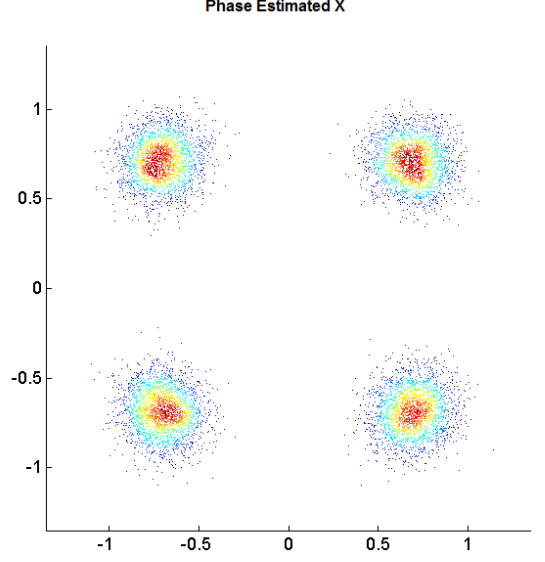

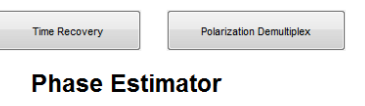
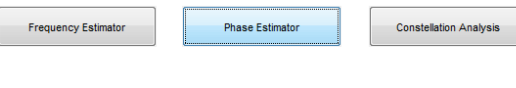

Figura 3.12 - Bloco estimador de fase

Em seguida, é feita a decisão dos símbolos em cada polarização e calculada a taxa de erro de bits, a partir do fator de qualidade da constelação (Q-Factor). A Figura 3.13 mostra o bloco análise de constelação após todos os algoritmos terem feitos suas devidas correções. Neste bloco é feito a análise da BER e do fator $Q$, onde pode ser visto também a compensação total da dispersão, a frequência estimada e se a informação chegou de forma distinta ou não. 


\begin{tabular}{|c|c|c|c|c|c|}
\hline \multirow[t]{2}{*}{ options } & Signal Received & Orhonormaization & \multirow{2}{*}{ Cromatic Dispersion } & Time Recovery & Polarization Demultiplex \\
\hline & & & & \multicolumn{2}{|c|}{ Constellation Analysis } \\
\hline \multicolumn{2}{|c|}{ Counted BER } & \multicolumn{2}{|c|}{ Estimated BER } & \multicolumn{2}{|c|}{ Quality factor } \\
\hline Total $=$ & $0.000 \mathrm{e}+000$ & Total $=$ & $1.327 \mathrm{e}-008$ & Total = & $5.563 \mathrm{e}+000$ \\
\hline$Q \mathrm{x}=$ & $0.000 \mathrm{e}+000$ & $Q x=$ & $1.253 e-009$ & $Q \mathrm{x}=$ & $5.961 e+000$ \\
\hline $\mathrm{x}=$ & $0.000 \mathrm{e}+000$ & $\mathrm{Ix}=$ & $1.588 \mathrm{e}-009$ & $\mathrm{Ix}=$ & $5.922 e+000$ \\
\hline$Q y=$ & $0.000 \mathrm{e}+000$ & $Q y=$ & $2.571 \mathrm{e}-008$ & $Q y=$ & $5.446 \mathrm{e}+000$ \\
\hline$y=$ & $0.000 \mathrm{e}+000$ & $\mathrm{ly}=$ & $2.453 e-008$ & $\mathrm{I} y=$ & $5.455 e+000$ \\
\hline \multicolumn{2}{|c|}{$\begin{array}{l}\text { Differential } \\
\text { Counted BER }\end{array}$} & \multicolumn{2}{|c|}{$\begin{array}{c}\text { Differential } \\
\text { Estimated BER }\end{array}$} & \multicolumn{2}{|c|}{ Cycle slips } \\
\hline Total = & $0.000 \mathrm{e}+000$ & Total $=$ & $2.654 \mathrm{e}-008$ & Total = & $0.000 \mathrm{e}+000$ \\
\hline $\mathrm{Qx}=$ & $0.000 e+000$ & $Q \mathrm{x}=$ & 2.50be-0uy & $Q x=$ & $0.000 e+000$ \\
\hline $\mathrm{x} x=$ & $0.000 e+000$ & $1 x=$ & $3.175 \mathrm{e}-009$ & $\mathrm{Ix}=$ & $0.000 e+000$ \\
\hline$Q y=$ & $0.000 \mathrm{e}+000$ & $\mathrm{Qy}=$ & $5.142 \mathrm{e}-008$ & $Q y=$ & $0.000 \mathrm{e}+000$ \\
\hline $\mathrm{ly}=$ & $0.000 \mathrm{e}+000$ & $l y=$ & $4.906 \mathrm{e}-008$ & $y=$ & $0.000 e+000$ \\
\hline Status & Distinct information & FreqEst Total & $1.999 \mathrm{e}+009 \mathrm{~Hz}$ & CD Total & $1675 \mathrm{ps} / \mathrm{nm}$ \\
\hline $\begin{array}{l}\text { Status } \\
\text { Differential }\end{array}$ & Distinct information & Total Errors & $0.000 e+000$ & $\begin{array}{r}\text { Total Errors } \\
\text { Differential }\end{array}$ & $0.000 e+000$ \\
\hline
\end{tabular}

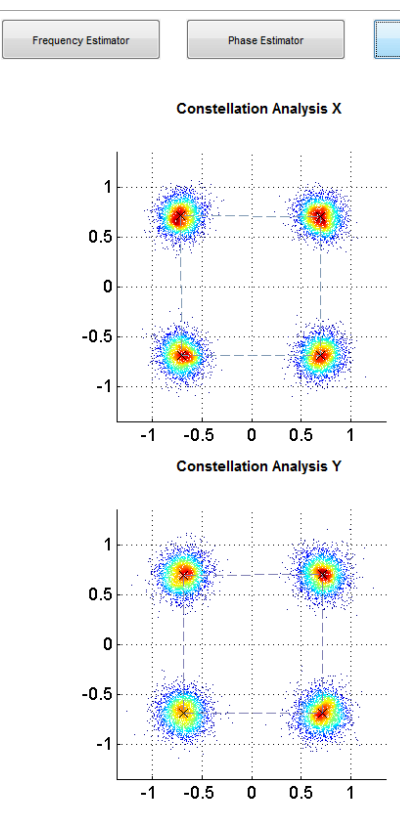

Figura 3.13 - Bloco de análise de constelação

Uma vez que foram apresentados os conceitos do transmissor, receptor, da modulação DP-QPSK e do algoritmo de processamento digital de sinais, a próxima seção irá apresentar os conceitos dos geradores ópticos e sua implementação no software utilizado para as simulações e alguns resultados parciais da geração de multiportadoras ópticas.

\subsection{Transmissão}

Como descrito na tabela 3.1 vários formatos de modulação já foram avaliados em laboratórios e várias distâncias de transmissão alcançadas com diversas taxas de transmissão de supercanais ópticos. Nestes experimentos, mesmo com o uso de detecção direta e compensação de dispersão ao longo do enlace, distâncias em torno de 1.000 km foram alcançadas. Porém, para enlaces sem compensação de dispersão e amplificação com detecção coerente, transmissões por milhares de quilômetros já foram demonstradas por vários experimentos [52].

Todos esses resultados experimentais comprovam a viabilidade da transmissão de multiportadoras com taxas acima de terabis/s (Tb/s) em redes- 
tronco, na qual a transmissão por longas distâncias é necessária. Também demonstram que o uso de novas fibras como, fibra de sílica pura (com atenuações mais baixas e dispersão mais alta) pode ser útil no aperfeiçoamento do desempenho dos novos sistemas de próxima geração com altas taxas de dados [52].

\subsection{Geradores ópticos "Comb"}

Inicialmente, o crescimento da capacidade dos sistemas ópticos era obtido com um aumento na taxa de transmissão, que por sua vez era limitada pela velocidade da eletrônica existente na época e pelas próprias limitações impostas pela fibra. Logo após o desenvolvimento da técnica WDM e de amplificadores ópticos, o incremento da capacidade também foi obtido pelo aumento da velocidade de transmissão e do número de canais utilizados. Este incremento é limitado pela largura de banda disponível dos amplificadores ópticos e pela interferência entre os canais adjacentes, estabelecendo um compromisso entre espaçamento de canais e densidade espectral [54].

Diferentes técnicas foram estudadas e propostas para o aumento da capacidade dos sistemas dentre elas destacam-se: os novos formatos de modulação, a redução das limitações de propagação das fibras pelos códigos de correção de erros (FEC), o aumento da largura de banda, a redução dos ruídos nos amplificadores ópticos e o aumento no número de canais [55].

Um dos fatores que têm atraído muita atenção, com a mudança para taxas mais elevadas, é a densidade de espectral informação alcançada no transmissor. Uma abordagem promissora envolve a utilização de técnicas de transmissão de multiportadora espectralmente eficientes com o espaçamento entre os canais igual à taxa de símbolo aplicada em cada canal, podendo-se alcançar esse aumento no 
número de canais, com uma penalidade mínima provocada através da interferência entre os canais, por meio de portadoras ópticas mutuamente ortogonais [56], [57].

Uma maneira de obter uma transmissão com altas taxas de dados por fibra óptica é utilizar as multiportadoras ortogonais coerentes, também conhecida como coherent WDM (CO-WDM), que utilizam uma única fonte laser (desta forma, coerente em fase) para gerar múltiplas portadoras no domínio óptico. Este sinal de varias subportadoras com taxas mais baixas e de alta taxa total resultante, produzido por uma única fonte de laser e composto por múltiplas portadoras sincronizadas em fase e moduladas de um modo síncrono, tem sido nomeado superchannel. Neste tipo de sinal a interferência entre as portadoras moduladas (onde no processo de modulação as portadoras geradas vão se tornar mutuamente ortogonais) pode ser eliminada controlando-se a fase dos canais adjacentes [54].

Para que um canal possa ser detectado entre vários outros canais adjacentes, com a menor penalidade possível devido a interferências entre os canais, algumas condições têm de ser satisfeitas, tais como [49]:

a) A separação entre canais é igual à taxa de símbolos de modulação de cada portadora;

b) Os símbolos, nas portadoras moduladas, estão alinhados no tempo;

c) A largura de banda do transmissor é grande o bastante para acomodar as portadoras;

d) Uma taxa de amostragem e uma filtragem anti-aliasing são aplicadas.

Uma característica essencial do supercanal, ocupando uma banda finita é que quanto maior for a quantidade de portadoras menor será a separação entre elas e a taxa de transmissão de símbolos de cada uma, ou seja, é importante gerar 
portadoras estáveis, sem variação do intervalo frequência entre elas e com a mesma taxa de transmissão. A geração do pente óptico pode ser obtida de diversas maneiras, três das quais serão estudadas nesta dissertação:

a) Cascateamento de moduladores Mach-Zehnder (MZM) - técnica normalmente utilizada para a geração de sinais com duas a onze portadoras sendo sua limitação principal o pequeno número de portadoras geradas, que é determinado pela largura de banda eletroóptica dos moduladores (Mach Zehnder, MZM, ou de fase) e pela amplitude máxima do sinal de alimentação [58].

b) Recirculating Frequency Shifting (RFS) - técnica baseada na conversão de frequência produzida pela modulação de banda lateral única. Esta técnica permite a geração de um grande número de portadoras e grande estabilidade [59].

c) Laser de Modo Discreto (DM) alimentado por onda senoidal: esta técnica é similar ao gain switching em lasers semicondutores, mas resulta numa saída de fase travada. Embora também não seja mais indicada para geração de um grande número de raias, apresenta as vantagens como simplicidade e baixo custo [60].

\subsubsection{Recirculating Frequency Shifting (RFS)}

É uma técnica baseada na conversão da frequência produzida pela modulação de banda lateral única, que permite a geração de um grande número de portadoras altamente estáveis. O sinal óptico gerado pela fonte laser é deslocado em frequência dentro de um anel de recirculação. $O$ gerador óptico de múltiplas portadas ortogonais, também conhecido como gerador óptico Comb (Optical Comb 
Generator - OCG ), é baseado na técnica RFS e constitui a célula básica do transmissor óptico dos sistemas Co-WDM. Esse gerador é formado por um laser monomodo e um anel de recirculação. Esse anel, no qual são geradas as múltiplas portadoras, é formado por:

a) Um acoplador óptico $2 \times 2$;

b) Um modulador óptico do tipo Mach-Zehnder duplo, que possui a função de geração de um sinal de banda lateral única;

c) Um amplificador óptico, EDFA, que compensa as perdas no anel;

d) Um filtro óptico, que limita o número de portadoras geradas;

A figura 3.14 ilustra um diagrama de um Comb Generator. A técnica RFS, representada na Figura 3.14, funciona da seguinte maneira:

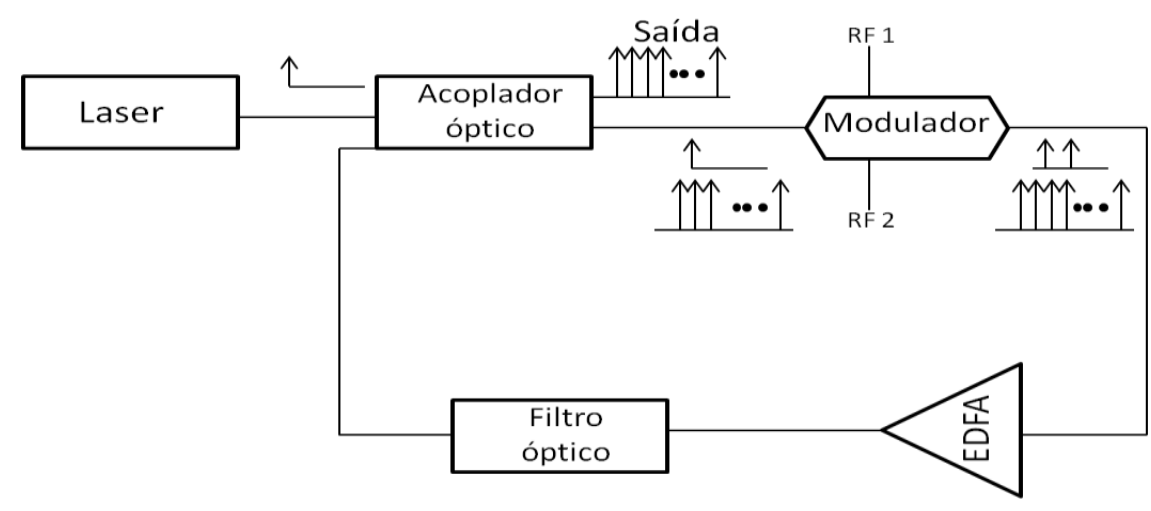

Figura 3.14 - Diagrama esquemático de um Gerador óptico comb

O sinal óptico gerado pela fonte laser é dividido em duas partes pelo acoplador óptico, metade para a saída do acoplador e a outra metade vai para o anel de recirculação, no qual serão geradas as múltiplas portadoras. A parte do sinal que é acoplada no anel passa por um modulador Mach-Zehnder acionado por sinais senoidais de RF e controlado por um conjunto de sinais de alimentação contínua (DC). O modulador é ajustado de maneira a prover uma modulação do tipo SSB-SC (Single Sideband Supressed Carrier). O sinal de saída do modulador é inserido no 
amplificador EDFA e na saída do amplificador o sinal é filtrado, limitando a banda de ruído e rejeitando as portadoras ópticas geradas que excedam a banda do filtro. $\mathrm{A}$ saída do filtro óptico é inserida no acoplador juntamente com o sinal do laser e lá os sinais são acoplados através do acoplador óptico.

A cada volta no recirculador óptico, o modulador óptico causa, no sinal que entra no anel, um deslocamento espectral igual ao valor da frequência do sinal RF aplicado ao modulador. Ao final de diversas voltas, o espectro do sinal que está circulando no anel é deslocado para fora da banda de operação do filtro óptico, terminando assim a circulação do sinal e limitando o número de portadoras na saída do gerador, como mostra a Figura 3.15.

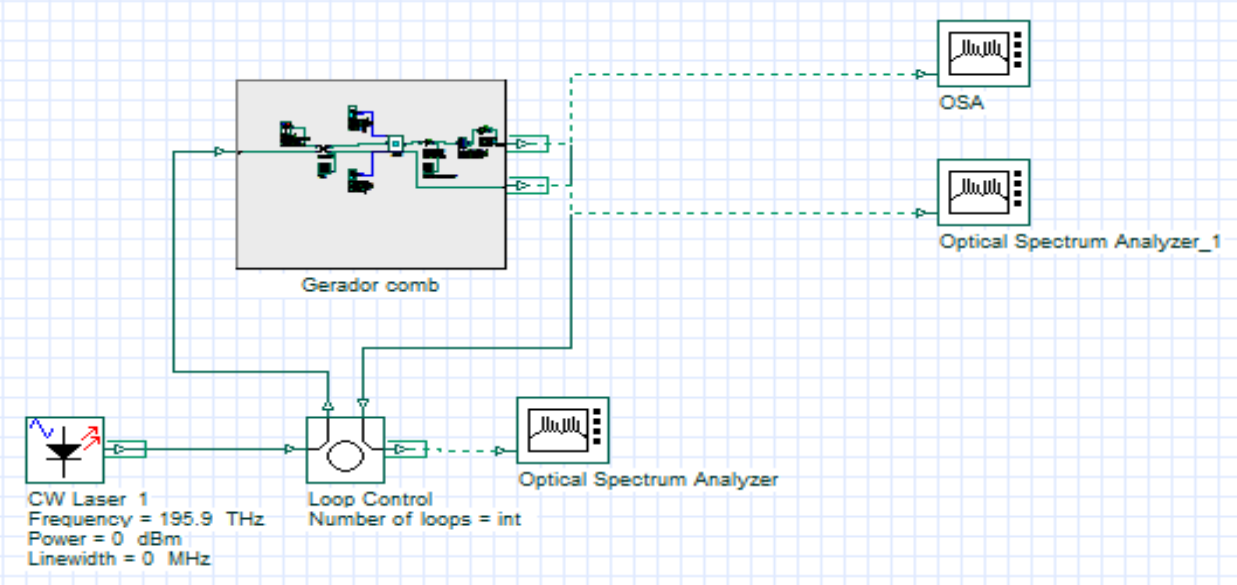

Figura 3.15 - Transmissor óptico com RFS

A figura 3.16 ilustra a saída do transmissor óptico com RFS simulado. O sinal gerado é caracterizado por 10 subportadoras ópticas espaçadas em $25 \mathrm{GHz}$ após 10 voltas no anel de recirculação (na implementação prática são necessárias 9 voltas no anel). 


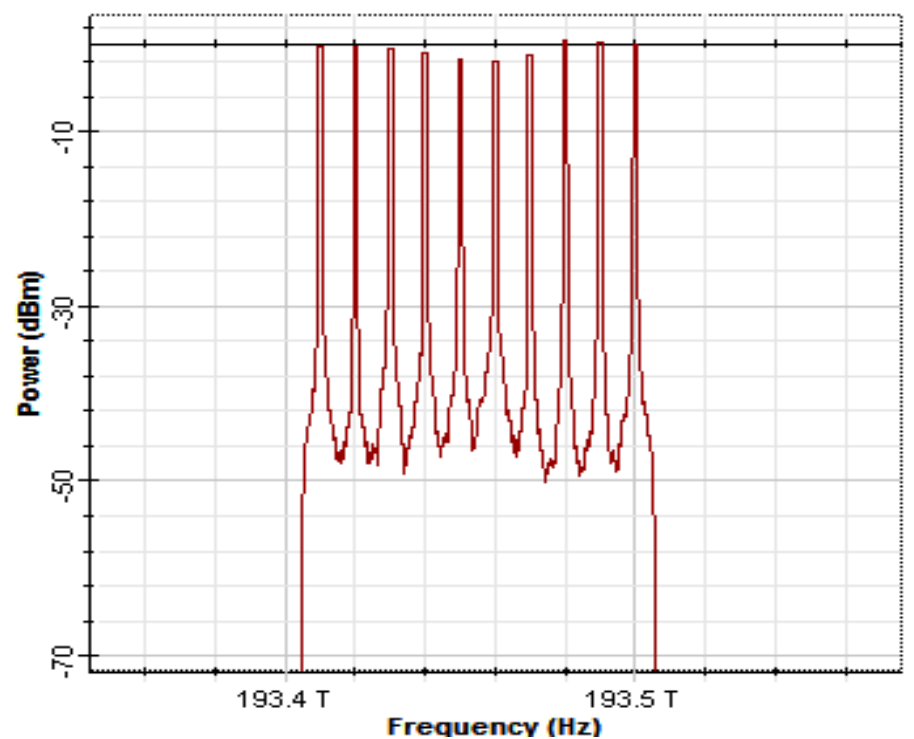

Figura 3.16 - Espectro óptico na saída do gerador óptico comb

\subsubsection{Cascateamento de moduladores Mach-Zehnder}

Esta técnica é geralmente utilizada para gerar sinais com 2 a 11 portadoras, a limitação desta técnica é o pequeno número de portadoras geradas, que é determinado pela largura de banda eletro-óptica dos MZMs.

A Figura 3.17 ilustra a configuração para a simulação do transmissor proposto nessa seção. A simulação foi realizada no software Optisystem 9.0 , e os parâmetros utilizados tais como a perda de inserção e a figura de ruído foram considerados aqueles dos componentes utilizados para a demonstração experimental conforme [58]. 


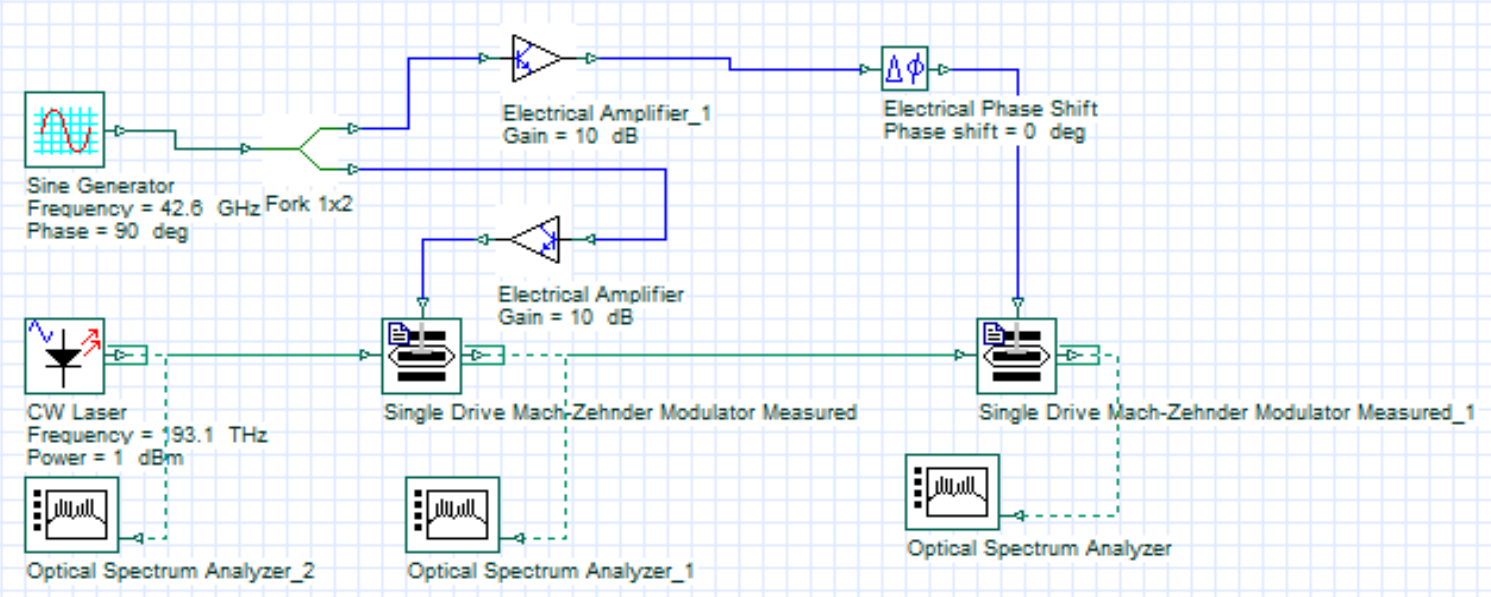

Figura 3.17- Transmissor óptico com cascata de moduladores Mach-Zehnder

A fim de gerar o pente óptico de onda contínua, dois moduladores de amplitude Mach-Zehnder foram acionados por um gerador de RF embora outros cascateamentos pudessem ser implementados, por exemplo, um modulador de amplitude e um modulador de fase. Cada modulador produz uma série de bandas laterais deslocadas de acordo com a frequência de RF inserida no modulador. O pente óptico pode ser produzido com amplitudes iguais através do seguinte artifício: o pente gerado (10 canais) após os moduladores é aplicado em um demultiplexador WDM para que uma atenuação controlada seja aplicada separadamente em cada canal. Desta forma, o sinal gerado torna-se plano (canais com a mesma amplitude). Após essa atenuação o sinal é modulado e colocado em um multiplexador WDM para transmissão. Para obter-se a ortogonalidade os canais são independentemente modulados à uma mesma taxa correspondente à separação entre as subportadoras geradas através da cascata de moduladores Mach-Zehnder. Os sinais modulados são então multiplexados para se obter o supercanal. 
A Figura 3.18 ilustra o espectro gerado no transmissor óptico proposto nessa seção. O espectro de 10 portadoras foi gerado a partir de um único laser, quando os moduladores foram acionados pelo gerador RF.

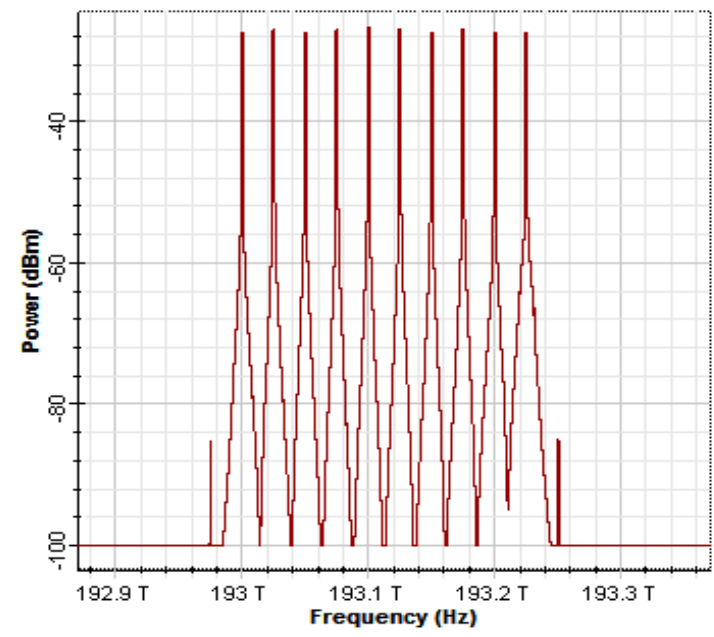

Figura 3.18 - Espectro gerado com cascata de moduladores Mach-Zehnder

\subsubsection{Laser de Modo discreto}

A maior parte dos estudos envolvendo sistemas OFDM ópticos tem utilizado moduladores Mach-Zehnder simples ou em cascata, com ou sem loop de recirculação, para gerar os pentes ópticos. Embora esta técnica e suas variantes sejam bem avaliadas, fatores como perda de inserção do modulador e baixa eficiência de modulação podem torná-las proibitivas para produção em escala, principalmente no aspecto de custo do transmissor. Em particular, para aplicações de mais curto alcance, esta técnica torna-se ainda menos adequada, pois o número de componentes ópticos adicionais que ela requer aumentam a complexidade da integração do transmissor [60].

Nesta seção, iremos apresentar o método de geração do comb óptico que utiliza um laser diretamente alimentado por uma onda senoidal intensa e que funciona de modo similar ao gain switching, resultando num pente com sincronismo 
de fase na saída. Esta técnica possui vantagens importantes como o emprego de componentes de custo mais baixo e o baixo nível de ruído acrescentado ao sinal [60]. Na nossa implementação, um sinal senoidal de $25 \mathrm{GHz}$ foi amplificado e aplicado diretamente a um laser de modulação direta. O processo de geração de impulsos é obtida de maneira semelhante ao método de chaveamento de ganho, como pode ser visto na Figura 3.19. Embora não esteja representado na figura, na saída do laser de modulação direta foi utilizado um demultiplexador para tornar possível a aplicação, sobre cada canal, de uma atenuação ajustável visando a equalização de amplitude dos canais. Em seguida, o sinal foi multiplexado para se obter o supercanal.

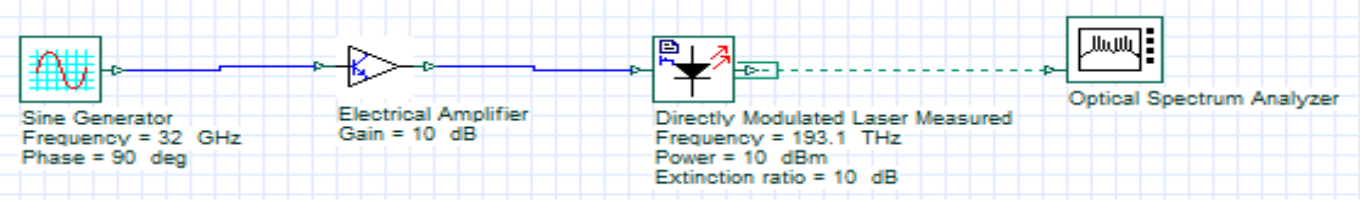

Figura 3.19 - Transmissor óptico alimentado por uma onda senoidal

Como nos casos anteriores, a onda continua foi centrada em 1552,52nm e o espectro de dez portadoras espaçadas de $25 \mathrm{GHz}$ está ilustrado na Figura 3.20, obtido no analisador de espectro óptico colocado à saída do multiplexador óptico. Com um aparato relativamente simples, esta técnica pode ser empregada como um transmissor de menor custo. 


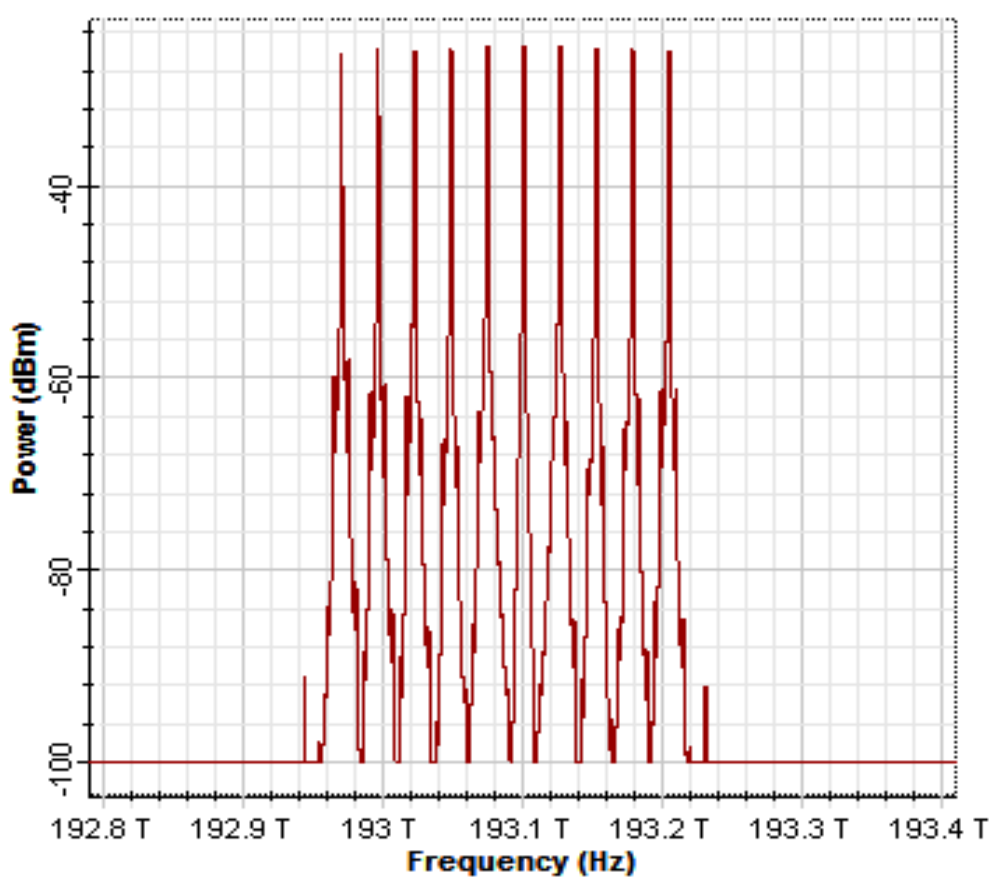

Figura 3.20 - Espectro de saída utilizando laser de modo discreto

Do ponto de vista de implementação experimental, o laser de modo discreto pode ser do tipo Fabry-Perot com espectro modificado, durante a fabricação, para se obter uma operação monomodo. Mesmo assim, sua fabricação é mais simples que a dos lasers normalmente empregados em sistemas de alta velocidade, tipicamente, DFB (distributed feedback) e DBR (distributed Bragg reflector) e, em comparação a estes, apresenta vantagens importantes para um gerador comb: mais alta supressão de modo lateral, operação estável sobre uma grande faixa de temperatura, largura de linha mais estreita e baixa sensibilidade a feedback óptico [61].

Implementações experimentais com grau maior de sofisticação podem empregar uma estrutura contendo um laser externo (mestre), que gera uma luz a ser injetada na cavidade de um laser de modulação direta (escravo), o que expande a faixa de operação do subsistema (i.e. permite o aumento do número de raias no pente óptico). Isso é possível devido ao deslocamento em frequência do pico de ressonância no processo de modulação, sob condição de injeção de luz [62]. No 
nosso estudo estas implementações mais complexas não serão abordadas e será utilizado o componente do simulador correspondente a um laser de modulação direta comumente empregado em sistemas convencionais, com parâmetros default do simulador. 


\section{Resultados}

Este capítulo tem como objetivo apresentar e discutir os resultados sistêmicos onde todo o processo de geração, transmissão e recepção dos supercanais ocorre no domínio óptico. No Capítulo 3, foram descritas as três técnicas de geração do comb óptico que, em combinação com a modulação DPQPSK, resultam em supercanais de 10 raias, utilizados nas simulações deste capítulo. A paleta da simulação sistêmica é validada por um experimento realizado na Fundação $\mathrm{CPqD}$ e serve como base para comparação entre as três técnicas em condições de tráfego pelas redes ópticas a que os supercanais estarão sujeitos. Desta forma, seu desempenho é comparado diante dos efeitos de estreitamento espectral, causado pela concatenação de filtros ópticos, ao acúmulo de ruído ASE, causado por cascatas de amplificadores ópticos, e aos efeitos de propagação pela fibra.

\subsection{Transmissão de um supercanal óptico - validação da paleta de simulação}

Nesta seção apresenta-se a transmissão de um supercanal óptico [64] utilizada para validar as paletas de simulação. $O$ experimento base demonstra a transmissão por $452 \mathrm{~km}$ de um supercanal composto por 10 portadoras NGI-COOFDM (no-guard-interval coherent OFDM), moduladas a uma taxa total de 1,12 Tb/s. Na geração deste supercanal foi utilizada a técnica RFS, descrita na seção 3.6.1. As portadoras geradas, espaçadas de $28 \mathrm{GHz}$ e moduladas a uma taxa de $112 \mathrm{~Gb} / \mathrm{s}$ no 
formato DP-QPSK (Dual Polarization, Quadrature Phase Shift Keying), foram transmitidas por um anel de recirculação de enlace óptico constituído de seis amplificadores ópticos e cinco enlaces de fibra de sílica pura. Na recepção, utilizouse um receptor óptico coerente, como descrito na seção 3.4, para a recuperação da amplitude e fase do sinal transmitido. O processamento digital das amostras do sinal é necessário para separar os canais de diferentes portadoras, para isso é realizado um processamento digital de sinal off-line utilizando o algoritmo representado na seção 3.4, um módulo desenvolvido por pesquisadores da Fundação CPqD. Assim, após as simulações sistêmicas no Optsystem, os resultados são automaticamente salvos e processados neste módulo PDS (implementado em Matlab), descrito em detalhes na referência [53].

O arranjo simulado, apresentado na Figura 4.1, pode ser dividido em 5 blocos funcionais: o gerador de pente 9 (ou comb) óptico, a modulação DP-QPSK, o enlace de fibra (meio de transmissão), o receptor óptico coerente e o processamento de sinal.

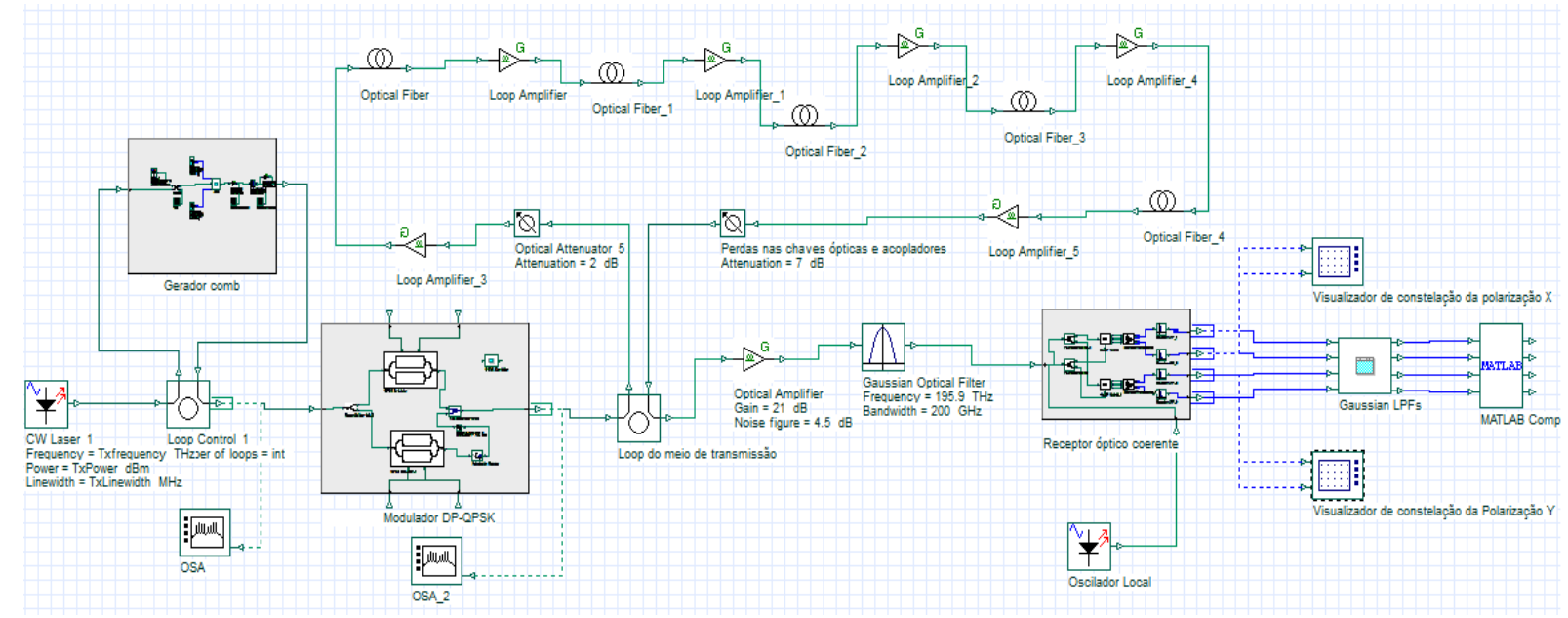

Figura 4.1 - Arranjo Simulado

O laser semente está centrado na frequência de 195,9 THz e a Figura 4.2 mostra as 10 portadoras ópticas, espaçadas de $28 \mathrm{GHz}$, na saída do gerador comb. 
Como pode ser observado na figura 4.2, os canais mais altos, comprimento de onda maior, apresentam um maior nível de ruído, o que também afeta a relação sinal ruído dos canais mais altos (comprimento de onda maior). A consequência deste maior nível de ruído, inerente à técnica de geração do pente utilizada, será mais bem avaliada mais adiante.

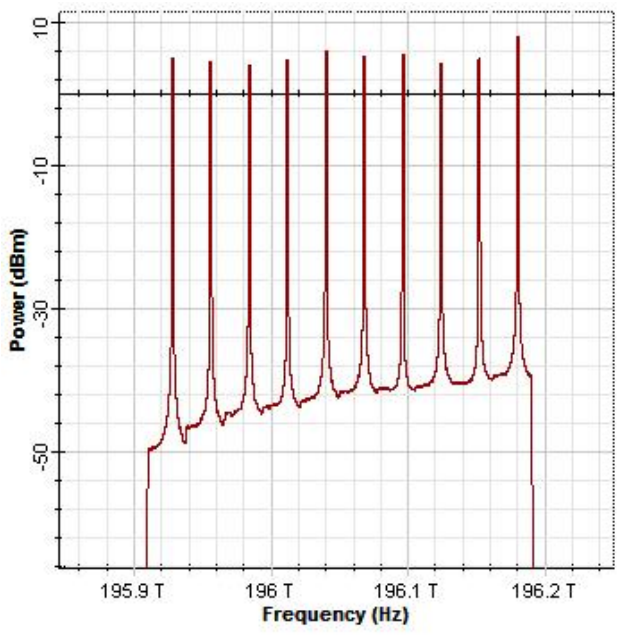

(a)

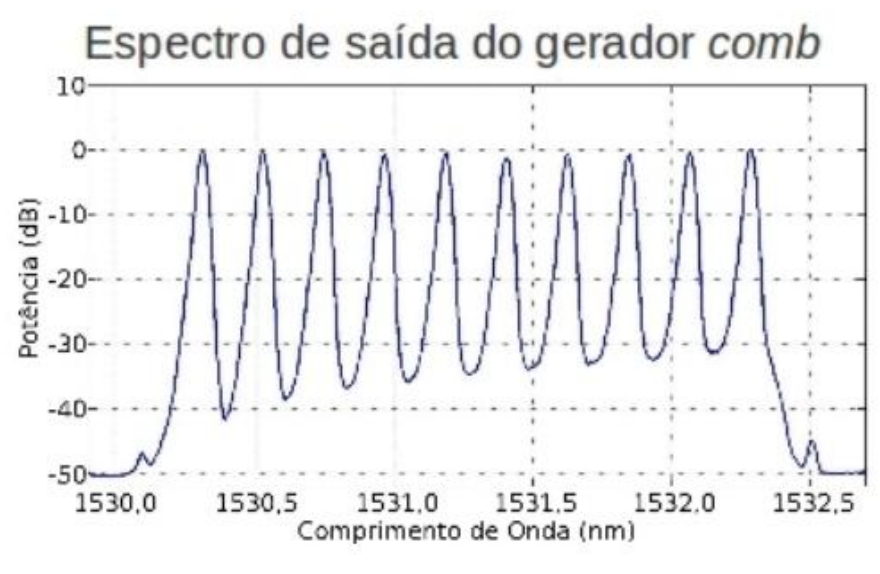

(b)

Figura 4.2 - Espectro de saída do comb generator: (a) Simulado, (b) Experimental [64]

As 4 sequências de dado PRBS (Pseudorandom binary sequence) IX, QX, IY, QY são inseridas no modulador DP-QPSK, cada uma a taxa de $28 \mathrm{~Gb} / \mathrm{s}$. As sequências de dados IX e QX são utilizadas para modular o sinal óptico com polarização $\mathrm{X}$ e as sequências IY e QY, o sinal com polarização $Y$. O bloco modulador é composto por um divisor de potência 1:2, dois moduladores QPSK, um rotacionador de polarização, que irá deslocar a polarização em 90 graus, e um combinador de polarização, responsável por combinar as duas polarizações. 0 espectro de saída após o modulador DP-QPSK pode ser visto na Figura 4.3. 


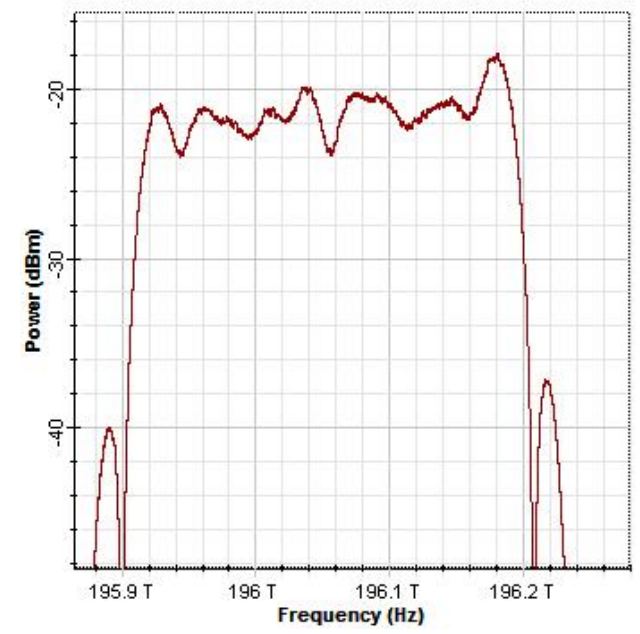

(a)
Espectro de saída do modulador DP-QPSK

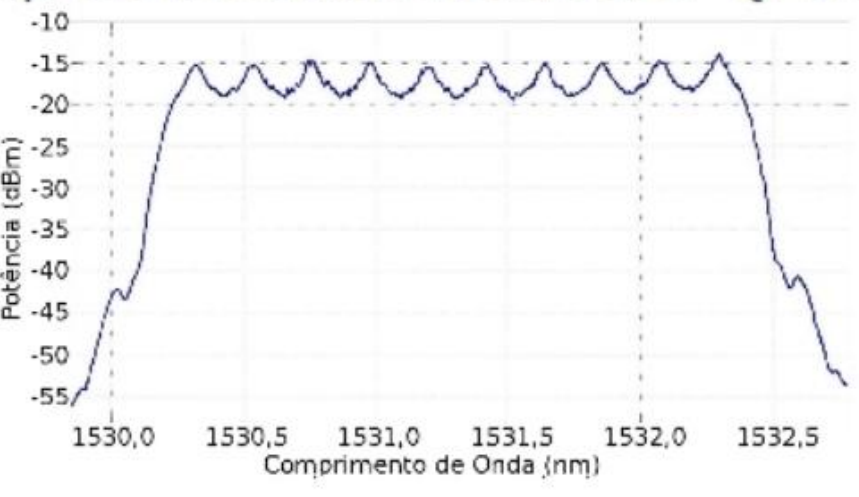

(b)

Figura 4.3 - Espectro após o modulador DP-QPSK: (a) Simulado, (b)Experimental[64]

O enlace óptico é constituído por 5 lances de fibra de sílica pura, G.654, sendo quatro de $50 \mathrm{~km}$ e uma de $26 \mathrm{~km}$, seis amplificadores ópticos e um controlador de loops, para controlar o número de voltas até o comprimento do enlace desejado, e dois atenuadores ópticos. Primeiramente, o sinal sai do modulador e chega ao controlador de loop, passando pelo primeiro atenuador óptico para garantir que a potência de entrada no primeiro amplificador seja de 0,2 dBm. Os amplificadores são ajustados para prover um ganho conforme a atenuação da fibra, à exceção do último amplificador (\#6), colocado apenas para compensar as perdas nas chaves ópticas e acopladores do loop no experimento, conforme [64]. A potência total lançada na fibra, medida no medidor de potência, é $9 \mathrm{dBm}$. Na saída do anel de recirculação, correspondente ao meio de transmissão, são colocados um préamplificador, para melhorar a sensibilidade da recepção, e um filtro óptico passa banda de $200 \mathrm{GHz}$, para selecionar o canal a ser avaliado.

$\mathrm{Na}$ entrada do receptor óptico coerente o sinal é dividido em duas polarizações ortogonais através do componente Polarization Splitter, e cada componente de polarização é misturada com o sinal, gerado no oscilador local, em 
uma híbrida de $90^{\circ}$. Após essa mistura, o sinal é detectado por 4 pares de fotodetectores balanceados, cada par é dedicado a uma sequência de dados. Tendo isso em vista, essas sequências de dados são digitalizadas para serem processadas utilizando um algoritmo de processamento de sinal digital, descrito na seção 3.4. Esse processamento de sinal fornece uma independência maior entre os sinais, compensa as deformações dos sinais advindas da fibra, determina e ajusta os erros de temporização do receptor causados pelos erros de fase entre o sinal e o oscilador local [53].

Os resultados obtidos após esse processamento digital pode ser visto nas curvas da Figura 4.4 para o canal \#1, canal \#5 e canal \#10.

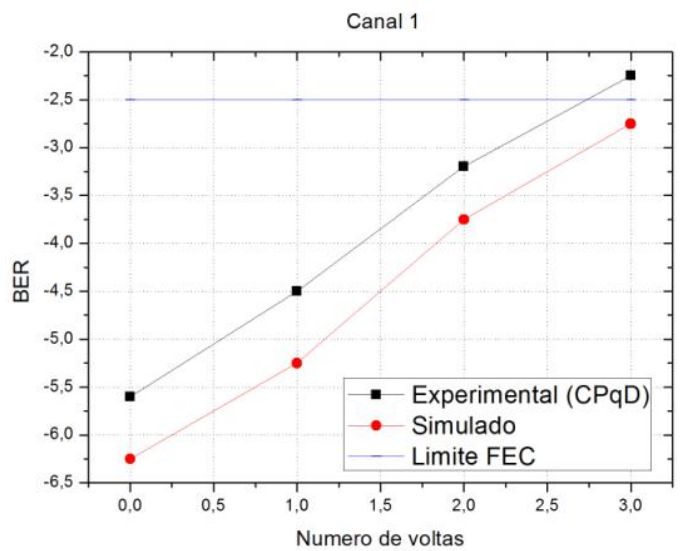

(a)

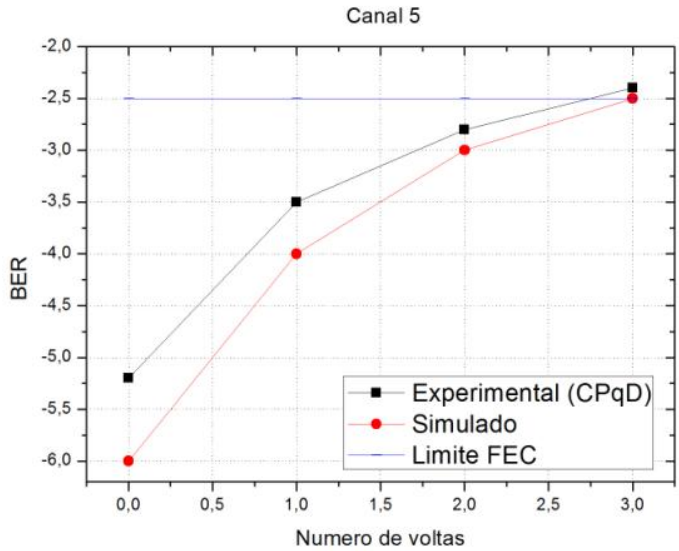

(b)

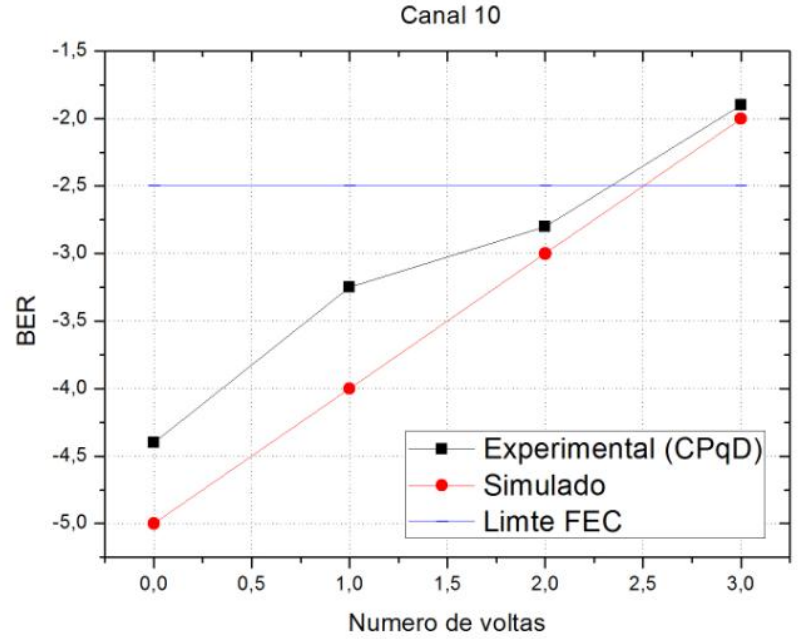

(c) 
A concordância entre os resultados simulados e experimentais é relativamente boa. Os simulados apresentam consistentemente um melhor desempenho, atribuído a não incluírem com exatidão todos os parâmetros que contribuíram para a degradação sistêmica. A Figura 4.4 ilustra as taxas de erro de bit, para o canal \#1, canal \#5 e canal \#10, em função do número de voltas do meio de transmissão, como vimos no experimento proposto por [64], após duas voltas no anel de recirculação, a BER obtida ficou acima do limite da FEC de $3,8 \times 10^{-3}$. A partir de três voltas no anel a BER medida para todas as portadoras ficou acima do limite do FEC. A Figura 4.5 ilustra os diagramas de constelação para as duas polarizações $X, Y$ para 2 voltas no anel de recirculação. $O$ experimento comprovou não ser aceitável (por ultrapassar o limite do FEC) transmitir o supercanal por uma distância superior a $452 \mathrm{Km}$ mas os resultados simulados, apresentados na Figura 4.5, demonstram a possibilidade de mais uma volta do supercanal a uma taxa de $1,12 \mathrm{~Tb} / \mathrm{s}$ e eficiência espectral de $4 \mathrm{~b} / \mathrm{s} / \mathrm{Hz}$. Uma vez razoavelmente aferida a paleta de simulação, seu transmissor e receptor serão usados como base para outras análises de desempenho sistêmico em diferentes configurações sistêmicas. 
Constellation Analysis X

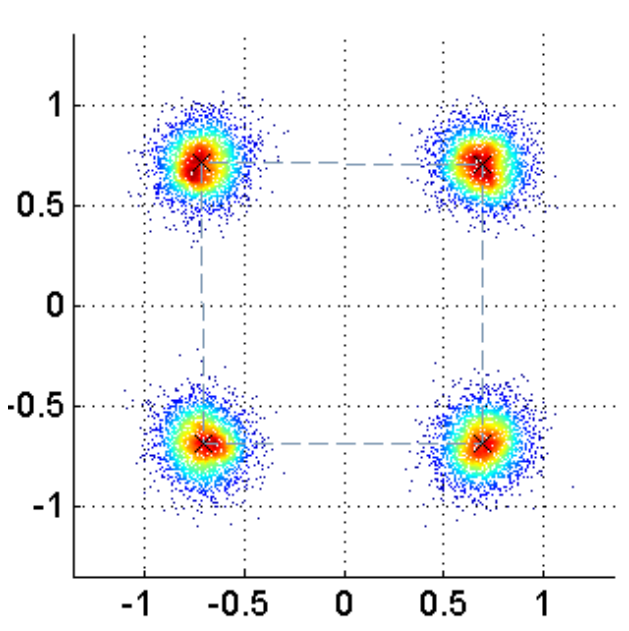

(a)
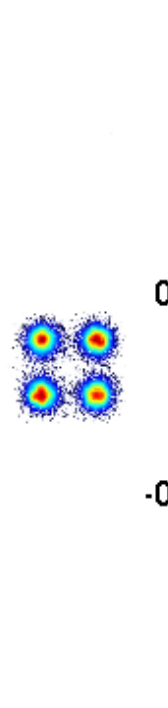

Constellation Analysis Y

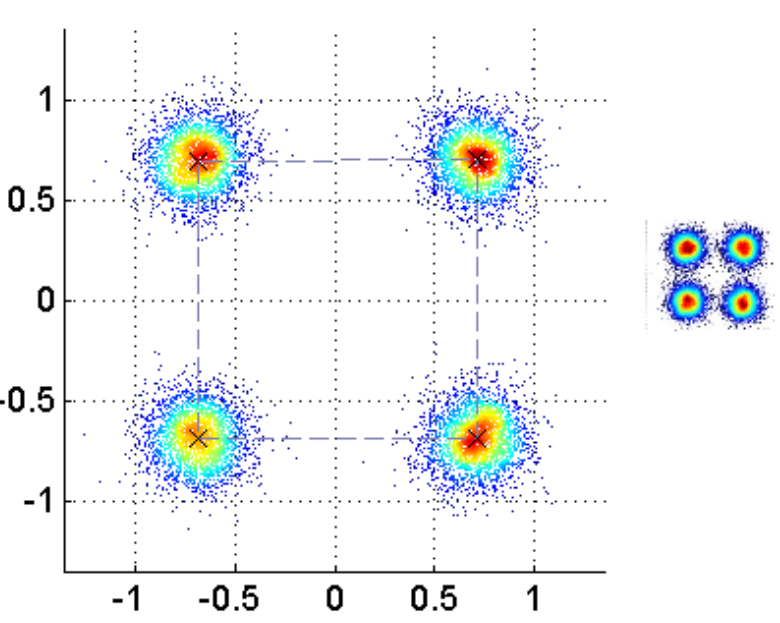

(b)

Figura 4.5 - Constelações simuladas para os modos de polarização ortogonais do canal 1 no eixos (a) $X$ e (b) $Y$ (No inset são apresentadas as constelações obtidas no experimento)

\subsection{Desempenho sistêmico das três técnicas de geração de supercanais ópticos}

Para avaliar as técnicas estudadas na seção 3.6, foi elaborado um arranjo de simulação, adaptado da paleta anterior, composto por um transmissor DP-QPSK para taxa de $112 \mathrm{~Gb} / \mathrm{s}$, um anel de recirculação por um enlace de fibra óptica com um amplificador de linha, e um receptor coerente. Como anteriormente, após o receptor coerente é utilizado o mesmo tratamento digital dos sinais simulados através do programa Matlab. A Figura 4.6 ilustra o sistema base configurado no simulador. 


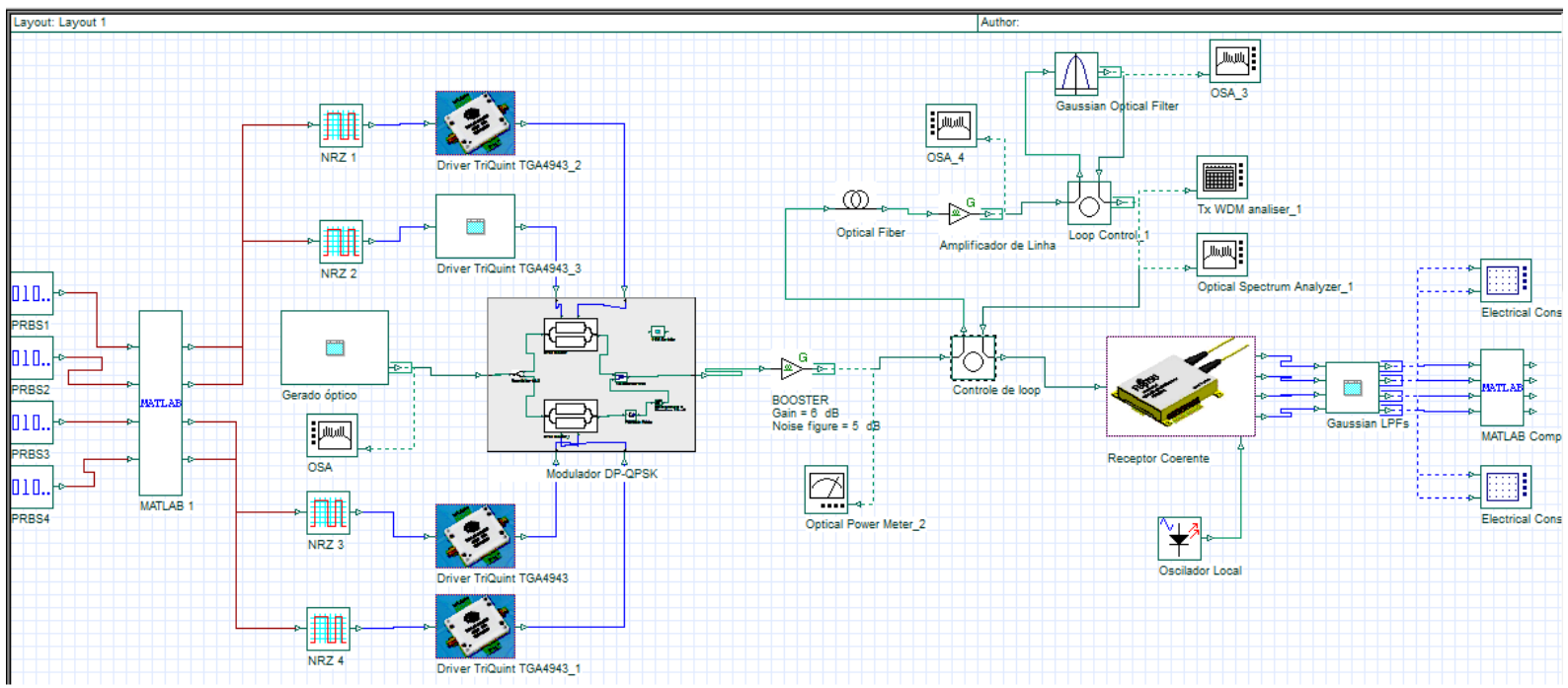

Figura 4.6 - Sistema DP-QPSK com $112 \mathrm{~Gb} / \mathrm{s}$

Como indicado, a paleta contém quatro geradores de sequências PRBS (Pseudo-random binary sequency) que serão salvas no ambiente Matlab inserido no Optisystem, para que esses dados sejam guardados em arquivo e, após passarem no Matlab passam por um gerador de pulsos NRZ (non return to zero), para então serem inseridos no modulador DP-QPSK. Esses sinais codificados em NRZ são amplificados por amplificadores elétricos para que suas amplitudes sejam compatíveis com as tensões de polarização do modulador. O pente óptico gerado pelo laser semente é então modulado pelo modulador DP-QPSK e inserido no anel de recirculação, composto por um controle de loop, uma fibra óptica (100 km) SMF G.652, e um amplificador com um ganho referente à atenuação da fibra. Após o amplificador óptico outro controle de loop com um filtro óptico é inserido para simular diversas filtragens em cascata. Em seguida, o sinal sofre o batimento com o sinal do oscilador local, no receptor coerente, que vai transferir as características do sinal do domínio óptico para o elétrico. Os quatros sinais de saída dos fotodetectores balanceados $X Y_{I Q}$ (polarização $X$ e $Y$, fase e quadratura) são filtrados eletricamente com banda de $30 \mathrm{GHz}$, para caracterizar a filtragem elétrica que acontece no 
osciloscópio usado nos experimentos, conforme [35]. Após essas filtragens os sinais são processados no Matlab para realização do processamento digital.

Nesse arranjo simulado, as configurações de cada componente foram ajustadas para serem semelhantes à de componentes comerciais e na fibra óptica foram considerados todos os efeitos não lineares. Os parâmetros que podem ser controlados no simulador são listados na Tabela 4.1.

Tabela 4.1 - Parâmetros de simulação para OFDM óptico

\begin{tabular}{|c|c|c|}
\hline Parâmetro & Valor & Unidade \\
\hline Taxa de bits & 112 & $\mathrm{~Gb} / \mathrm{s}$ \\
\hline Amostras por bit & 4 & \\
\hline Voltas no anel de recirculação & 1 & \\
\hline Desvio de Frequência & 2 & $\mathrm{graus}$ \\
\hline Largura de banda do filtro óptico & 280 & $\mathrm{GHz}$ \\
\hline Número de filtragem óptica por volta & $1,2,3$ & \\
\hline Frequência do laser & 193,4 & $\mathrm{THz}$ \\
\hline Largura de linha & 0,5 & $\mathrm{MHz}$ \\
\hline Frequência do oscilador local & $193,4+$ desvio de frequência & $\mathrm{THz}$ \\
\hline Largura de linha do oscilador local & 0,5 & $\mathrm{MHz}$ \\
\hline Dispersão da fibra & 16,75 & $p s\left(\mathrm{~nm}{ }^{2} . \mathrm{km}\right)$ \\
\hline Atenuação da fibra & 0,2 & $\mathrm{~dB} / \mathrm{km}$ \\
\hline PMD & 0,1 & $\mathrm{ps} \sqrt{\mathrm{km}}$ \\
\hline Figura de ruído do amplificador & 6 & $\mathrm{~dB}$ \\
\hline Ganho do amplificador & 20 & $\mathrm{~dB}$ \\
\hline
\end{tabular}

\subsubsection{Efeito da Concatenação de Filtros Ópticos}

O primeiro teste comparativo analisa, isoladamente, o efeito da cascata de filtros sobre o supercanal. Para tal, o controle do loop de enlace é ajustado para 0 
voltas e o controle do loop de filtros é variado. É importante avaliar o comportamento do supercanal diante de uma sequência de filtros, pois esta é uma situação frequente em redes de longa distância com vários nós do tipo ROADM (reconfigurable optical add and drop multiplexer) na percorrida pelo sinal. Para permitir o tráfego de supercanais OFDM, é necessário considerar que a rede óptica possui ROADMs com banda flexível. No caso dos testes realizados, a banda mínima necessária para passagem dos 10 canais é de $280 \mathrm{GHz}$, portanto, as avaliações foram realizadas neste pior caso (isto é, todos os filtros com banda de $280 \mathrm{GHz}$ ). Com o sistema montado de acordo com a Tabela 4.1 e potência total lançada na fibra de $1 \mathrm{dBm}$ (10 portadoras), foram geradas as curvas para os três tipos de geração de supercanais estudadas nessa dissertação. Os resultados mais importantes para uma avaliação global são relativos ao canais \#1, \#5 e \#10. O canal 10 possui a pior relação sinal ruído e está na borda, bem como o canal 1, e canal 5 pode sofrer mais interferências dos outros canais por estar localizada no centro. Os resultados da BER em função do número de voltas no loop de filtro são sumarizados na Figura 4.7. 


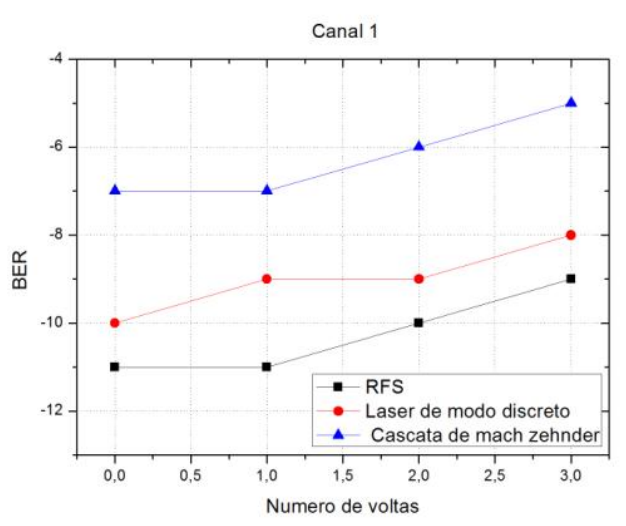

(a)

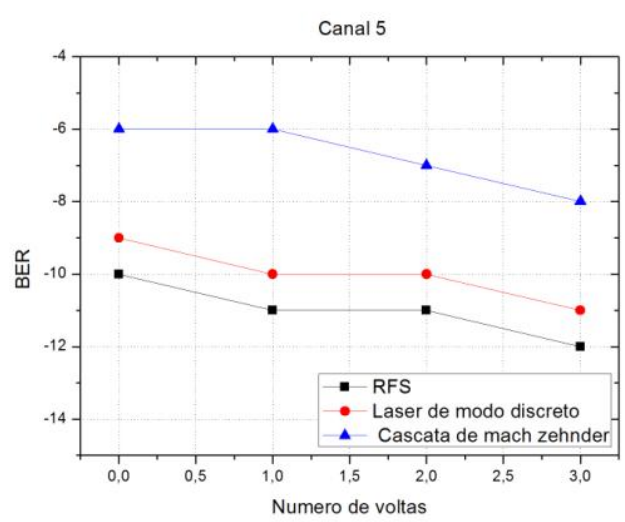

(b)

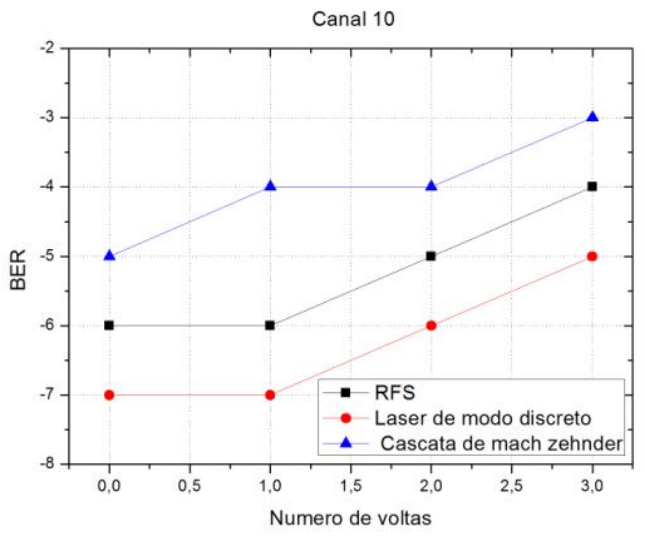

(c)

Figura 4.7-BER x Número de voltas do filtro óptico para às três técnicas de geração de supercanal para os canais : (a) \#1, (b)\#5, (c)\#10

Analisando os resultados, vemos que à medida que se aumenta o número de filtros em cascata (número de voltas do loop), a taxa de erro para o canal 5 vai melhorando, já para os canais 10 e 1 vai piorando, pois eles estão nas bordas e, como era de se esperar, sofrem mais severamente o efeito do estreitamento da janela espectral. Apesar desta consequência indesejável, isso acaba melhorando a taxa de erro dos canais que ficam mais ao centro. Uma possível explicação para a melhoria da BER dos canais centrais eria a redução do efeitos da interferência entre canais, decorrente da supressão dos canais de borda. As três técnicas apresentaram um desempenho com tendência semelhante, mas com diferença de ordens de grandeza entre si. Todos os parâmetros de simulação foram utilizados de 
forma igual para efetuar uma comparação justa entre as técnicas e, dos resultados, podemos concluir que, do ponto de vista do estreitamento espectral, a melhor técnica de geração do comb óptico é a RFS, seguida do laser de modo discreto e da cascata de moduladores. Estudos posteriores terão que ser feitos para melhor avaliar as causas do pior desempenho da técnica da cascata de moduladores. Acredita-se que a combinação de moduladores MachZehnder e de fase possa resultar em algum ganho de desempenho.

\subsubsection{Efeito da Concatenação de Amplificadores Ópticos e Enlaces de Fibra}

Tendo como base o mesmo sistema anterior, novas simulações foram realizadas, desta vez zerando o controle do loop de filtro óptico da Figura 4.6, e habilitando o controle do loop de enlace, composto de um amplificador óptico (ajustado para compensar a perda na fibra) e $100 \mathrm{~km}$ de fibra convencional. Com estes testes são avaliados, simultaneamente, o efeito da cascata de amplificadores e da propagação pelas fibras. Pelo nível de potência lançada na fibra, é razoável supor que somente os efeitos lineares de propagação estão presentes. Isso é necessário, considerando que o módulo de processamento digital de sinal não opera, ainda, para correção de efeitos não lineares. As curvas da Figura 4.8 exibem a BER em função do número de voltas que o sinal passa no loop da fibra, também para os canais \#1, \#5 e \#10, o que resulta em um limite de três voltas (300 km de extensão) com resultados abaixo do limite da FEC. 


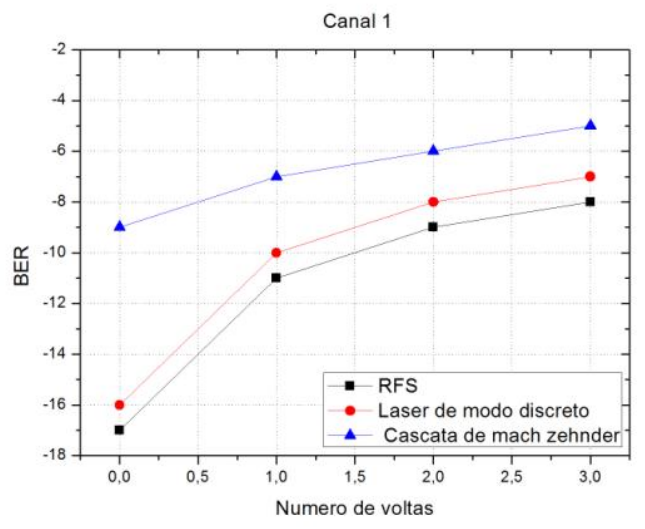

(a)

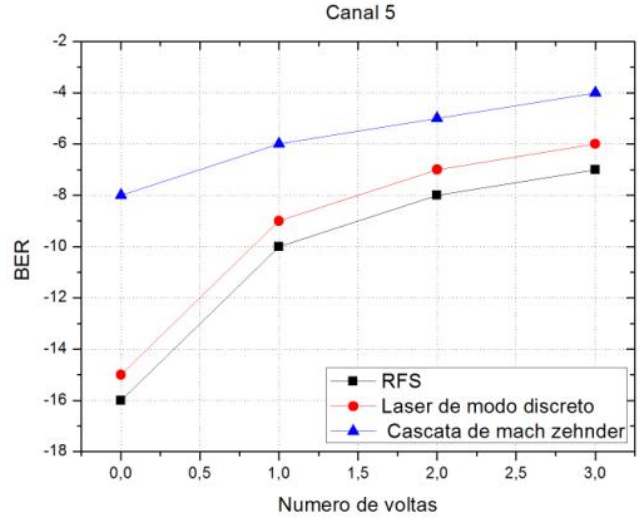

(b)

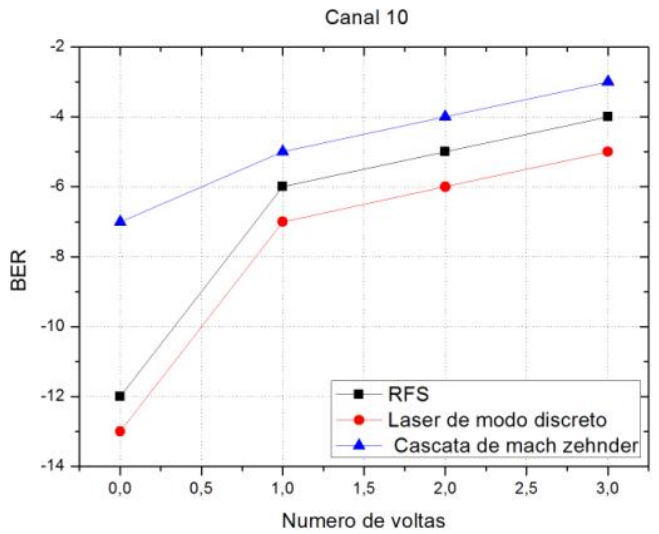

(c)

Figura 4.8 - BER x número de voltas da fibra óptica para às três técnicas de geração de supercanais ópticos para os canais: (a)\#1, (b)\#5 e (c)\#10

Como no estudo de caso anterior, a tendência das curvas de BER é a mesma para as três técnicas de geração do comb óptico. A técnica de recirculação de frequência obteve uma taxa de erro para o canal 1 de aproximadamente $10^{-8}$, enquanto a técnica de cascata de moduladores obteve uma taxa de erro de $10^{-5}$, já no laser de modo discreto teve uma taxa de aproximadamente $10^{-7}$. No caso do canal 5, o laser de modo discreto obteve uma taxa de $10^{-6}$, a técnica da cascata de moduladores a uma taxa de erro de aproximadamente $10^{-4}$ e a técnica de recirculação de frequência a uma taxa de $10^{-7}$. Já no caso do canal 10 , o desempenho da técnica de recirculação de frequência foi pior, pois o canal 10 apresenta, com já foi demonstrado anteriormente, uma pior relação sinal ruído. Esse 
fato é inerente ao processo de geração do supercanal, onde o último canal acaba acumulando mais ruído dos amplificadores ópticos em relação aos outros canais.

A técnica da cascata de moduladores apresentou o pior desempenho em todas as simulações. Uma possível explicação é que a perda de inserção dos moduladores leva à necessidade de uma amplificação óptica adicional do sinal antes de ser lançado na fibra, lembrando que o supercanal sempre foi lançado na fibra com a mesma potência, independente da técnica de geração. A necessidade de amplificação extra não ocorre para a técnica do laser de modo discreto, pois ela requer apenas amplificação do sinal RF injetado diretamente no laser. A técnica de recirculação de frequência tem amplificadores na geração e seu ganho ajuda a manter uma boa relação de potência entre os canais, apesar da adição de ruído de emissão espontânea.

\subsubsection{Outras considerações}

Em relação ao número de raias no pente óptico, da maneira como foram descritas, a técnica RFS apresenta a vantagem de permitir a geração de um maior número de canais. Porém, a combinação da RFS com a cascata de moduladores pode ser empregada para resolver este problema [64]. Mesmo o laser de modo discreto pode ser associado com um modulador de fase, visando o aumento de raias [62]. Estas análises serão realizadas na continuidade deste trabalho. 


\section{Conclusões e Trabalhos Futuros}

Foi feita uma revisão bibliográfica da técnica de transmissão OFDM óptico em dois cenários: "domínio elétrico-óptico" e "domínio óptico". O primeiro caso refere-se à geração de um supercanal elétrico que modula uma portadora óptica. No segundo caso, o chamado "supercanal óptico" é gerado unicamente no domínio óptico. Para efeito de ilustração, foram realizadas simulações de sistemas elétricoópticos tendo como referência resultados publicados de transmissão de tais sinais, tanto com detecção direta quanto deteç̧ão coerente. Os resultados comprovam que a técnica com detecção coerente resulta em melhor desempenho sistêmico.

A dissertação focalizou em mais detalhes o OFDM no domínio totalmente óptico, onde as implementações sistêmicas somente se viabilizam com recepção coerente. Foram então descritos e simulados três tipos de técnicas de geração de supercanais ópticos: RFS (recirculating frequency shifting), cascata de moduladores e laser de modo discreto. Tendo como referência a configuração e os resultados obtidos de um experimento de transmissão de supercanal $(1,12 \mathrm{~Tb} / \mathrm{s})$ por $452 \mathrm{~km}$ de fibra de sílica pura, uma paleta de simulação foi validada para ser, posteriormente, adaptada e empregada nos estudos de avaliação sistêmica das três técnicas de geração de comb óptico. Em todos os casos estudados, para o cálculo da BER por portadoras, foi realizado o processamento digital de sinal das amostras utilizando-se um algoritmo padrão para a modulação DP-QPSK, com recepção coerente, desenvolvido na Fundação CPqD. 
Dois casos foram analisados numa paleta de simulação com dois controles de loop: efeito da cascata de filtros e efeito da combinação da cascata de amplificadores e fibra (monomodo padrão). Das 10 portadoras, foram selecionadas para análise as portadoras de número \#1, \#5 e \#10. A concatenação de filtros requer uma gerência da largura de banda de ROAMs, flexíveis em banda, que permita a passagem de um supercanal com margem para o estreitamento espectral que ocorrerá. No caso estudado, a banda passante dos filtros foi ajustada em $280 \mathrm{GHz}$, o que não deixou uma margem para os canais de borda, que sofreram penalidade devido ao estreitamento espectral. Por outro lado, o fato destes canais terem sido 'cortados' resultou numa redução da interferência entre canais, o que levou a uma melhoria dos canais centrais, ilustrada pelo comportamento do canal \#5. Como nesta análise não houve acúmulo de ASE, a técnica RFS mostrou-se mais eficiente, seguida da técnica do laser de modo discreto.

No segundo estudo, onde ocorre acúmulo de ASE e de efeitos de propagação, destacou-se a técnica do laser de modo discreto, que apresenta a melhor relação sinal-ruído na entrada da fibra. Este resultado é promissor e motiva estudos futuros para uma melhor modelagem do processo de geração do comb óptico.

A técnica da cascata de moduladores apresentou o pior desempenho em todas as simulações. Uma possível explicação é que a perda de inserção dos moduladores leva à necessidade de uma amplificação óptica adicional do sinal antes de ser lançado na fibra, lembrando que o supercanal sempre foi lançado na fibra com a mesma potência, independente da técnica de geração. A necessidade de amplificação extra não ocorre para a técnica do laser de modo discreto, pois ela requer apenas amplificação do sinal RF injetado diretamente no laser. A técnica de 
recirculação de frequência tem amplificadores na geração e seu ganho ajuda a manter uma boa relação de potência entre os canais, apesar da adição de ruído de emissão espontânea.

Em relação ao número de raias no pente óptico, da maneira como foram descritas a técnica RFS apresenta a vantagem de permitir a geração de um maior número de canais. Porém, a combinação da RFS com a cascata de moduladores pode ser empregada para resolver este problema. Mesmo o laser de modo discreto pode ser associado com um modulador de fase, visando o aumento de raias.

Estas análises serão realizadas em trabalhos futuros, que preveem, além da continuidade das simulações em outros estudos de caso, a modelagem e implementação prática da técnica do laser de modo discreto, para testes sistêmicos experimentais. Outros aspectos a serem estudados: algoritmos de processamento de sinais aplicados na recepção visando uma redução nas interferências das portadoras, uma melhor separação no tratamento do sinal das portadoras geradas, e compensação de efeitos não lineares de transmissão.

\subsection{Trabalhos Publicados}

1. Ferreira, R.J. L.; Rocha, M. L.; Pataca, D. M.; Feres, M. M. Optical Comb Generation Techniques, International Workshop on telecommunications, Santa Rita do Sapucaí, 2013.

2. Ferreira, R. J. L; Rocha, M. L; Silva, G. E. V. Análise do Gerador Óptico Comb para Transmissão em Redes Ópticas, Computeronthebeach, Florianópolis, 2013. 



\section{Referências Bibliográficas}

[1] J. Armstrong, "OFDM for Optical Communications", Journal of Lightware Technology, v. 27, no 3, Fevereiro 2009.

[2] R. Freund, L. Molle, H. Thiele, "System Margin and Parameter Tolerances of Optical Transmission Sections in Metro-Networks for 40-Gbit/s NRZ-ASK Transmission", Optical Fiber Communication Conference and Exposition and The National Fiber Optic Engineers Conference, Technical Digest (CD) (Optical Society of America), paper NThB1, Março 2005.

[3] W. Shieh, C. Athaudage, "Coherent optical orthogonal frequency division multiplexing", Electron Lett, v.42, p.587-589, Maio 2006.

[4] A. J. Lowery, Du L, J. Armstrong, "Orthogonal frequency division multiplexing for adaptive dispersion compensation in long haul WDM systems", Opt. Fiber Commun. Conf., paper no. PDP 39. Anaheim, CA, Março 2006.

[5] I. B. Djordjevic, B. Vasic, "Orthogonal frequency division multiplexing for highspeed optical transmission”, OptExpress, v.14, p. 3767-3775, Maio 2006.

[6] T. Kobayash, A. Sano, E. Yamada, "Electro-optically subcarrier multiplexed 110 Gb/s OFDM signal transmission over 80 km SMF without dispersion compensation", IET Electron v. 44, ํo 3, p.225-226, Janeiro 2008.

[7] W. Shieh e I. Djordjevic, "OFDM for Optical Communications", Academic Press, 2010.

[8] A. S. Campos, "A convergência de voz em dados", disponível em: http://www.teleco.com.br/tutoriais/tutorialconvdados/pagina 4.asp, Teleco, Acesso em: 25 de fevereiro de 2012. 
[9] J. L. Arthur, B. D. Liang, "Optical orthogonal division multiplexing for long haul optical communications: A review of the first five years", Department of electrical and computer systems engineering, Monash University, Welligton Road, Clayton, VIV 3800, Australia, v. 17, no 5, p.421-438, Outubro 2011.

[10] MATHWORKS, Disponível em: http://www.mathworks.com, Acesso em: 04 de janeiro de 2013.

[11] J. SALZ, S. B. WEINSTEIN, "Fourier transform communication system", Acm Symposium On Problems In The Optimization Of Data Communications Systems, P. 99-128, New York, 1969.

[12] Jr. L. J. CIMINI, "Analysis and simulation of digital mobile channel using orthogonal frequency division multiplexing", IEEE Transactions on Communications, v. 33, n.7, p. 665-675, Amsterdam, Julho 1985.

[13] R. LASSALLE, M. ALARD, "Principles of modulation and channel coding for digital broadcasting for mobile receivers", EBU Technical Review, n. 224, p.168-190, Geneva, Fevereiro 1987.

[14] E. TELATAR, "Capacity of Multi-Antenna Gaussian Channels". European Transactions on Telecommunications, v. 10, n.6, p. 585-595, New York, Dezembro 1999.

[15] G. J. FOSCHINI, M. J. GANS, "On limits of wireless communications in a fading environment when using multiple antennas". Wireless Personal Communications, v.6, p. 311-335, New York, Julho 1998.

[16] I. KOFFMAN, V. ROMAN, "Broadband wireless access solutions based on OFDM access", IEEE 802.16. IEEE Communications Magazine, v.40, n. 4, p. 96-103, Amsterdam, Abril 2002.

[17] R. W. Chang, "Orthogonal Frequency Multiplex Data Transmission System," United States Patent US3488445, 1966. 
[18] R. B. Dutra, "Avaliação do desempenho da modulação OFDM em canais HF para rádios cognitivos", dissertação de mestrado, UFRJ, Março 2010.

[19] L. Kazovsky, "Multichannel coherent optical communications systems". J Lightwave Technol, v.5, n.8, p.1095-102, Agosto 1987.

[20] J. M. Kahn, I. M. I. Habbab, C. R Giles, "1Gbit/s zero-IF DPSK coherent optical system using a single photodetector". IET Elect Lett, v.24, p.1455-1457, Novembro1988.

[21] Z. Wang, G. B. Giannakis, "OFDM or single-carrier block transmissions?" IEEE Trans Commun, V.52, no 3, p.380-394, Março 2004.

[22] J. Yu, X. Zhou, M. Huang, "21.7 Tb/s (161 114 Gb/s) polmux-RZ-8PSK transmission over $662 \mathrm{~km}$ of ultra-low loss fiber using C-band EDFA amplification and digital coherent detection", Eur. Conf. Opt. Commun., Brussels, Belgium, Novembro 2008.

[23] Cisco Inc. Approaching the zettabyte era Information available at http://www.cisco.com/en/US/solutions/collateral/ns341/ns525/ns537/ns705/ns827/whi te paper c11-481374 ns827 Networking Solutions White Paper.htm, Acesso em: 25 de abril de 2012.

[24] Proceedings of the IEEE, centenal special issue, http://ieeexplore.ieee.org/xpl/tocresult.jsp?isnumber=6198296\&punumber $=5$, acesso em: 01 de dezembro de 2012.

[25] P. Lucena, A. Macílio, "Estudos sobre Sistemas de Comunicação com Sinais Não-Ortogonais Superpostos em Frequência". Tese de doutorado da UFC, Dezembro 2006.

[26] Y. Jianjun, Z. Xiang, "Ultra-High-Capacity DWDM Transmission System for 100G and Beyond", IEEE Communications Magazine, v.48, no 3, p. S56-S54, Março 2010. 
[27] M. Seimetz, "High-Order Modulation for Optical Fiber Transmission", Springer series in optical Sciences, 2009.

[28] M. Nakazawa, Challenges, "FDM-QAM Coherent Transmission with Ultrahigh Spectral Efficiency", European Conference on Optical Communication (ECOC), 34, Brussels, Belgium, Setembro 2008.

[29] I. B. Djordjevic and B. Vasic, "Orthogonal Frequency Division Multiplexing for High-Speed Optical Transmission", Optics Express, v.14, n9, p. 3767-3775, Maio 2006.

[30] S. L. Jansen, I. Morita, T. C. W. Schenk, D. V. D Borne, H. Tanaka, "Optical OFDM - A Candidate for Future Long-Haul Optical Transmission Systems," Optical Fiber communication/National Fiber Optic Engineers Conference, Fevereiro 2008.

[31] G. P. Agrawal, "Fiber Optic Communication", 3rd ed., The Institute of Optics University of Rochester, Rochester, NY, 2002.

[32] S. Coleri, M. Ergen, "Channel Estimation Techniques Based on Pilot Arrangement in OFDM Systems", IEEE Trans. Broadcasting, v. 48, $n^{\circ} 3$ p. 223-229, Setembro 2002.

[33] S. Ryu, "Coherent Lightwave Communication Systems", Artec House, Boston, 1995.

[34] J. Salz, AT\&T Tech. J. 64, 2153 (1985), IEEE Commun. Mag. 24 (6), 38, 1986.

[35] V. B. Ribeiro, A. C. Bordonalli, J. C. R. F, Oliveira, "Filtros Digitais para Recepção Coerente em 112Gb/s de Sinais Ópticos com Modulação QPSK e Multiplexação por Divisão em Polarização", Dissertação de Mestrado, Universidade Estadual de Campinas, Agosto 2012.

[36] S. Haykin, "Communication System", Wiley, 4 edição, 2000. 
[37] D. N. C. Vieira, "Estudo sobre a viabilidade de utilização de sistemas com multiplexação por subportadora", dissertação de mestrado, Março 2007.

[38] Y. Tang, W. Shieh, X. Yi, R. Evans, "Optimum Design for RF-to-Optical UpConverter in Coherent Optical OFDM Systems", IEE Photonics Technology Letters, v. 19, n07, p. $483-485$, Abril 2007.

[39] T. Morioka, K. Mori, and M. Saruwatari, "More than 100-wavelength-channel picosecond optical pulse generation from a single laser source using supercontinuum in optical fibers," Electron. Lett., v. 29, n. 10, p. 862-864, Maio1993.

[40] T. Okoshi, K. Kikushi, "Coherent Optical Fiber Communications", Kluwer Academic Publishers, Dordrecht, Dezembro 1988.

[41] Z. XU, R. HUI, M. O'SULLIVAN, "Dual-band OOFDM system based on tandem single-sideband modulation transmitter", Optics Express, Washington, v. 17, n. 16, p. 13479-13486, Agosto 2009.

[42] R. T. F. Gomes, "Transmissão de Sinais com Etiqueta Óptica em Redes Ópticas Comutadas". Dissertação de Mestrado, Instituto Superior Técnico de Lisboa, Dezembro 2008.

[43] A. J. Lowery, L. B. Du, J. Armstrong, "Performance of Optical OFDM in Ultralong-Haul WDM Lightwave Systems, Journal of Lightwave Technology", V. 25, $\mathrm{N}^{\circ} 1$, p.131-138, Janeiro 2007.

[44] H. S. CHUNG, S. H. CHANG, K. KIM, "Companding transform based SPM compensation in coherent optical OFDM transmission", Optical Express, Washigton, v. 19, n. 26, p. B702-B709, Dezembro 2011.

[45] Optical Internetworking Forum, OIF, "100G Ultra Long Haul DWDM Framework" Document, http://www.oiforum.com/public/documents/OIF-FD-100G-DWDM-01.0.pdf, acesso em: 10 de abril de 2009. 
[46] D. M. Pataca, F. D. Simões, M. L. Rocha, "Sistemas ópticos de próxima geração", Cadernos CPqD Tecnologia, Campinas v.7, $n^{0}$ 2, p.43-58, Dezembro 2011.

[47] T. Pollet, M. V. Bladel, M. Moeneclaey, "BER sensitivity of OFDM systems to carrier frequency offset and Wiener phase noise". IEEE Trans. Commun, v.43, $n^{\circ} 4$ p.191-193, Abril 1995.

[48] J. Armstrong, "Analysis of new and existing methods of reducing intercarrier interference due to carrier frequency offset in OFDM". IEEE Trans. Commun. V.47,n³, p.365-369, Março 1999.

[49] S. Chandrasekhar, X. Liu, "Terabit Superchannels for High Spectral Efficiency Transmission", ECOC, Italy, Setembro 2010.

[50] A. R. Shah, R. C. J. Hsu, A. Tarighat, A. H. Sayed, B. Jalali, "Coherent optical MIMO (COMIMO)", IEEE Journal of Lightwave Technology, v. 23, n. 8, p. 24102419, Agosto 2005.

[51] Implementation Agreement for Integrated Dual Polarization Intradyne Coherent Receivers, http://www.oiforum.com/public/documents/OIF DPC RX-01.0.pdf, acesso em: 15 de novembro de 2010.

[52] S. Chandrasekhar, X. Liu, "Experimental investigation on the performance of closely spaced multi-carrier PDM-QPSK with digital coherent detection". Optics Express, v.17, n.24, p.21.350-21.361, 2009.

[53] V. B. Ribeiro, "Equalização Dinâmica via CMA e DPC-CMA com Adaptação de Ganho em Sistemas Ópticos Coerentes PDM-QPSK a 112 Gb/s," SBrT, Outubro 2011.

[54] D. M. Pataca, F. D. Simões, M. L. Rocha, "Optical Frequency Comb Generator for Coherent WDM System in Tb/s Applications", International Microwave and Optoelectronics Conference (IEEE/SBMO), Natal, Novembro 2011. 
[55] P. J. Winzer, "Beyond 100G Ethernet". IEEE Communications Magazine, v.48, n.7, p. 26-30, julho 2010.

[56] J. Zhao, A. D. Ellis, "Spectral Efficiency Enhancement Using Coherent WDM with Multi-Level Offset-QAM", European Conference on Optical Communication (ECOC), Geneva, Switzerland, Setembro 2011.

[57] Y. MA, "1Tb/s per channel coherent optical OFDM transmission with subwavelength bandwidth access", Optical Fiber Conference (OFC), 35, Março 2009.

[58] A. Ellis, F. Gunning, "Spectral density enhancement using coherent WDM. IEEE Photonics Technology Letters", v. 17, nº 2, p.504-506 Fevereiro 2005.

[59] T. Kawanishi, "Optical frequency comb generator using optical fiber loops with single-sideband modulation". IEICE Eletronics Express, v.1, n.8, p.217-221, Julho 2004.

[60] R. Maher, "Low cost comb source in a coherent wavelength division multiplexed system", European Conference on Optical Communication (ECOC), 36, Torino, Italy, Setembro 2010.

[61] C. Herbert, D. Jones, A. Kaszubowska-Anandarajh, B. Kelly, M. Rensing, J. O'Carrikkm R. Phelan, P. Anandarajah, P. Perry, L.P. Barry, J. O'Gorman, "Discrete mode lasers for communication applications", IET Optoelectronics, v. 3, n. 1. p. 1-17, Fevereiro 2009.

[62] R. Zhou, S. Latkowski, J. O'Carroll, R. Phelan, L. P. Barry, P. Anandarajah, "40nm wavelength tunable gain-switched optical comb source", Optics Express, v. 19, n 26, p. B415-B420, Dezembro 2011.

[63] J. Yu, Z. Dong, J. Zhang, X. Xiao, H. C. Chien, N. Chi, "Generation of Coherent and Frequency-Locked Multi-Carriers Using Cascaded Phase Modulators for $10 \mathrm{~Tb} / \mathrm{s}$ Optical Transmission System", Journal of Lightwave Technology, v.30, $n^{\circ} 4$, p.458465, Fevereiro 2012. 
[64] D. M. Pataca, L. H. H. Carvalho, C. B. F. Adami, F. D. Simões, J. C. R. F. Oliveira, "Transmissão de um supercanal OFDM de 1,12 Tb/s por $452 \mathrm{~km}$ com eficiência espectral de 4b/s/Hz", Simpósio Brasileiro de Telecomunicações, Brasília, setembro 2012. 